\title{
Driving performance and neurocognition of patients with long-term medicinal drug treatment
}

Citation for published version (APA):

van der Sluiszen, N. (2020). Driving performance and neurocognition of patients with long-term medicinal drug treatment. [Doctoral Thesis, Maastricht University]. Ridderprint. https://doi.org/10.26481/dis.20200709ns

Document status and date:

Published: 01/01/2020

DOI:

10.26481/dis.20200709ns

Document Version:

Publisher's PDF, also known as Version of record

\section{Please check the document version of this publication:}

- A submitted manuscript is the version of the article upon submission and before peer-review. There can be important differences between the submitted version and the official published version of record.

People interested in the research are advised to contact the author for the final version of the publication, or visit the DOI to the publisher's website.

- The final author version and the galley proof are versions of the publication after peer review.

- The final published version features the final layout of the paper including the volume, issue and page numbers.

Link to publication

\footnotetext{
General rights rights.

- You may freely distribute the URL identifying the publication in the public portal. please follow below link for the End User Agreement:

www.umlib.nl/taverne-license

Take down policy

If you believe that this document breaches copyright please contact us at:

repository@maastrichtuniversity.nl

providing details and we will investigate your claim.
}

Copyright and moral rights for the publications made accessible in the public portal are retained by the authors and/or other copyright owners and it is a condition of accessing publications that users recognise and abide by the legal requirements associated with these

- Users may download and print one copy of any publication from the public portal for the purpose of private study or research.

- You may not further distribute the material or use it for any profit-making activity or commercial gain

If the publication is distributed under the terms of Article $25 \mathrm{fa}$ of the Dutch Copyright Act, indicated by the "Taverne" license above, 


\title{
Driving performance and neurocognition of patients with long-term medicinal drug treatment
}

\author{
Nick N.J.J.M. van der Sluiszen
}




\section{COLOPHON}

Cover design: $\quad$ Ridderprint, the Netherlands

Typesetting: $\quad$ Nick N.J.J.M. van der Sluiszen

Printing: $\quad$ Ridderprint, the Netherlands

ISBN: $\quad$ 978-94-6375-975-5

Copyright ( 2020 Nick N.J.J.M. van der Sluiszen

Parts of this dissertation contain work that was financially supported by the Dutch Ministry of Infrastructure and Water Management 


\title{
Driving performance and neurocognition of patients with long-term medicinal drug treatment
}

\author{
DISSERTATION \\ To obtain the degree of doctor at Maastricht University, \\ on the authority of Rector Magnificus, prof. dr. R.M. Letschert, \\ in accordance with the decision of the Board of Deans, \\ to be defended in public on
} Thursday 09.07.2020 at 12:00 hours

by

Nick Nicolaas Johannes Joy Maria van der Sluiszen 


\title{
Promotor
}

prof. dr. J.G. Ramaekers

\section{Copromotor}

dr. A. Vermeeren

\author{
Assessment committee \\ prof. dr. A. Blokland (Chairman) \\ prof. dr. J.J. de Gier (Rijksuniversiteit Groningen) \\ prof. dr. W.J. Riedel \\ dr. B.E. Smink (Gezondheidsraad, Den Haag) \\ dr. E.L. Theunissen
}

The research in this dissertation was conducted at the Department of Neuropsychology and Psychopharmacology, Maastricht University, The Netherlands.

\section{Collaborating centres}

- Department of Pharmacology, University Utrecht, The Netherlands

- Department of Clinical and Developmental Neuropsychology, University of Groningen, The Netherlands

- Stichting Epilepsie Instelling Nederland (SEIN), Heemstede, The Netherlands

- Sleep Medicine Centre Kempenhaeghe, Heeze, The Netherlands 


\section{Table of Content}

\section{Chapter 1}

General introduction

\section{Chapter 2}

Influence of long-term benzodiazepine use on neurocognitive skills related to driving performance in patient populations: a review

\section{Chapter 3}

Driving performance and neurocognitive skills of long-term users of 37 benzodiazepine anxiolytics and hypnotics

\section{Chapter 4}

Driving performance of depressed patients who are untreated or receive long69 term antidepressant (SSRI/SNRI) treatment

\section{Chapter 5}

On-the-road driving performance and neurocognition of patients with longterm antidepressant treatment

\section{Chapter 6}

On-the-road driving performance of patients with central disorders of hypersomnolence on stable treatment

\section{Chapter 7}

General discussion

Summary / Samenvatting

Valorisation Addendum

Acknowledgements

Curriculum Vitae (English / Nederlands / Português do Brasil / Deutsch) 



\section{CHAPTER 1}

General introduction 


\section{Chapter 1}

\section{Background}

Driving is a complex task that involves the successful integration of sensory-, motor- and attention processes. Medicinal drugs, such as antidepressants and benzodiazepines, can cause sleepiness, sedation, and loss of attention, which in turn may lead to driving impairment (Dassanayake, Michie, Carter, \& Jones, 2011). Informing patients and practitioners about the potentially impairing effects of medicinal drugs promotes traffic safety (DuPont et al., 2012). Efforts have been made to rate and classify the impairing effects of medication on driving performance in order to develop drug classification systems (Alvarez, de Gier, Mercier-Guyon, \& Verstraete, 2007; de Gier, Alvarez, Mercier-Guyon, \& Verstraete, 2009). These systems quantify and qualify the potential harms of medicinal drugs on driving performance, which propagates knowledge communication to relevant stakeholders (i.e. patients, practitioners, government agencies). Drug classification systems apply a graded level warning system that categorizes the magnitude of medicinal drug induced impairment in relationship to a wellknown benchmark drug, such as alcohol, for which a clear relationship between crash risk and an increase of blood-alcohol concentration (BAC) has been demonstrated (Blomberg, Peck, Moskowitz, Burns, \& Fiorentino, 2009; Borkenstein, Crowther, \& Shumate, 1974). Classifications that are commonly used to define drug effects on driving in equivalent alcohol units are: no/minor influence (category 0/I, BAC $<0.5 \mathrm{mg} / \mathrm{ml}$ ), moderate influence (category II, $0.5 \mathrm{mg} / \mathrm{ml} \leq \mathrm{BAC} \leq 0.8 \mathrm{mg} / \mathrm{ml}$ ), and severe influence (category III, BAC $>0.8 \mathrm{mg} / \mathrm{ml}$ ). As such, patients and practitioners can be informed about the expected increase in driving related impairment associated with the use of a certain kind of medication. If applicable, medication can be selected which is deemed most safe for operating a vehicle in traffic.

\section{Driving performance and long-term treatment}

Drug classification systems combine epidemiological crash risk data from patients' medicinal drug prescriptions and the research outcomes of double-blind placebo controlled studies in healthy volunteers, which assess the acute or short-term effects of medicinal drugs. These data form a detailed overview of the expected driving impairment at, and shortly after, treatment initiation. Tolerance for the impairing effects of medication may develop following repeated administration with either antidepressants or benzodiazepines (Ramaekers, 2003; Vermeeren, 2004). In studies with healthy volunteers, the duration of treatment is often limited to a maximum of $2-3$ weeks. Therefore, experimental data on long-term effects of medications on driving performance in patients is lacking. 
In the Netherlands, just over 1 million prescriptions are registered for an antidepressant (Genees- en Hulpmiddelen Informatie Project, 2018a), and approximately 460.000 prescriptions for a benzodiazepine(-like) anxiolytic or hypnotic (Genees- en Hulpmiddelen Informatie Project, 2018b). Antidepressants are frequently described for depression or pain (Arroll et al., 2005; Nikolaus \& Zeyfang, 2004), whereas benzodiazepines are commonly used to treat anxiety or sleep disorders (Cloos \& Ferreira, 2009; Lader, 2011). Although prolonged treatment with either antidepressants or benzodiazepines is not recommended (NHGwerkgroep, 2014, 2019), a proportion of patients will develop persistent clinical symptomatology that will result in long-term treatment. It is therefore of interest to determine the influence of long-term medication usage and its potential implications for traffic safety.

The definition of "long-term treatment" has been examined by a recent review (Kurko et al., 2015). Within the scientific literature, the different criteria used for defining "long-term treatment" varies between 6 weeks and 1 year, with the most common definitions being $>3$ months or $>6$ months. To promote maximum inclusion of scientific literature, the minimal criteria for what is considered "long-term treatment" was set to "at least 6 weeks of treatment" in the present studies.

From epidemiological data, it is known that benzodiazepines usage is associated with an increased risk of involvement in a traffic accident during the onset of treatment (Dassanayake et al., 2011; Smink, Egberts, Lusthof, Uges, \& De Gier, 2010; van Schie et al., 2016), whereas the overall risk decreases over a 2-month time window after treatment initiation (Neutel, 1995, 1998). Tricyclic antidepressants and selective serotonin reuptake inhibitors have been associated with either an increased risk of becoming involved in a traffic accident (Leveille et al., 1994; Meuleners et al., 2011; Ravera, van Rein, De Gier, \& de Jong-van den Berg, 2011; Ray, Fought, \& Decker, 1992), or show no increased risk in traffic accidents at all (Barbone, McMahon, \& Davey, 1998; Rapoport et al., 2011). It can be argued that crash risk varies depending on patient characteristics, such as clinical symptomatology and duration of treatment (Ravera, Ramaekers, \& de Gier, 2012). It is important to determine the role of pharmacological interventions and clinical symptomatology on driving performance in long-term treated patients. For instance, affective- and sleep-wake disorders are associated with cognitive and executive impairment. Such clinical symptomatology can be expected to negatively affect operating a vehicle in traffic (Ferrari et al., 2013; Fortier-Brochu, Beaulieu-Bonneau, Ivers, \& Morin, 2012; Pizza et al., 2015). 


\section{Chapter 1}

Besides the potentially negative impact of pharmacological treatment on driving performance, patients may benefit from such treatment with regard to their clinical symptomatology. Significant improvements in patients driving performance after treatment initiation were observed after 2 - 4 weeks of treatment (Brunnauer et al., 2015; Brunnauer et al., 2008; O’Hanlon, Vermeeren, Uiterwijk, Van Veggel, \& Swijgman, 1995; van Laar, Volkerts, \& van Willigenburg, 1992), possibly due to a combination of drug tolerance development and reductions in clinical symptomatology. Focussing on pharmacological intervention and clinical symptomatology would potentially allow for the identification of patient groups that are at a low risk or negligible risk of operating a vehicle in traffic. Identifying such patients groups may warrant a change in drug classification systems. For patients treated with category III medication (severe influence, BAC $>0.8 \mathrm{mg} / \mathrm{ml}$ ), the quantification of expected driving impairment might be overly conservative, given the development of drug tolerance and improvements in clinical symptomatology.

Although previous research has shown improvements in patient's performance after long-term use in comparison to treatment onset, it has to be determined to what extend this improvement (and remaining impairment) is of clinical relevance. In order to determine the clinical relevance of performance impairment, results can be standardized by means of comparison with alcoholinduced performance changes (Jongen et al., 2017; Jongen, Vuurman, Ramaekers, \& Vermeeren, 2016). This comparison is done by comparing the difference between long-term treated patients and a control-group to an equivalent performance change as seen at a BAC of $0.5 \mathrm{mg} / \mathrm{ml}$ or higher. Alcohol is a well-known benchmark drug known to jeopardize traffic safety and shows a clear exponential dose-dependent relationship with accident crash risk (Blomberg et al., 2009; Borkenstein et al., 1974). To establish the comparison between drugrelated impairment and alcohol-related impairment, a test needs to be able to detect the impairing effects of alcohol at different BAC levels (i.e. a BAC of $0.5 \mathrm{mg} / \mathrm{mL}$ and $0.8 \mathrm{mg} / \mathrm{mL}$ ). The standardized on-the-road driving test is one of the few tests in which performance related benchmarks for alcohol, among other drugs, have been well-established (Ramaekers, 2017). For neurocognitive tests, such as the Digit Symbol Substitution Task or Trail-making-Test, it is of importance to select tasks that are able to detect drug-related impairment (Jongen, Vuurman, Ramaekers, \& Vermeeren, 2016), preferably at different BAC levels. 


\section{Aim of the dissertation}

The aim is to assess the influence of long-term medication use on driving performance in patient populations. The presented studies outline the potential influence of medication use on actual on-the-road driving performance and neurocognition. Of interest is explaining individual driving performance in light of clinical symptomatology, pharmacological intervention, and duration of treatment.

\section{Outline}

Chapter 2: this chapter reviews the scientific literature with regard to the effects of long-term (>6 weeks) benzodiazepine usage with a focus on the domains of driving performance. The thirteen studies included provide an overview of the published literature in the past 30 years (between 1986 - 2016).

Chapter 3: presents a study assessing the influence of long-term ( $>6$ months) benzodiazepine treatment on real-world driving- and neurocognitive performance. Patients are treated, with either anxiolytics or hypnotics, and compared to a normative control group consisting of healthy volunteers.

Chapter 4: presents a study assessing the influence of long-term ( $>6$ weeks) antidepressant (either selective serotonin re-uptake inhibitors, SSRI / selective noradrenaline reuptake inhibitors, SNRI) treatment and depressive symptomology on real-world driving performance. Data from two studies were retrieved from historical datasets. Depressed patients either were without specific antidepressant treatment or received long-term treatment.

Chapter 5: presents a study which assesses the influence of long-term ( $>6$ months) antidepressant (amitriptyline or mirtazapine) treatment on real-world driving performance and neurocognition. Long-term treated patients were compared to a normative control group of healthy volunteers.

Chapter 6: presents a study assessing driving performance of patients with central disorders of hypersomnolence on stable treatment ( $>6$ weeks). The real-world driving performance of patients is compared to a normative control group consisting of healthy controls.

Chapter 7: discusses the aims as mentioned in chapter 1 in the context of the obtained results in chapter 2 up to and including chapter 6. 


\section{Chapter 1}

\section{References}

Alvarez, J., de Gier, H., Mercier-Guyon, C., \& Verstraete, A. (2007). Categorization system for medicinal drugs affecting driving performance. International Council on Alcohol, Drugs, \& Traffic Safety Working Group. Retrieved July, 6, 2010.

Arroll, B., Macgillivray, S., Ogston, S., Reid, I., Sullivan, F., Williams, B., \& Crombie, I. (2005). Efficacy and tolerability of tricyclic antidepressants and SSRIs compared with placebo for treatment of depression in primary care: a meta-analysis. The Annals of Family Medicine, $3(5), 449-456$.

Barbone, F., McMahon, A., \& Davey, P. (1998). Use of benzodiazepines increased road traffic accidents whereas use of tricyclic antidepressants and SSRIs did not. Lancet, 24, 1331-1336.

Blomberg, R. D., Peck, R. C., Moskowitz, H., Burns, M., \& Fiorentino, D. (2009). The long beach/fort lauderdale relative risk study. Journal of safety research, 40(4), 285-292.

Borkenstein, R. F., Crowther, R., \& Shumate, R. (1974). The role of the drinking driver in traffic accidents (The Grand Rapids Study). Blutalkohol, 11(Suppl.), 1-131.

Brunnauer, A., Buschert, V., Fric, M., Distler, G., Sander, K., Segmiller, F., . . Laux, G. (2015). Driving performance and psychomotor function in depressed patients treated with agomelatine or venlafaxine. Pharmacopsychiatry, 48(02), 65-71.

Brunnauer, A., Laux, G., David, I., Fric, M., Hermisson, I., \& Möller, H.-J. (2008). The impact of reboxetine and mirtazapine on driving simulator performance and psychomotor function in depressed patients. The Journal of clinical psychiatry, 69(12), 1,478-1886.

Cloos, J.-M., \& Ferreira, V. (2009). Current use of benzodiazepines in anxiety disorders. Current Opinion in Psychiatry, 22(1), 90-95.

Dassanayake, T., Michie, P., Carter, G., \& Jones, A. (2011). Effects of benzodiazepines, antidepressants and opioids on driving. Drug safety, 34(2), 125-156.

de Gier, J. J., Alvarez, F. J., Mercier-Guyon, C., \& Verstraete, A. G. (2009). Prescribing and dispensing guidelines for medicinal drugs affecting driving performance. In J. Verster, S. PandiPerumal, J. Ramaekers, \& J. de Gier (Eds.), Drugs, Driving and Traffic Safety (pp. 121-134). Basel Birkaeuser Berlag AG.

DuPont, R. L., Voas, R. B., Walsh, J. M., Shea, C., Talpins, S. K., \& Neil, M. M. (2012). The need for drugged driving per se laws: a commentary. Traffic injury prevention, 13(1), 31-42.

Ferrari, A., Somerville, A., Baxter, A., Norman, R., Patten, S., Vos, T., \& Whiteford, H. (2013). Global variation in the prevalence and incidence of major depressive disorder: a systematic review of the epidemiological literature. Psychological Medicine, 43(03), 471-481.

Fortier-Brochu, É., Beaulieu-Bonneau, S., Ivers, H., \& Morin, C. M. (2012). Insomnia and daytime cognitive performance: a meta-analysis. Sleep Medicine Reviews, 16(1), 83-94.

Genees- en Hulpmiddelen Informatie Project. (2018a). Het aantal gebruikers van antidepressiva (https://www.gipdatabank.nl/databank\#/g//85_dep/gebr/bijlage). 
Genees- en Hulpmiddelen Informatie Project. (2018b). Het aantal gebruikers van slaap-en kalmeringsmiddelen. https://www.gipdatabank.nl/databank\#/g//85_ben/gebr/bijlage)

Jongen, S., Vermeeren, A., van der Sluiszen, N. N. J. J. M., Schumacher, M. B., Theunissen, E. L., Kuypers, K. P. C., . . Ramaekers, J. G. (2017). A pooled analysis of highway driving studies in actual traffic measuring standard deviation of lateral position (i.e. "weaving") while driving at a blood alcohol concentration of $0.5 \mathrm{~g} / \mathrm{L}$. Psychopharmacology, 234(5), 837 - 844. doi:10.1007/s00213-016-4519-z

Jongen, S., Vuurman, E. F. P. M., Ramaekers, J. G., \& Vermeeren, A. (2016). The sensitivity of laboratory tests assessing driving related skills to dose-related impairment of alcohol: A literature review. Accident Analysis \& Prevention, 89, 31-48.

Kurko, T., Saastamoinen, L., Tähkäpää, S., Tuulio-Henriksson, A., Taiminen, T., Tiihonen, J., . . Hietala, J. (2015). Long-term use of benzodiazepines: definitions, prevalence and usage patterns-a systematic review of register-based studies. European Psychiatry, 30(8), 1037-1047.

Lader, M. (2011). Benzodiazepines revisited—will we ever learn? Addiction, 106(12), 20862109 .

Leveille, S. G., Büchner, D. M., Koepsell, T. D., McCloskey, L. W., Wolf, M. E., \& Wagner, E. H. (1994). Psychoactive medications and injurious motor vehicle collisions involving older drivers. Epidemiology, 5(6), 591-598.

Meuleners, L. B., Duke, J., Lee, A. H., Palamara, P., Hildebrand, J., \& Ng, J. Q. (2011). Psychoactive Medications and Crash Involvement Requiring Hospitalization for Older Drivers: A Population-Based Study. Journal of the American Geriatrics Society, 59(9), 1575-1580.

Neutel, I. (1995). Risk of traffic accident injury after a prescription for a benzodiazepine. Annals of epidemiology, 5(3), 239-244.

Neutel, I. (1998). Benzodiazepine-related traffic accidents in young and elderly drivers. Human Psychopharmacology: Clinical and Experimental, 13(S2), S115-S123.

NHG-werkgroep. (2014). NHG-Standaard Slaapproblemen en slaapmiddelen. Retrieved from https://www.nhg.org/standaarden/volledig/nhg-standaard-slaapproblemen-en-

slaapmiddelen\#Richtlijnenbeleidoverigeslaapstoornissen

NHG-werkgroep. (2019). NHG-Standaard Depressie. Retrieved from

https://www.nhg.org/standaarden/volledig/nhg-standaard-depressie-tweede-herziening

Nikolaus, T., \& Zeyfang, A. (2004). Pharmacological treatments for persistent non-malignant pain in older persons. Drugs \& aging, 21(1), 19-41.

O’Hanlon, J. F., Vermeeren, A., Uiterwijk, M., Van Veggel, L., \& Swijgman, H. F. (1995). Anxiolytics' effects on the actual driving performance of patients and healthy volunteers in a standardized test. Neuropsychobiology, 31(2), 81-88. 


\section{Chapter 1}

Pizza, F., Jaussent, I., Lopez, R., Pesenti, C., Plazzi, G., Drouot, X., . . Dauvilliers, Y. (2015). Car crashes and central disorders of hypersomnolence: a French study. PloS one, 10(6), e0129386.

Ramaekers, J. (2003). Antidepressants and driver impairment: empirical evidence from a standard on-the-road test. The Journal of clinical psychiatry, 64(1), 20-29.

Ramaekers, J. (2017). Drugs and driving research in medicinal drug development. Trends in pharmacological sciences, 38(4), 319-321.

Rapoport, M. J., Zagorski, B., Seitz, D., Herrmann, N., Molnar, F., \& Redelmeier, D. A. (2011). At-fault motor vehicle crash risk in elderly patients treated with antidepressants. The American Journal of Geriatric Psychiatry, 19(12), 998-1006.

Ravera, S., Ramaekers, J. G., \& de Gier, J. J. (2012). Are selective serotonin reuptake inhibitors safe for drivers? What is the evidence? Clinical therapeutics, 34(5), 1070-1083.

Ravera, S., van Rein, N., De Gier, J. J., \& de Jong-van den Berg, L. (2011). Road traffic accidents and psychotropic medication use in the Netherlands: a case-control study. British Journal of Clinical Pharmacology, 72(3), 505-513.

Ray, W. A., Fought, R. L., \& Decker, M. D. (1992). Psychoactive drugs and the risk of injurious motor vehicle crashes in elderly drivers. American journal of epidemiology, 136(7), 873-883.

Smink, B. E., Egberts, A. C., Lusthof, K. J., Uges, D. R., \& De Gier, J. J. (2010). The relationship between benzodiazepine use and traffic accidents. CNS drugs, 24(8), 639-653.

van Laar, M., Volkerts, E. R., \& van Willigenburg, A. (1992). Therapeutic effects and effects on actual driving performance of chronically administered buspirone and diazepam in anxious outpatients. Journal of clinical psychopharmacology, 12(2), 86-95.

van Schie, M. K., Werth, E., Lammers, G. J., Overeem, S., Baumann, C. R., \& Fronczek, R. (2016). Improved vigilance after sodium oxybate treatment in narcolepsy: a comparison between in-field and in-laboratory measurements. Journal of sleep research, 25(4), 486-496.

Vermeeren, A. (2004). Residual effects of hypnotics. CNS drugs, 18(5), 297-328. 




\section{CHAPTER 2}

\section{Influence of long-term}

benzodiazepine use

on neurocognitive

skills related to driving

performance in patient

populations: a review

\section{Published as}

van der Sluiszen, N.N.J.J.M., Vermeeren, A., Jongen, S., Vinckenbosch, F.R.J. and Ramaekers, J.G. (2017). Influence of long-term benzodiazepine use on neurocognitive skills related to driving performance in patient populations: a review. Pharmacopsychiatry, 50(5), 189-196, DOI: 10.1055/s-0043-112755. 
Chapter 2

\begin{abstract}
Acute benzodiazepine intoxication produces severe impairment of neurocognitive skills related to driving. It is less clear whether such impairments also occur in patients who use benzodiazepines chronically. The current review evaluated neurocognitive skills of long-term benzodiazepine users and addressed two major questions: Do long-term users develop tolerance for the impairing effects of benzodiazepines on neurocognitive performance and, if so, does tolerance warrant a change in driver fitness classification systems that currently deem users of benzodiazepines unfit to drive? Neurocognitive impairments were reported in patients who on average used benzodiazepines for 5 - 15 years. In addition, sensitivity to acute benzodiazepine impairment decreased in long-term users, suggesting (partial) tolerance. Definitions of clinical relevance of neurocognitive impairments in long-term users and how these were affected by duration of benzodiazepine use were generally lacking. Also, sensitivity of neurocognitive tasks to drug effects and their validity to predict fitness to drive were generally unknown. Because of these limitations, no firm conclusion can be drawn regarding a re-classification of long-term benzodiazepine effects on driver fitness.
\end{abstract}




\section{INTRODUCTION}

Benzodiazepines are frequently prescribed medicinal drugs [1], and commonly used to treat anxiety- [2] and sleep related disorders [3]. Benzodiazepines bind to the $\mathrm{GABA}_{\mathrm{A}}$ receptor in the brain, promoting anxiolytic and sleep-inducing effects, but also psychomotor and cognitive impairment [4]. This in turn, may lead to impairment in daily activities, such as operating a vehicle [5].

Epidemiological data show that benzodiazepine usage is associated with an increased risk of becoming involved in a traffic accident [6,7] and performing unsafe driving behaviour [8]. The effects of benzodiazepines on driving performance have been extensively studied in randomized-placebo controlled studies with healthy volunteers. These studies suggest that a single dose leads to moderate or severe impairment in driving performance, depending on factors such as dose, half-life and time after administration [5,9]. Moreover, repeated dosing studies with healthy volunteers, over a 3 week period, suggest that partial tolerance for psychomotor and memory impairment occurs [10,11].

Studies on the effects of benzodiazepines on cognition and driving performance in patients support the development of partial tolerance $[12,13]$. For example, repeated dosing of diazepam in anxious patients resulted in significant driving impairment up to 4 weeks after treatment initiation, but the magnitude of impairment decreased over time. From epidemiological studies, it is known that benzodiazepine usage is associated with an increased risk of becoming involved in a traffic accident [14,15]. However, the overall risk of traffic accident involvement decreases when benzodiazepines are taken over a two month time window [16]. Likewise it has been demonstrated that repeated users of benzodiazepines have a lower risk of traffic accidents compared to new users [17]. However, despite the development of tolerance, elevated crash risk has still been demonstrated in drivers after 1 year of benzodiazepine use [18,19].

The development of tolerance in long-term benzodiazepine users may have implications for the classification of the magnitude of benzodiazepine-induced impairment on driving performance. Drug classification systems (see [20,21]) apply a graded level warning system to inform patients and practitioners about the potential increase in driving impairment associated with use of a certain drug. Classifications that are commonly used to define drug effects on driving are: no/minor influence (category 0 / I), moderate influence (category II) and severe influence (category III). Patients who use category III medication are advised not to drive and to seek medical advice after a period of treatment about the conditions to restart driving again. 


\section{Chapter 2}

Benzodiazepines are considered category III medication because acute administration has shown to produce severe driving impairment in healthy subjects and patients, i.e. comparable to driving under the influence of a blood alcohol concentration $>0.8 \mathrm{mg} / \mathrm{ml}$. However, this quantification might be overly conservative for long-term users of benzodiazepines in the event that they develop partial or complete tolerance to the impairing effects of benzodiazepines throughout treatment.

This review summarizes the literature on controlled studies investigating long-term ( $\geq 6$ weeks) benzodiazepine usage and neurocognitive measures of driving performance in patient populations published between 1986 - 2016, and aims to address two major questions: Do longterm users develop tolerance for the impairing effects of benzodiazepines on driving performance and, if so, does tolerance warrant a change in driver fitness classification systems that currently deem all users of benzodiazepines unfit to drive?

\section{METHODS}

The literature search was limited to the effects of long-term benzodiazepine usage on driving performance in patient populations for studies published between 1986 and 2016. The following search terms were used in various search engines (e.g.: Pubmed, Medline, PsychInfo): "anxiolytic", "benzodiazepine", "driving performance", "fitness to drive", "hypnotic", "on-theroad driving", "simulated driving", "long-term treatment, "chronic treatment". The following criteria where used to evaluate the papers: (1) includes description of patients samples with long-term benzodiazepine use (i.e. $\geq 6$ weeks), (2) assessment of experimental, neurocognitive tasks that are related to dimensions of driving (e.g.: "attention, reaction time, executive functioning, vigilance") or driving tasks performed in actual traffic, (3) controlled studies: i.e. performance of long-term users is either placebo-controlled, compared to a control group or other patient groups, (4) does not solely describe withdrawal or discontinuation effects of benzodiazepine use, (5) does not describe a review or meta-analysis, (6) published in a peerreviewed journal. After considering all these criteria, 13 studies were selected.

\section{Terminology}

Papers either use "chronic" or "long-term" usage to describe patient samples. The original terminology of each included paper is used in the results section. For other parts, one overarching term is used (i.e. "long-term users"). 


\section{RESULTS}

Thirteen studies were included in this review. Ten studies compared neurocognitive and/or driving performance of long-term users to other patient groups [22-24], to healthy controls [2527] or both [28-31]. Three studies have assessed the influence of acute benzodiazepine administration on neurocognitive and/or driving performance of long-term users in comparison to the acute effects of a benzodiazepine in treatment naïve controls [32], placebo [33] or both [34]. Most studies included patients that had been using benzodiazepines for a number of years. Mean duration of benzodiazepine use ranged from 5-15 years between studies. Primary indications for benzodiazepine prescription were insomnia or anxiety, sometimes in combination with additional psychiatric disorders such as depression or social phobia. Detailed characteristics of patient populations, type and duration of treatment as well as a summary of the major results are presented in Table 1 for each study. Papers are reported in chronological order (i.e. oldest - newest).

\section{Comparative studies in long-term benzodiazepine users and control groups}

Lucki et al [22] compared the performance of 43 chronic benzodiazepine users with 26 drugfree anxious controls. Chronically treated patients either used benzodiazepine mono-therapy $(n=33)$ or poly-therapy $(n=10)$ treatment. Neurocognitive measures included tests of digit symbol substitution, symbol copying, letter cancelation, critical flicker fusion and verbal memory. Results showed that performance of chronic users did not significantly differ from controls, except for the critical flicker fusion test, in which chronic users displayed poorer performance. Subgroup analysis based on benzodiazepine half-life (short vs. long) revealed no significant performance difference between these two chronic user subgroups.

Golombok et al [28] compared the cognitive ability of 50 long-term benzodiazepine users with 34 ex-benzodiazepine users, as well as a group of 27 matched controls. The study aimed to identify neurocognitive measures affected by benzodiazepine exposure. Benzodiazepine exposure was defined as the duration of use multiplied with dose. Neurocognitive measures included the cancelation test, reaction time, digit symbol substitution test, symbol copying test, verbal recall memory, visual perceptual analysis, trail-making test, category sorting test and the word association test. Benzodiazepine exposure significantly impaired performance in the digit symbol substitution test, symbol copying test and visual perceptual analysis. The magnitude of performance impairment increased with higher levels of benzodiazepine exposure. 


\section{Chapter 2}

Sakol and Power [26] investigated the effect of graded withdrawal on psychomotor in 12 longterm benzodiazepine users. Before discontinuation of benzodiazepine treatment, their performance was compared with that of 10 healthy controls, using a four choice reaction time task (i.e. decision- and movement component), a sensory threshold detection task and a key tapping rate task. Results showed that long-term users performed worse than controls on the four choice reaction time decision component and the sensory threshold detection task. No significant differences were found on the movement component and key tapping rate.

Tata et al [27] investigated the effect of withdrawal in long-term benzodiazepine users on psychomotor- and cognitive performance. Before discontinuation of benzodiazepine treatment the performance of 21 long-term benzodiazepine users was compared with that of 21 normal controls, using measures of logical memory, paired associate learning, digit span, digit symbol substitution and trail making. Results showed that long-term benzodiazepine users performed worse than controls on all measures.

Gorenstein et al [29] studied the discontinuation effects of benzodiazepines on neurocognitive performance. Performance of 28 long-term benzodiazepine users was compared with that of a group of 53 benzodiazepine free anxious patients and 56 healthy controls. Measures included the digit symbol substitution test, (symbol) copying test, cancellation task, ball bearing, digit span and verbal recall. Before benzodiazepine discontinuation, long-term benzodiazepine users performed significantly worse on the digit symbol substitution test, symbol copy test, digit-span (forward \& backward), immediate recall and delayed recall, in comparison to drug-free patients and healthy controls. Long-term benzodiazepine users as well as drug-free patients performed significantly worse on the ball bearing task as compared to healthy controls. No significant differences in performance were found between the groups on the symbol copy test.

Vignola et al [31] compared the neurocognitive performance of 20 chronic users of benzodiazepines hypnotics with 20 untreated insomnia patients and 20 self-defined good sleepers. Neurocognitive measures included the verbal paired associates task (i.e. immediate \& delayed recall), visual reproduction task (immediate \& delayed recall), digit span, symbol substitution, Purdue pegboard test, trail making test and the Wisconsin card sorting test. Performance was compared between groups, as well as with an age-matched normative dataset (normative data unavailable for the verbal paired associates and Wisconsin card sorting test). To facilitate the interpretation of results, authors performed principal component analysis on the neurocognitive variables to reduce the total number of variables. Identified components 
were: attention/concentration, memory, psychomotor speed, executive functioning. Results showed no significant differences between the three groups on measures of memory, psychomotor speed and executive functioning. Groups did, however, differ on measures of attention/concentration (digit span, forward \& backward). Chronic benzodiazepine users and untreated insomnia patients performed significantly poorer than good sleepers on the digit span forward component. Untreated insomnia patients also performed more poorly on the digit span backward component, as compared to good sleepers. Analysis with normative data revealed that all groups performed within normative range.

McAndrews et al [25] studied the withdrawal effects of benzodiazepines on neurocognitive performance. Before benzodiazepine discontinuation, the neurocognitive performance of 25 long-term benzodiazepine users was compared with that of 26 healthy controls. Measures belong to four (cognitive) domains, namely: a) mental processing (digit span, stroop test), b) psychomotor speed (trail-making, digit symbol substitution, finger tapping, bead-sorting), c) learning/memory (immediate recall, delayed recall, delayed recognition, total recall) and d) affective scales (SCL-90-R, state-trait anxiety index, geriatric depression scale). Before discontinuation of benzodiazepine treatment, long-term users performed significantly worse than controls in the mental processing and learning/memory domain, but not on psychomotor speed. However, when the composite score of the affective measures was included as a covariate in the analysis, no significant group effects were observed.

Leufkens et al [30] compared the performance of 22 chronic (i.e. frequent) benzodiazepine users to that of 20 infrequent benzodiazepine users and 21 healthy controls. Primary measures involved two standardized driving tests, the highway driving test (a measure of automated driving skills) and the car-following test (a measure of controlled driving skills). Secondary measures were the word learning test, digit span (forward \& backward), critical tracking test, divided attention test, stop signal test and the psychomotor vigilance task. Results showed no significant performances differences between the three groups on the two standardized driving tests and the neuropsychological tests. No significant differences between groups were found on the driving instructor's evaluation of driving quality and apparent sedation.

Manthey et al [23] compared the psychomotor performance of chronic benzodiazepine users in a large psychiatric population with either major depressive or anxiety disorders. Four subgroups were identified: non-users $(n=2404)$, benzodiazepine low dose $(n=288)$, intermediate dose $(n=74)$ and high dose $(n=57)$. Reaction time was the only neurocognitive measure. Results 


\section{Chapter 2}

showed significant impairment in reaction time of high dose users in comparison to non-users, but not in users of a low or intermediate dose. Within the group of chronic users $(n=419)$, dose, duration of use and type of benzodiazepine showed a positive relationship with reaction time. After correcting for co-variates, only dose remained significant.

Puustinen et al [24] studied withdrawal effects in long-term benzodiazepine users on cognition. Before benzodiazepine discontinuation, the performance of 89 long-term benzodiazepine users was assessed. Users were classified into subgroups based on duration of benzodiazepine use: i.e. shorter than 5 years $(n=14)$, use $5-10$ years $(n=42)$ and more than 10 years $(n=33)$. Measures involved simple reaction time, a two-choice reaction time test and a vigilance test. Results showed no significant difference in neurocognitive performance between the three subgroups on any measure. Because no control group was included, it was not possible to determine whether neurocognitive performance across these subgroups was actually impaired or not.

\section{Experimental studies of acute benzodiazepine administration in long-term users}

Voshaar et al [32] investigated the effects of an additional dose of oxazepam (10 and $30 \mathrm{mg})$ in 16 chronic users of oxazepam. The magnitude of both additional doses was compared to the acute effects observed in 18 treatment naïve matched controls. Measures included saccadic eye movement, acoustic startle reflex, reaction time and the 15-word memory test (delayed recall). Results indicated that tolerance for the impairing effects of oxazepam develop differentially in different domains. Acute doses of oxazepam did not affect psychomotor performance, as measured by reaction time, in chronic benzodiazepine users, but significantly impaired psychomotor function of treatment naïve controls. Oxazepam produced memory impairment in both groups.

Leufkens et al [34] examined the residual effects of a single dose of zopiclone $7.5 \mathrm{mg}$ on actual driving performance in 16 chronic benzodiazepine users (intake $\geq 4$ days a week) and 16 infrequent benzodiazepine users (intake $\leq 3$ days a week). The residual effect of zopiclone $7.5 \mathrm{mg}$ in both patient groups were compared with the residual effects observed in 16 treatment naïve matched controls. Primary and secondary measures were the same as in the previous study by Leufkens et al [30]. Results indicated that the magnitude of impairment (i.e. zopiclone placebo) was significantly less in chronic users as compared to controls in the highway driving test. The magnitude of impairment and serum concentration of zopiclone only correlated significantly in the control group. In the same task, no significant differences were found 
between infrequent users and controls. No effects of zopiclone on the parameters of the car following test were observed. For the neurocognitive tests, infrequent users performed poorer on immediate recall after zopiclone administration, whereas chronic users performed poorer on immediate recall to controls during placebo. No effects of zopiclone were observed on the psychomotor vigilance task or critical tracking task for either group. The magnitude of impairment on the tracking component of the divided attention test was significant in both patient groups, but not in controls. Controls and infrequent users showed significant impairment in the stop signal task after zopiclone administration, but this effect was not observed in chronic users.

Pomara et al [33] examined the effects of a single dose of lorazepam in elderly long-term users of lorazepam. The lorazepam dose was calibrated for each individual participant and based on the highest daily dose of lorazepam. The performance of 37 long-term lorazepam users was assessed after placebo and lorazepam treatment. Comparisons between placebo and lorazepam treatment were made at baseline (pre-treatment), and 1, 2.5 and 5 hours post-dose. Measures included the Buschke selective reminding test and the Purdue pegboard test. Results showed significant memory impairment, compared to placebo, until at least $2.5 \mathrm{~h}$ post-lorazepam dosing. Psychomotor impairment remained significant up to $5 \mathrm{~h}$ post-lorazepam dosing.

\section{DISCUSSION}

The present review examined the effect of long-term benzodiazepine usage on measures of neurocognitive skills related to driving performance. Comparative studies indicated that longterm users of benzodiazepines display impairment in the domains of attention, concentration, or memory when compared to controls $[26,29,31]$. Increased benzodiazepine exposure further modulated these impairments [28]. Several studies suggested that psychomotor function of long-term benzodiazepine users was comparable to that of drug-free patients [22] or healthy controls [30,31]. In contrast, other studies reported the presence of psychomotor impairment [25,27,29], particularly at higher benzodiazepine dosages [23]. Overall, comparative studies indicate the presence of neurocognitive impairments in patients who, on average, had been using benzodiazepines for 5-15 years. Neurocognitive impairments increased with higher benzodiazepine exposure or doses which supports the notion that these are (partly) caused by long-term treatment and do not just reflect an underlying psychopathological disorder. The presence of neurocognitive impairments in long-term benzodiazepine users is in line with 


\section{Chapter 2}

epidemiological studies that report a significant association between cognitive impairment and long-term benzodiazepine use $[35,36]$.

Comparative studies in long-term benzodiazepine users and controls do not allow for strong conclusions on the development of tolerance for the impairing effects of benzodiazepines throughout treatment. Most of the studies were not designed to assess changes in neurocognitive impairment as a function of treatment duration. The only exception is the study by Puustinen et al [24] that assessed neurocognitive function of patient populations who used benzodiazepines for less than 5 years, between 5 - 10 years and more than 10 years. They reported no differences in neurocognitive performance between groups, which seems to suggest that tolerance reaches a plateau. However, it is unclear whether their test battery was sensitive to benzodiazepine impairment given that no control group was included. It is therefore impossible to determine whether neurocognitive performance of long-term users that participated in this study was impaired or not. The only suggestion that comes from the studies comparing long-term benzodiazepine users and controls is that tolerance, if it occurs, is only partial because neurocognitive impairments were generally detectable in long-term benzodiazepine users.

Studies assessing the acute effects of benzodiazepines in long-term users did provide evidence for development of tolerance over time. These studies [32-34] demonstrated that single doses of benzodiazepines produce impairment of neurocognitive function and actual driving performance in long-term users as well as healthy controls, and that the magnitude of performance impairment was significantly less in the former. These findings strongly suggest that long-term users of benzodiazepines develop tolerance for the impairing properties of benzodiazepine treatment but also indicate that tolerance is not complete. In other words, neurocognitive impairments may mitigate with prolonged benzodiazepine treatment but is unlikely to fully disappear.

Unfortunately, the present studies provided little information regarding the clinical relevance of neurocognitive impairments observed in long-term benzodiazepine users. Most studies did not quantify the magnitude of neurocognitive impairments in terms of clinical relevance for day to day operations, such as operating a vehicle. The only exception is the study by Leufkens et al [34] that assessed the influence of zopiclone $7.5 \mathrm{mg}$ on actual driving and neurocognitive functioning in frequent and infrequent benzodiazepine users, as well as healthy controls. Driving impairment following zopiclone administration was significantly less in frequent benzodiazepine users as compared to healthy controls. Driving impairment in the frequent user 
group was on average of lesser magnitude than that produced by a blood alcohol concentration of $0.5 \mathrm{mg} / \mathrm{ml}$, which is the legal limit for driving a car in many countries. Driving impairment following zopiclone administration in healthy controls on the other hand was larger than that observed after driving with a blood alcohol concentration of $0.5 \mathrm{mg} / \mathrm{ml}$. This study thus clearly suggests that the magnitude of driving impairment in long-term benzodiazepine users may be relatively mild in magnitude. It is also an indication that current classification systems that quantify the impairment effects of benzodiazepines on driving as severely impairing (i.e. equivalent to a blood alcohol concentration $>0.8 \mathrm{mg} / \mathrm{ml}$ ) may be too conservative for long-term benzodiazepine users.

It is however too early to draw definitive conclusions regarding the classification of benzodiazepine effects on driver fitness after long-term use. The present studies have a number of limitations that need to be addressed in future studies that are needed to provide a stronger scientific rationale for including treatment duration as a determining factor in classification systems of drug induced driving impairment. These limitations include: 1) the lack of criterion measures to determine the clinical relevance of drug induced impairments in neurocognitive function, 2) the absence of assessing neurocognitive impairments as a function of duration of benzodiazepine use, and 3) unknown sensitivity of many neurocognitive tests to assess drug effects or unknown validity to predict driver fitness.

Criterion measures allow for the comparison of neurocognitive impairments to those caused by a benchmark drug that shows a clear exponential dose-dependent relationship with accident crash-risk, such as alcohol [37,38]. Neurocognitive and driving impairments observed in longterm benzodiazepine users should be compared to alcohol induced impairments at a predefined alcohol cut-off above which crash risk is known to exponentially increase; i.e. a blood alcohol concentration of $0.5 \mathrm{mg} / \mathrm{ml}$ [38]. Such comparisons will allow expressing drug effects on performance in alcohol equivalents and will help to identify patient groups that are at risk in traffic. An example is the study by Leufkens et al [34] that evaluated the acute effects of zopiclone $7.5 \mathrm{mg}$ on actual driving against alcohol induced impairment to determine its clinical relevance.

Most studies in the present review did not include treatment duration as an independent variable in their study design. Future studies however should aim to study long-term effects of benzodiazepine use on neurocognition and driving as a function of treatment duration. Such designs will allow determining whether benzodiazepine impairment decreases over time during 


\section{Chapter 2}

prolonged treatment periods. Besides treatment duration, monitoring drug levels in the blood could be used to explain neurocognitive and driving related performance following prolonged benzodiazepine treatment. Moreover, explaining benzodiazepine related impairment as a function of treatment duration or drug-blood levels may indicate a critical duration of benzodiazepine use or drug-blood levels that is needed before tolerance mitigates the magnitude of impairment below the level of clinical relevance.

It should be noted that the present studies employed a range of neurocognitive tests of which their sensitivity to drug induced impairments is generally unknown. Moreover, their ability to predict actual driving ability has not been validated, although conceptually they measure skills related to driving performance [39]. Many of the present studies used classical neurocognitive tasks such as the symbol substitution test, the symbol copying test, the pegboard test and the trail making test that are insensitive to low and moderate doses of alcohol (i.e. blood alcohol concentrations below $0.8 \mathrm{mg} / \mathrm{ml}$ ) [40]. It is therefore advisable to include neurocognitive tasks with demonstrated sensitivity to low doses of drugs and alcohol, such as the psychomotor vigilance tasks, the divided attention task and the go/no go task, in future studies [40]. Yet, it should be noted that even neurocognitive tasks with high sensitivity to alcohol and drug effects are only moderately correlated to drug effects as assessed in an actual test of driving performance [41,42]. Future studies on long-term effects of benzodiazepine use on driver fitness should therefore include measures of on-the-road driving performance in addition to neurocognitive tasks to maximize generalizability of study findings.

In summary, the current literature demonstrates the presence of neurocognitive impairments in long-term benzodiazepine users that increase with increasing benzodiazepine exposure. In addition, sensitivity to acute benzodiazepine impairment was shown to decrease in long-term users. Together, these findings suggest that long-term users develop tolerance for the impairing properties of benzodiazepine treatment, but also, that tolerance development is not complete. The present studies, however, do not allow drawing firm conclusions regarding the classification of benzodiazepine effects on driver fitness after long-term use, given a number of limitations that hamper their interpretation. These include the general lack of criterion measures to determine the clinical relevance of drug impairment, the absence of assessing neurocognitive impairments as a function of duration of benzodiazepine use, and the unknown sensitivity of many neurocognitive tests to assess drug effects or the unknown validity to predict driver fitness. 
Influence of long-term benzodiazepine use on driving

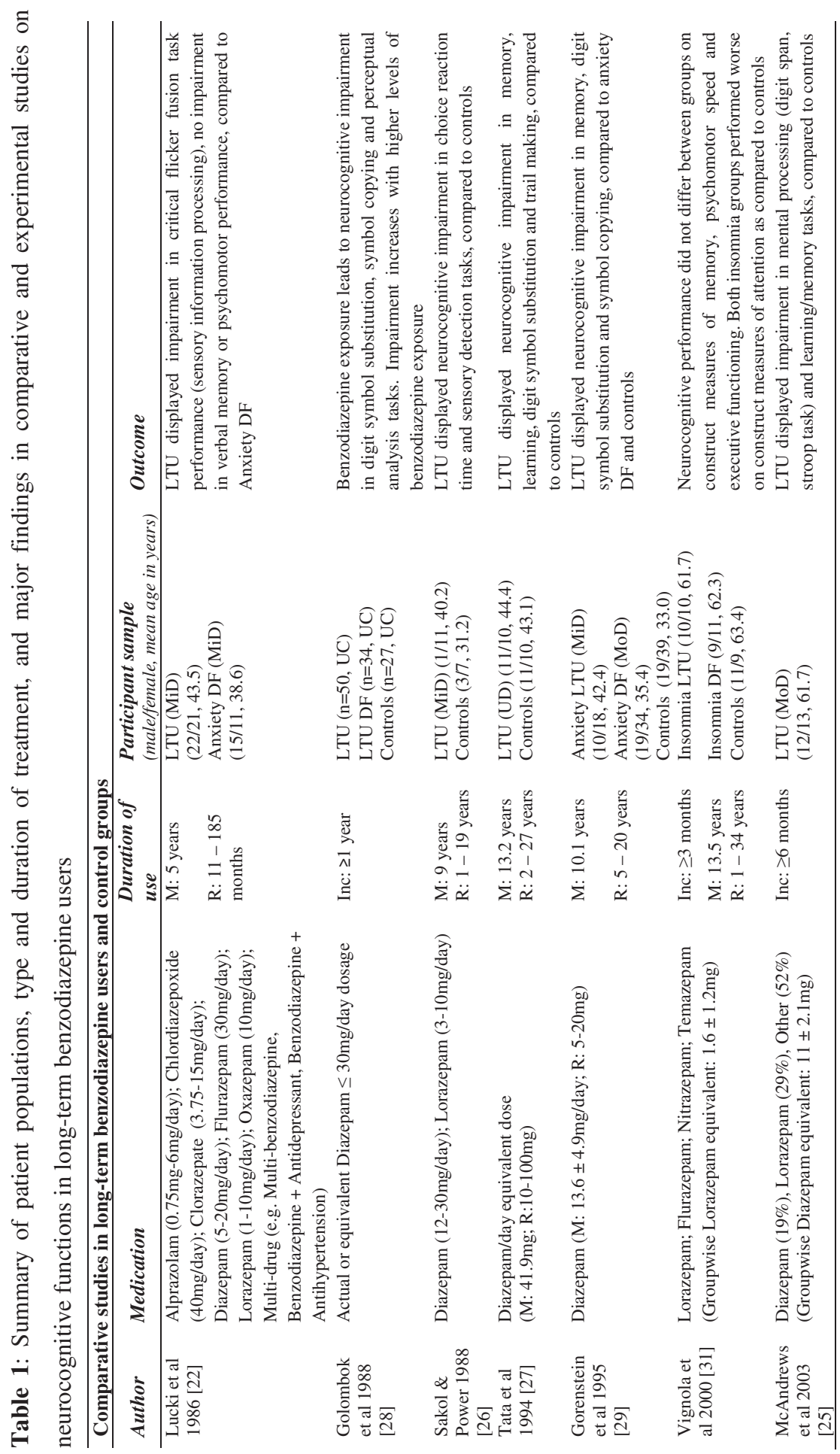




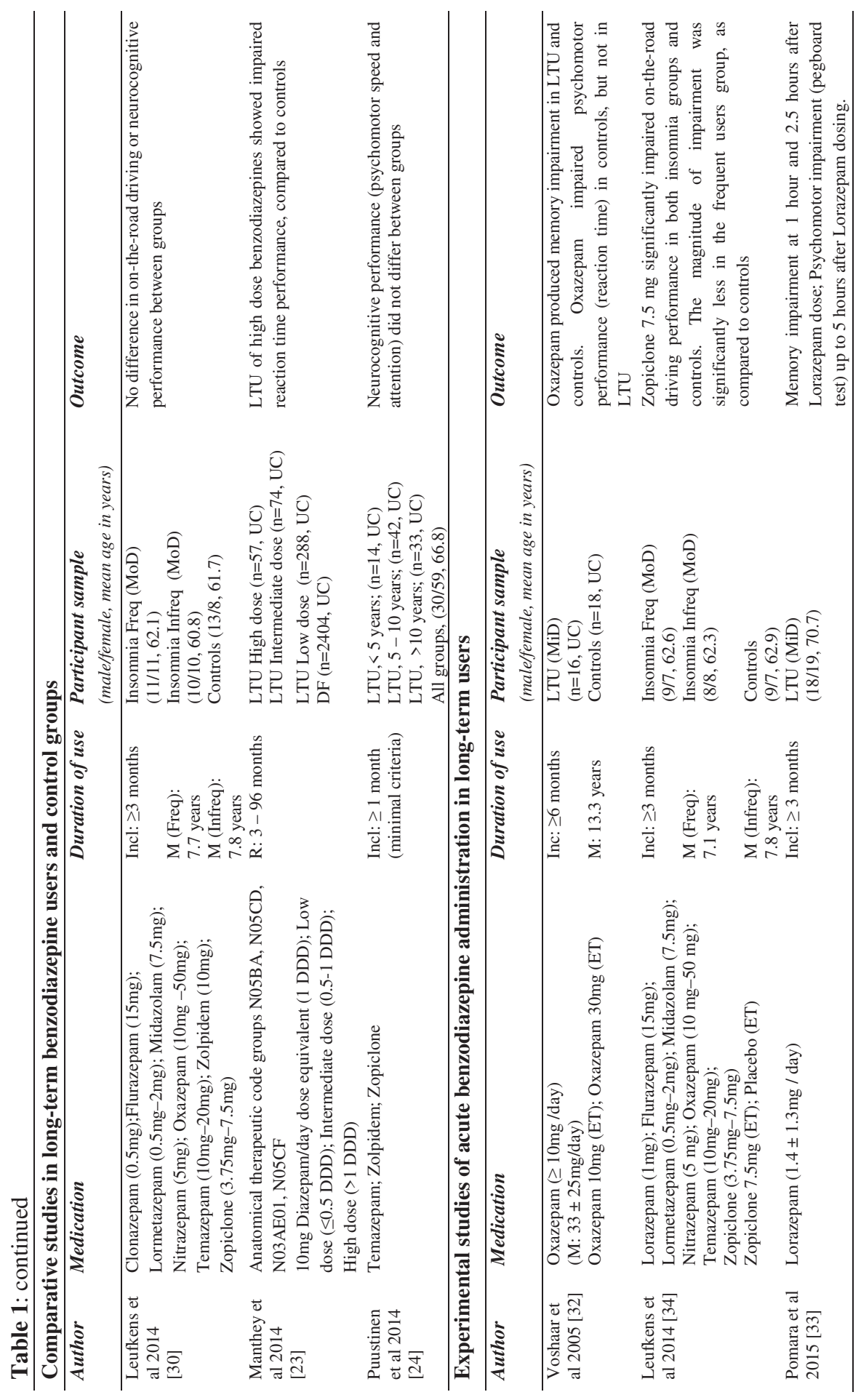




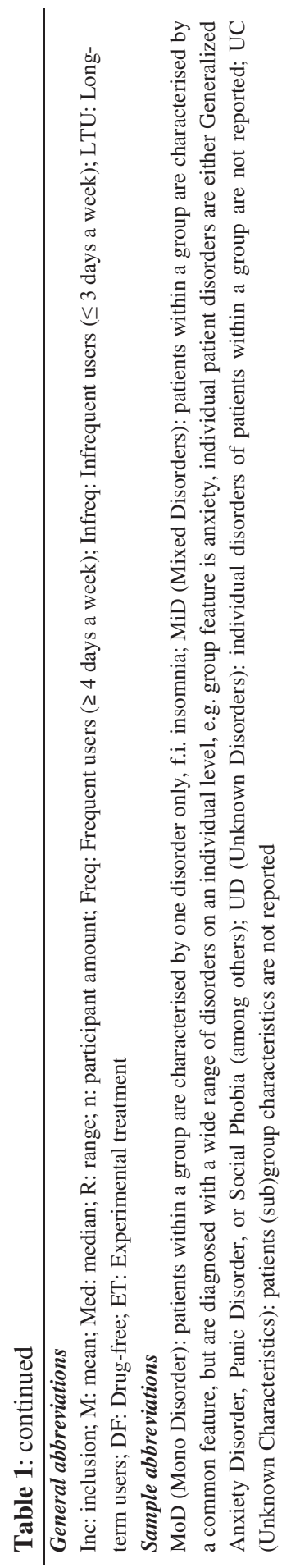




\section{REFERENCES}

1. Lader M. Benzodiazepines revisited—will we ever learn? Addict 2011; 106: 2086-2109

2. Cloos J-M, Ferreira V. Current use of benzodiazepines in anxiety disorders. Curr Opin Psychiatry 2009; 22: 90-95

3. Morin AK, Jarvis CI, Lynch AM. Therapeutic Options for Sleep-Maintenance and Sleep-Onset Insomnia. Pharmacother: J Hum Pharmacol Drug Ther 2007; 27: 89-110

4. Carvey P. Ch 6. Sedative-Hypnotics and Anxiolytics. Drug action in the Central Nervous System. Oxford: University Press; 1998: 123-150

5. Vermeeren A. Residual effects of hypnotics. CNS drugs 2004; 18: 297-328

6. Barbone F, McMahon A, Davey P et al. Association of road-traffic accidents with benzodiazepine use. The Lancet 1998; 352: 1331-1336

7. Ray WA, Fought RL, Decker MD. Psychoactive drugs and the risk of injurious motor vehicle crashes in elderly drivers. Am J Epidemiol 1992; 136: 873-883

8. Dubois S, Bedard M, Weaver B. The impact of benzodiazepines on safe driving. Traffic Inj Prev 2008; 9: 404-413

9. Vermeeren A, Leufkens TR, Verster JC. Effects of anxiolytics on driving. Drugs, driving and traffic safety: Springer; 2009: 289-305

10. Ghoneim M, Mewaldt S, Berie J et al. Memory and performance effects of single and 3-week administration of diazepam. Psychopharmacol 1981; 73: 147-151

11. Pomara N, Tun H, DaSilva D et al. The acute and chronic performance effects of alprazolam and lorazepam in the elderly: relationship to duration of treatment and selfrated sedation. Psychopharmacol bull 1998; 34: 139-154

12. O'Hanlon JF, Vermeeren A, Uiterwijk M et al. Anxiolytics' effects on the actual driving performance of patients and healthy volunteers in a standardized test. Neuropsychobiology 1995; 31: 81-88

13. van Laar M, Volkerts ER, van Willigenburg A. Therapeutic effects and effects on actual driving performance of chronically administered buspirone and diazepam in anxious outpatients. J Clin Psychopharmacol 1992; 12: 86-95

14. Dassanayake T, Michie P, Carter G et al. Effects of benzodiazepines, antidepressants and opioids on driving. Drug Saf 2011; 34: 125-156

15. Smink BE, Egberts AC, Lusthof KJ et al. The relationship between benzodiazepine use and traffic accidents. CNS drugs 2010; 24: 639-653

16. Neutel I. Risk of traffic accident injury after a prescription for a benzodiazepine. Ann Epidemiol 1995; 5: 239-244

17. Neutel I. Benzodiazepine-related traffic accidents in young and elderly drivers. Hum Psychopharmacol: Clinical and Experimental 1998; 13: S115-S123

18. Hansen RN, Boudreau DM, Ebel BE et al. Sedative hypnotic medication use and the risk of motor vehicle crash. Am J Public Health 2015; 105: e64-e69

19. Hemmelgarn B, Suissa S, Huang A et al. Benzodiazepine use and the risk of motor vehicle crash in the elderly. JAMA 1997; 278: 27-31

20. de Gier JJ, Alvarez FJ, Mercier-Guyon C et al. Prescribing and dispensing guidelines for medicinal drugs affecting driving performance. In: Verster J, Pandi-Perumal S, 
Ramaekers J, de Gier J eds, Drugs, Driving and Traffic Safety. Basel Birkaeuser Berlag AG; 2009: 121-134

21. Ravera S, Monteiro SP, de Gier JJ et al. A European approach to categorizing medicines for fitness to drive: outcomes of the DRUID project. Br J Clin Pharmacol 2012; 74: 920 931

22. Lucki I, Rickels K, Geller AM. Chronic use of benzodiazepines and psychomotor and cognitive test performance. Psychopharmacol 1986; 88: 426-433

23. Manthey L, Loenen-Frösch F, Giltay EJ et al. High dose benzodiazepines prolong reaction times in chronic users who have major depressive and/or anxiety disorders. $\mathrm{Br}$ J Clin Pharmacol 2014; 77: 571-577

24. Puustinen J, Lähteenmäki R, Polo-Kantola P et al. Effect of withdrawal from long-term use of temazepam, zopiclone or zolpidem as hypnotic agents on cognition in older adults. Eur J Clin Pharmacol 2014; 70: 319-329

25. McAndrews MP, Weiss RT, Sandor $\mathrm{P}$ et al. Cognitive effects of long-term benzodiazepine use in older adults. Hum Psychopharmacol 2003; 18: 51-57

26. Sakol MS, Power KG. The effects of long-term benzodiazepine treatment and graded withdrawal on psychometric performance. Psychopharmacol 1988; 95: 135-138

27. Tata PR, Rollings J, Collins M et al. Lack of cognitive recovery following withdrawal from long-term benzodiazepine use. Psychol Med 1994; 24: 203-213

28. Golombok S, Moodley P, Lader M. Cognitive impairment in long-term benzodiazepine users. Psychol Med 1988; 18: 365-374

29. Gorenstein C, Bernik M, Pompéia $S$ et al. Impairment of performance associated with long-term use of benzodiazepines. J Psychopharmacol 1995; 9: 313-318

30. Leufkens T, Ramaekers J, de Weerd A et al. On-the-road driving performance and driving-related skills in older untreated insomnia patients and chronic users of hypnotics. Psychopharmacol 2014; 231: 2851-2865

31. Vignola A, Lamoureux C, Bastien $\mathrm{CH}$ et al. Effects of chronic insomnia and use of benzodiazepines on daytime performance in older adults. J Gerontol B 2000; 55: P54P62

32. Voshaar RCO, Verkes R-J, van Luijtelaar GL et al. Effects of additional oxazepam in long-term users of oxazepam. J Clin Psychopharmacol 2005; 25: 42-50

33. Pomara N, Lee SH, Bruno D et al. Adverse performance effects of acute lorazepam administration in elderly long-term users: Pharmacokinetic and clinical predictors. Prog Neuropsychopharmacol Biol Psychiatry 2015; 56: 129-135

34. Leufkens T, Ramaekers J, de Weerd A et al. Residual effects of zopiclone $7.5 \mathrm{mg}$ on highway driving performance in insomnia patients and healthy controls: a placebo controlled crossover study. Psychopharmacol 2014, DOI: 1-14

35. Bierman E, Comijs H, Gundy $\mathrm{C}$ et al. The effect of chronic benzodiazepine use on cognitive functioning in older persons: good, bad or indifferent? Int J Geriatr Psychiatry 2007; 22: 1194-1200

36. Paterniti S, Dufouil C, Alpérovitch A. Long-term benzodiazepine use and cognitive decline in the elderly: the Epidemiology of Vascular Aging Study. J Clin Psychopharmacol 2002; 22: 285-293 
Chapter 2

37. Blomberg RD, Peck RC, Moskowitz $\mathrm{H}$ et al. The long beach/fort lauderdale relative risk study. J Safety Res 2009; 40: 285-292

38. Borkenstein RF, Crowther R, Shumate R. The role of the drinking driver in traffic accidents (The Grand Rapids Study). Blutalkohol 1974; 11: 1-131

39. Kay GG, Logan BK. Drugged driving expert panel report: a consensus protocol for assessing the potential of drugs to impair driving. 2011

40. Jongen S, Vuurman E, Ramaekers $\mathrm{J}$ et al. The sensitivity of laboratory tests assessing driving related skills to dose-related impairment of alcohol: A literature review. Accid Anal Prev 2016; 89: 31-48

41. Ramaekers JG. Antidepressants and driver impairment: empirical evidence from a standard on-the-road test. J Clin Psychiatry 2003; 64: 20-29

42. Verster JC, Roth T. Predicting psychopharmacological drug effects on actual driving performance (SDLP) from psychometric tests measuring driving-related skills. Psychopharmacol 2012; 220: 293-301 




\section{CHAPTER 3}

Driving performance and neurocognitive skills of long-term

users of benzodiazepine anxiolytics and hypnotics

Published as

van der Sluiszen, N.N.J.J.M., Vermeeren, A., Verster, J.C., van de Loo, A.J.A.E., van Dijken, J.H., Veldstra, JL., Brookhuis, K.A., de Waard, D. and Ramaekers, J.G. (2019). Driving performance and neurocognitive skills of long-term users of benzodiazepine anxiolytics and hypnotics.

Human Psychopharmacology: Clinical and Experimental, 34(6), e2715, DOI: 10.1002/hup.2715 
Chapter 3

\begin{abstract}
Objective: To compare actual driving performance and skills related to driving of patients using benzodiazepines anxiolytics or hypnotics for at least six months to that of healthy controls.
\end{abstract}

Methods: Participants were 44 long-term users of benzodiazepine anxiolytics $(n=12)$ and hypnotics $(\mathrm{n}=32)$ and 65 matched healthy controls. Performance was assessed using an onthe-road driving test measuring standard deviation of lateral position (SDLP, in $\mathrm{cm}$ ) and a battery of neurocognitive tasks. Performance differences between groups were compared to a blood alcohol concentration of $0.5 \mathrm{mg} / \mathrm{ml}$ to determine clinical relevance.

Results: Compared to controls, SDLP was significantly increased in hypnotic users $(+1.70 \mathrm{~cm})$, but not in anxiolytic users $(+1.48 \mathrm{~cm})$. Anxiolytic and hypnotic users showed significant and clinically relevant impairment on neurocognitive task measuring executive functioning, vigilance and reaction time. For patients using hypnotics for at least 3 years, no significant driving impairment was observed.

Conclusion: Impairing effects of benzodiazepine hypnotics on driving performance may mitigate over time following long-term use of 3 years, although neurocognitive impairments may remain. 


\section{INTRODUCTION}

Benzodiazepines are frequently prescribed to treat anxiety- and sleep related disorders (Cloos \& Ferreira, 2009; Morin, Jarvis, \& Lynch, 2007). It is well known that these drugs may cause psychomotor- and cognitive impairments that interfere with daily activities such as operating a vehicle (Dassanayake, Michie, Carter, \& Jones, 2011; Vermeeren, 2004; Verster, Veldhuijzen, \& Volkerts, 2005).

Epidemiological studies showed that benzodiazepine use is associated with an increase in risk of becoming involved in a traffic accident (Dassanayake et al., 2011; Neutel, 1995; Neutel, 1998; Smink, Egberts, Lusthof, Uges, \& De Gier, 2010). Crash risk was highest directly following treatment initiation, but gradually decreased after prolonged exposure (Neutel, 1995). Likewise, the risk of becoming involved in a traffic accident was found to be lower for repeated users of benzodiazepines in comparison to new users (Neutel, 1998). Yet, despite indications of tolerance, crash risk was still shown to be significantly higher in drivers after one year of benzodiazepine usage (Hansen, Boudreau, Ebel, Grossman, \& Sullivan, 2015; Hemmelgarn, Suissa, Huang, Jean-Francois, \& Pinard, 1997).

In experimental studies, the clinical relevance of benzodiazepine induced performance impairment is established by comparison to alcohol, given its well documented dose-dependent association with crash risk (Blomberg, Peck, Moskowitz, Burns, \& Fiorentino, 2009; Borkenstein, Crowther, \& Shumate, 1974). Most experimental studies focussed on performance impairments observed after single doses of benzodiazepines when administered to healthy volunteers (Roth, Eklov, Drake, \& Verster, 2014; Vermeeren, 2004; Vermeeren, Leufkens, \& Verster, 2009; Verster, Veldhuijzen, Patat, Olivier, \& Volkerts, 2006). Results showed that after a single day or night of treatment, benzodiazepines produce moderate or severe impairment of driving performance equivalent to driving under the influence of a blood alcohol concentration (BAC) of $0.5 \mathrm{mg} / \mathrm{ml}$ or more. Differences between benzodiazepines with regard to their level of impairment exist and mainly depend on dosage, time of administration and drug half-life (Leufkens, Lund, \& Vermeeren, 2009; Vermeeren, 2004; Vermeeren et al., 2009; Verster, Veldhuijzen, \& Volkerts, 2004).

Data from experimental studies on drug effects on driving and neurocognitive function have also been used to classify fitness to drive. Such classification systems (de Gier, Alvarez, Mercier-Guyon, \& Verstraete, 2009; Ravera et al., 2012) express drug-induced impairment in BAC equivalents. Classifications that are commonly used to define drug effects on driving, in 


\section{Chapter 3}

relation to alcohol, are: no/minor influence (category 0/I, BAC $<0.5 \mathrm{mg} / \mathrm{ml}$ ), moderate influence (category II, $0.5 \mathrm{mg} / \mathrm{ml} \leq \mathrm{BAC} \leq 0.8 \mathrm{mg} / \mathrm{ml}$ ), and severe influence (category III, BAC $>0.8 \mathrm{mg} / \mathrm{ml}$ ). A limitation of existing drug categorisation systems is their lack of information about the effect of long-term drug usage on driving performance. Current classifications are mainly based on acute effects of single doses or short-term treatment in healthy volunteers. Consequently, most benzodiazepines are put in category III because their acute effects on performance are usually severe. Yet, it is known that tolerance to benzodiazepine impairment might develop after repeated administration in healthy volunteers (Ghoneim, Mewaldt, Berie, \& Hinrichs, 1981; Pomara et al., 1998) and patients (O'Hanlon, Vermeeren, Uiterwijk, Van Veggel, \& Swijgman, 1995; van Laar, Volkerts, \& van Willigenburg, 1992).

Nevertheless, driving performance may not completely normalize, as suggested by impairment found in a range of neuropsychological functions of long-term benzodiazepine users (Barker, Greenwood, Jackson \& Crowe, 2004; Crowe \& Stranks 2017). The severity and relevance of such impairment with respect to patients' driving performance is not clear however. The classification of benzodiazepines in Category III, irrespective of duration of use, may be overly conservative for drivers who have been receiving long-term treatment, limiting their mobility. As a partial solution, taking duration of use into account, current Dutch laws state that benzodiazepine users are unfit to drive when treated for less than 3 years, but can request an individual driver fitness evaluation after more than 3 years of stable usage (Ministry of Infrastructure and Water Management, 2000). The criterion of 3 years seems rather arbitrary, because there is no clear scientific support for this particular cut-off point. As far as we know there are no published studies comparing driving performance of long-term benzodiazepine users before and after 3 years of use.

The primary objective of the present study was to evaluate driving performance of long-term users of benzodiazepine anxiolytics and long-term users of hypnotics separately, as compared to that of a normative control group consisting of healthy volunteers. Only users of benzodiazepines classified as category III were included. Long-term usage was defined as longer than 6 months. The secondary objective was to evaluate driving performance separately for patients who had been using treatment for less than 3 years, and those whose use exceeded 3 years. Driving performance was assessed by a standardized highway driving test in actual traffic and various neurocognitive tests related to driving. 


\section{METHODS}

\section{Design}

The study was designed as a multicentre trial (Universities of Maastricht, Utrecht and Groningen, The Netherlands) comparing groups of long-term users of benzodiazepines with healthy controls. Patients treated with benzodiazepines anxiolytics and hypnotics were analysed separately, because of the difference between these groups in time of drug intake relative to time of driving. It is known that the impairing effects of benzodiazepines on driving decrease with increased time after intake. Hypnotics are taken at bedtime and driving occurs the next day, 8 hours or more after administration. In contrast, anxiolytics are administered during the day, and driving is likely to occur within 8 hours of administration. A combination of selfreported indication and usual time of drug administration was used to classify a patient as user of hypnotics or anxiolytics.

To explore the potential difference in impairment before and after 3 years of use, hypnotic users were subdivided into two groups based on duration of treatment, i.e. long-term use between 6 months - 3 years (LT3-) and long-term use > 3 years (LT3+). Anxiolytic users could not be divided based on treatment duration due to the low sample size of this group.

\section{Participants}

Patients were recruited via patient organisations, hospitals, practitioners affiliated with UPPER (Koster, Blom, Philbert, Rump, \& Bouvy, 2014) and regional advertisement. Controls were recruited via flyers and advertisement in local newspapers.

Study participants were informed about the study's goal, procedures and potential hazards. The Medical Ethics Committee of Maastricht University and the Maastricht Academic Hospital approved the study. Furthermore, the study was conducted in agreement with the code of ethics on human experimentation established by the Declaration of Helsinki (1964), amended in Edinburgh (2000), Seoul (2008) and Fortaleza (2013). Written informed consent was obtained from each volunteer before enrolment. Volunteers received a financial compensation for their participation in the study.

\section{Patients}

A group of 44 long-term users of benzodiazepines or benzodiazepine-like drugs (i.e. Z-drugs) was recruited (12 users of anxiolytics and 32 users of hypnotics). All patients used category III 


\section{Chapter 3}

benzodiazepines that are expected to severely affect fitness to drive. These included: alprazolam, bromazepam, brotizolam, diazepam, lorazepam, lormetazepam, midazolam, nitrazepam, oxazepam, temazepam, zolpidem or zopiclone. Initial screening was based on a medical history questionnaire that was evaluated by a clinician.

The following inclusion criteria had to be met: use of a category III benzodiazepine or benzodiazepine-like drug over a period of at least six months with a frequency of at least 2 times a week ( $\approx 90$ days a year), possession of a valid driver's licence for at least three years, driving an average of at least $500 \mathrm{~km}$ per year, normal or corrected to normal vision, body mass index (BMI) between 17 and $35 \mathrm{~kg} / \mathrm{m}^{2}$. Although Dutch law deems benzodiazepine users who have been treated for less than 3 years unfit to drive, many of them drive a motor vehicle simply because they are unaware of this legal provision and because this provision is not actively enforced by the Dutch government either. Patients were excluded if they used concomitant medication classified as ICADTS cat. III. Concomitant medication classified as ICADTS cat. 0/I was allowed, whereas ICADTS cat. II was evaluated by a clinician on individual bases. Additional exclusion criteria were: alcohol use $>21$ glasses per week, smoking $>20$ cigarettes a day, use of illegal drugs.

Before test days, patients took their benzodiazepine(-like) medication as usual, i.e. in the evening or morning before testing. Patients usual dosing regimen was established at screening and monitored by self-report on the practice and test day.

\section{Controls}

A group of 65 healthy volunteers was recruited with comparable age, gender distribution and driving experience as patients. Inclusion criteria were: a valid driver's license for at least three years, driving an average of $3000 \mathrm{~km}$ per year, normal or corrected to normal vision, and a BMI between 19 and $29 \mathrm{~kg} / \mathrm{m}^{2}$. Exclusion criteria were: diagnosed with a neurological disorder or sleeping disorder; alcohol use $>21$ glasses per week); smoking $>10$ cigarettes a day, use of illegal drugs and psychoactive medication (e.g.: antidepressants, benzodiazepines, antiepileptics, anticonvulsants, antihistamines, opioids).

\section{Driving test}

In the standardized on-the-road highway driving test (Figure 1) (O'Hanlon, 1984; Ramaekers, 2017; Verster \& Roth, 2011) volunteers drive a specially instrumented car over a 100 km (61 miles) primary highway circuit accompanied by a licensed driving instructor having access to 
dual controls. The volunteers' task is to maintain a constant speed of $95 \mathrm{~km} / \mathrm{h}$ (58 miles per hour) and a steady lateral position between the delineated boundaries of the slower right hand traffic lane. The vehicle's speed and lateral position relative to the left lane delineation is continuously recorded. These signals are digitally sampled at $4 \mathrm{~Hz}$ and edited off-line to remove data recorded during overtaking manoeuvres or disturbances caused by roadway or traffic situations. The remaining data yields the standard deviation of lateral position and speed for each successive 5-km segment and, as the square root of pooled variance over all segments, for the test as a whole. The primary outcome variable is the Standard Deviation of Lateral Position (SDLP, in $\mathrm{cm}$ ) which is a measure of road tracking error, or 'weaving'. Drug-induced impairments in the standardized high way driving test have been compared to that of a wellknown benchmark drug (i.e. alcohol) that is known to jeopardize traffic safety and shows a clear exponential dose-dependent relationship with accident crash risk (Blomberg et al., 2009; Borkenstein et al., 1974). The clinical relevance of performance changes in the highway driving test have previously been determined by establishing the relationship between BAC and SDLP (Louwerens, Gloerich, DeVries, Brookhuis, \& O'Hanlon, 1987). A recent meta-analysis of nine alcohol-calibration studies revealed a mean increment in SDLP of $2.5 \mathrm{~cm}$ while operating the vehicle at a $\mathrm{BAC}$ of $0.5 \mathrm{mg} / \mathrm{ml}$, which has been defined as the minimal cut-off value to represent clinical relevant impairment (Jongen et al., 2017). The highway driving test has been used in more than 100 studies and has proven sensitivity to alcohol, benzodiazepines and many other sedating drugs (Ramaekers, 2017; Roth et al., 2014; Vermeeren, 2004).

\section{Neurocognitive tests}

\section{Trailmaking Test (TMT)}

The TMT is a paper and pencil test measuring selective and divided attention, as well as executive functions (Reitan, 1958). The test comprises two parts. In part A, the task of the volunteer is to connect, as fast as possible, 25 circles that contain the numbers 1 to 25 , by means of connecting the circles in ascending order. In part B, the 25 circles contain letters (A to L) and numbers (1 to 13). Volunteers are required to connect, as fast as possible, the 25 circles in an alternately ascending fashion (i.e. 1-A-2-B-3-C, and so on). The maximum time allowed for part A is 5 minutes, and for part B it is 6 minutes. The outcome measures for part A and B are the times (in seconds) needed to complete the task. 


\section{Chapter 3}

\section{Digit Symbol Substitution Test (DSST)}

The DSST is a paper and pencil test measuring executive attention and processing speed (Wechsler, 1958). Volunteers are presented with rows of digits (1 to 9) and have to respond by writing the corresponding symbol in a blank space, according to a key presented at the top of the paper. The primary outcome measure is the number of correctly substituted digits in 90 seconds.

\section{Adaptive Tachistoscopic Traffic Perception Test (ATTPT)}

The ATTPT assesses visual orientation ability, visual observational ability, speed of perception and skills in obtaining a traffic overview (Schuhfried, 2009). Volunteers are presented with pictures of traffic situations for a very short duration. After each picture, volunteers are required to indicate what was in the picture, by choosing from five answer options (i.e. cars, cyclists, pedestrians, traffic signs and / or traffic lights). Pictures are presented adaptively, meaning that the difficulty of the pictures is adapted to the abilities of the volunteer (i.e. volunteers who perform poorly receive pictures containing less complex traffic situations; vice versa for volunteers who perform well). The primary outcome is the number of correct answers. Time to complete the task is 10 minutes.

\section{Reaction Test (RT)}

The RT assesses reaction time and motor time in response to simple and complex visual or acoustic signals (Prieler, 2008). Before the test, volunteers are instructed to lay their index finger on a pressure-sensitive key (i.e. rest key). During the test, volunteers are required to press a target key, with their index finger, whenever a target stimulus is presented. After pressing the target key, they must return their index finger immediately to the rest key. By means of using a rest key and target key, it is possible to distinguish between reaction time (time between the presentation of the target stimulus and the moment the index finger is removed from the rest key) and motor time (the time between releasing the rest key and pressing the target key). The current experiment uses three versions of the reaction test, i.e: S1, in which volunteers have to respond whenever a yellow circle is shown on screen; S2, in which volunteers have to respond whenever they hear a tone; and S3, in which volunteers have to respond whenever they see a yellow circle on screen and a hear a tone in combination, all other stimuli combinations are to be ignored. Time to complete all three versions of this task is 10 minutes. Outcome measures for these tests are reaction time and motor time. 
The DT measures reactive stress tolerance, divided attention and mental flexibility (Neuwirth \& Benesch, 2007). The test measures the ability to sustain attention over a period of approximately $10 \mathrm{~min}$. Volunteers are presented with visual stimuli of varying colour and sounds with a different pitch, in a serial order. For each stimulus, a pre-defined button has to be pressed. The presentation of stimuli is adaptive to the reaction speed of the volunteer, meaning that the inter-stimulus-interval is shortened when volunteers make correct and fast responses, and is slowed down when volunteers make mistakes or make slow responses. During the task, volunteers are presented with the following stimuli and have to press the following corresponding buttons: a) visual coloured circles (white, yellow, red, green and blue), each presented colour has a matching coloured key on the keyboard; b) auditory signals (low pitch \& high pitch), each auditory signal has its own response key on the keyboard; c) motor signals (displayed as a white rectangle on the left or right side of the bottom of the screen), each motor signal required the volunteer to press a response pad with his right or left foot, depending on the position of the white rectangle on screen. The outcome measure is the average reaction time of all responses made.

\section{Risk-Taking Test Traffic (RTTT)}

The RTTT measures risk-taking behaviour in potentially dangerous driving situations (Hergovich, Bognar, Arendasy, \& Sommer, 2005). Volunteers are presented with 24 items (i.e. video clips) that show diverse driving situations, which are described in words before they are shown on-screen. Each driving situation is shown twice. During the first time, volunteers observe the entire driving situation. During the second time, volunteers are required to press a key on the keyboard, indicating the distance from the potential hazard at which the driving manoeuvre that has just been described becomes critical or dangerous (i.e. the point at which the volunteer would no longer perform the manoeuvre). The first item of the 24 items serves as a practice item. Time to complete the task is approximately 15 minutes. The variable "willingness to take risk in driving situations", is measured by obtaining the distance between the moment of a potential hazard, measured in hundreds of a second, and the moment the volunteer presses the key indicating that the potential hazard becomes critical or potentially dangerous. This distance is a measure of subjectively accepted level of risk. Higher scores indicate higher levels of subjectively accepted risk. 
Chapter 3

\section{Psychomotor Vigilance Test (PVT)}

The Psychomotor Vigilance Test (PVT) is based on a simple visual reaction time test (Dinges $\&$ Powell, 1985). The test measures the ability to sustain attention over a period of approximately $10 \mathrm{~min}$. Volunteers are required to respond to a visual stimulus presented at a variable interval $(2-10 \mathrm{sec})$ by pressing a button with the dominant hand. The visual stimulus is the presentation of a counter that starts running from 0 to $60 \mathrm{~s}$ at 1 -ms intervals. Volunteers are required to respond to this visual counter as soon as they perceive it on screen by pressing the corresponding button. If a response is made, the counter stops, stays on screen for $500 \mathrm{~ms}$ as visual feedback for the volunteer, and disappears. During this period, a variable interval is presented and afterwards the next counter appears on screen. This cycle repeats until 100 stimuli have been presented on screen. If a response has not been made within 60s, the clock resets and the counter restarts. Primary outcome measures are mean response speed and number of lapses (defined as responses with RT $\geq 500 \mathrm{~ms}$ ) (Basner \& Dinges, 2011). Performance on the PVT has been calibrated for dose-effects of alcohol and one night of sleep deprivation (Jongen, Perrier, Vuurman, Ramaekers, \& Vermeeren, 2015; Jongen, Vuurman, Ramaekers, \& Vermeeren, 2014).

\section{Questionnaires}

\section{Beck's Depression Inventory (BDI)}

The BDI (Beck, Steer, \& Carbin, 1988) is a 21-item self-report questionnaire measuring depression related symptomology. Answer options for each question range from 0 to 3 . The obtained total score for the BDI serves as an indicator for the presence of depression related symptoms, ranging from 0 to 63 . Higher total scores indicate the presence of more symptoms of depression.

\section{State-Trait anxiety index - Trait (STAI-T)}

The STAI-T (Spielberger, Gorsuch, \& Lushene, 1970) is the Trait dimension of the 40-item self-reported STAI questionnaire. The STAI-T contains 20-questions that measure trait anxiety (i.e. how individuals feel in general). Answer options for each questions range from 1 to 4, with total scores ranging from 20 to 80 . Higher total scores indicate more anxiety related symptoms. 
Pittsburgh Sleep Quality Index (PSQI)

The PSQI (Buysse, Reynolds III, Monk, Berman, \& Kupfer, 1989) is a self-report questionnaire that assesses the quality and patterns of sleep over the last month by rating seven sleep-related domains: "subjective sleep quality, sleep latency, sleep duration, habitual sleep efficiency, sleep disturbance, use of medication and daytime disturbance. A summary score ranging from 0 to 21 can be derived, with higher scores indicating poorer sleep quality. A summary score $\geq 5$ indicates a poor sleeper.

\section{Groningen Sleep Quality Scale (GSQS)}

The GSQS (Mulder-Hajonides van der Meulen, Wijnberg, Hollander, De Diana, \& van den Hoofdakker, 1980) is a 14-item self-report scale that assess subjective quality of sleep during the preceding night. Summary scores range from 0 to 14, with higher scores indicating poorer sleep quality. A total score $\geq 6$ indicates disturbed sleep.

\section{Procedure}

All volunteers completed a practice session and a test session, on two separate days with an interval of 1 week between both days. Volunteers started at 8:30h, 10:30h or 12:30h based on individual convenience, but the starting time was kept constant on practice and test days. On day 1 (practice day), volunteers filled out three questionnaires (BDI, PSQI and STAI-T), and were familiarized with the test procedures. Volunteers were individually trained to perform the driving test and all the neurocognitive tests. On day 2, (test day), volunteers first completed the GSQS, followed by the first part of the neurocognitive test battery (TMT, DSST, ATTPT, RT, DT). After a 15-minute break, volunteers completed the second part of the neurocognitive test battery (RTTT, PVT). Finally, volunteers were transported to the start of the highway to start the one-hour driving test. The total duration of a test day was approximately 4:00 hours (Figure 2).

\section{Statistical analysis}

Statistical power to detect a clinically relevant mean difference in SDLP of $2.5 \mathrm{~cm}$ between patients and controls was as follows: anxiolytic users vs controls, $\beta=0.58$; hypnotic users vs controls, $\beta=0.85$; hypnotic LT3- users vs controls, $\beta=0.50$ and hypnotic LT3+ users vs controls, $\beta=0.78$. Assumptions for these power calculations were: an alpha of 0.05 and a between-subject variance in SDLP of $4.3 \mathrm{~cm}$ (Jongen et al., 2017). 


\section{Chapter 3}

Matching variables (age, gender, driving experience) were included as covariates in an ANCOVA model. If none of the matching variables showed a significant influence on groupcomparisons with SDLP or a neurocognitive parameter, patient performance was compared to that of the entire group of controls $(n=65)$. Alternatively, if one (or more) matched variables did show a significant influence on a between-group comparison, only individually matched controls were included. The determination of the influence of matching variables was performed for SDLP and each neurocognitive parameter separately.

Next, non-inferiority analyses were used to determine whether the 95\% confidence interval CI of performance differences between patients and controls exceeded the criterion level of clinical relevance, i.e. an equivalent performance change as seen at a BAC of $0.5 \mathrm{mg} / \mathrm{ml}$. When evaluating the $95 \% \mathrm{CI}$ of differences between groups, three interpretations are possible (Figure 3). Patients' performance was considered not impaired (i.e. non-inferior) when the upper limit of the $95 \%$ CI of the difference from controls was below the alcohol criterion for impairment. Patients' performance was considered impaired (i.e. inferior) when the lower limit of the 95\% CI of the difference from controls was above zero and the upper limit exceeded the alcohol criterion for impairment. When the $95 \%$ CI of the difference from controls included both zero and the alcohol criterion for impairment, the results were considered inconclusive. The noninferiority limit for the on-the-road driving test (figure 4) was obtained from Jongen et al. (Jongen et al., 2017).

Clinical relevance of impairment of neurocognitive performance was also based on direct comparison impairing the effects of alcohol at a BAC of $0.5 \mathrm{mg} / \mathrm{ml}$. In a separate study (Verster et al., 2016), an alcohol-calibration was performed to determine which neurocognitive parameters were able to detect impairment at a BAC of $0.5 \mathrm{mg} / \mathrm{ml}$. Results of the calibration study showed that the only parameters sensitive for the impairing effects of alcohol were: TMTA, DSST, RT-S1, RT-S2, RT-S3, DT, PVT. Consequently, these are the only parameters that provided non-inferiority limits for the present study. The clinical relevance of neurocognitive tests used in the present study will only be discussed for these parameters.

All statistical analyses were conducted by using the IBM Statistical Package for the Social Sciences for Windows (version 24.0.01., IBM Corp., Armonk, N.Y., USA). Power calculations were performed using G*Power version 3.1 (Faul, Erdfelder, Lang, \& Buchner, 2007). 
Driving performance of long-term benzodiazepine users

\section{RESULTS}

\section{Group characteristics}

Table 1 summarizes the characteristics of the patient groups and control group. Age, gender and driving experience did not differ significantly between groups. As expected, patients had on average more complaints of anxiety, depression and sleep problems compared to controls. Differences in scores on BDI, STAI-T, PSQI and GSQS were significant for anxiolytic and hypnotic users, as well as for the hypnotic LT3- and LT3+ subgroups (all $p$ 's $<0.01$ ).

Table 2 gives an overview of psycho-active medication used per patient group. All participants took their medication at least 4 days per week. Users of anxiolytics indicated they used their medication daily, and users of hypnotics reported medication use at least 4 night per week. In total 30 patients used psychoactive co-medication (table 2), mostly second-generation antidepressants $(n=22)$ and second-generation antipsychotics $(n=6)$. Most antidepressants were SSRIs or SNRIs, which have minor effects on driving (category I). Second generation antipsychotics can have moderate effects on driving (category II). The proportion of patients using category II co-medication was higher in the LT3- group (44\%, 4 out of 9) than in the LT3+ group (26\%, 6 out of 23), and the anxiolytics group (25\%, 3 out of 12$)$.

\section{Missing data}

Data from the highway driving test were missing for one person in the control group, and for one patient in the hypnotic LT3- subgroup, due to problems with the recording system.

\section{Matching to controls}

Analyses showed no significant effect of age, gender or driving experience in the ANCOVA model on: SDLP, ATTPT, RTTT and PVT mean reaction time. For these parameters, the entire control group sample was used as a reference for comparison with patient groups. For the remaining parameters, matched healthy controls were used for each patient (sub)group.

\section{Highway driving test}

Mean $( \pm$ SE) SDLP of patient (sub)groups and controls are shown in Figure 4. Mean SDLP of patients using hypnotics differed significantly from controls $\left(F_{1,93}=4.12, p=0.04\right)$. The upper limit of the $95 \% \mathrm{CI}$ of this difference $(+1.70 \mathrm{~cm}, 95 \% \mathrm{CI}:+0.04 \mathrm{~cm},+3.35 \mathrm{~cm})$ exceeded the $+2.5 \mathrm{~cm}$ criterion, indicating clinically relevant impairment. The SDLP of patients using 
Chapter 3

anxiolytics did not significantly differ from controls $\left(F_{1,74}=1.50, p=0.23\right)$. The $95 \% \mathrm{CI}$ of the mean difference $(+1,48 \mathrm{~cm}, 95 \%$ CI: $-0.93 \mathrm{~cm},+3.88 \mathrm{~cm})$ included zero as well as the $+2.5 \mathrm{~cm}$ criterion, which indicates that the results are inconclusive.

ANOVA also showed a significant difference between LT3- hypnotic users and controls $\left(F_{1,71}\right.$ $=9.38, p<0.01)$, but not between LT3+ hypnotic users and controls $\left(F_{1,85}=0.64, p=0.43\right)$. Mean $(95 \% \mathrm{CI})$ difference in SDLP between LT3- patients and controls was $+4.56 \mathrm{~cm}$ $(+1.59 \mathrm{~cm} ;+7.53 \mathrm{~cm})$ and $+0.70 \mathrm{~cm}(-1.04 ;+2.44 \mathrm{~cm})$ for LT3+ patients. Non-inferiority testing revealed that only for LT3- patient, the lower and upper limit of the mean difference in overall SDLP exceeded zero and the $+2.5 \mathrm{~cm}$ criterion respectively, indicating clinically relevant impairment.

\section{Neurocognitive performance}

Table 3 shows the mean $( \pm$ SE) for all performance parameters for each patient (sub)group and healthy controls, and the results from ANOVA analyses. Table 4 shows an overview of the $95 \%$ CI of mean changes between patients and (matched) controls on alcohol sensitive parameters only, including inferiority limits and analyses. Comparisons between patients using anxiolytics and controls showed significant impairment of patients' performance on the DT and PVT MeanRT. $_{\text {. }}$ The $95 \%$ CI of mean changes in reaction time in the DT and PVT were above zero and exceeded the BAC $0.5 \mathrm{mg} / \mathrm{ml}$ criterion, indicating clinically relevant impairment.

ANOVA showed significant performance differences between patients using hypnotics and controls in the TMT-B, DSST, RT-S1 (motor- and reaction time), RT-S2 (motor- and reaction time), RT-S3 (motor- and reaction time), DT, RTTT and mean reaction time in PVT. Noninferiority analysis of alcohol sensitive parameters showed that the 95\% CIs of differences in DSST, RT-S1, RT-S2, RTS3 and PVT exceeded zero and the alcohol criterion indicating that impairment on these parameters can be considered clinically relevant.

ANOVA showed significant performance differences between LT3- hypnotic users and controls in the DSST, RT-S1 (motor time), RT-S2 (motor- and reaction time), RT-S3 (reaction time), DT and PVT mean reaction time. Non-inferiority analysis showed that the $95 \%$ CIs of differences in DSST, RT-S2, RT-S3, DT and PVT exceeded zero and the alcohol criterion indicating clinical relevant impairment.

ANOVA revealed significant performance differences between LT3+ hypnotic users and controls in the TMT-B, DSST, RT-S1 (motor time), RT-S3 (motor time), DT, RTTT and PVT 
mean reaction time. Non-inferiority analysis showed that the 95\% CIs of differences in DSST, DT and PVT exceeded zero and the alcohol criterion indicating impairment.

\section{DISCUSSION}

This study aimed to compare driving performance of long-term users of benzodiazepine anxiolytics and hypnotics to that of a normative control group consisting of healthy volunteers, in order to evaluate whether classification of these drugs in Category III may be too conservative for patients who receive long-term treatment. Overall, mean SDLP was significantly higher in patients treated with hypnotics as compared to controls, indicating their driving performance is worse than normal. This seemed mainly due to patients who had been using hypnotic less than 3 years, as the difference in SDLP form controls was significant in this group, but not in those who had received hypnotics treatment for more than 3 years. Mean SDLP did not differ significantly between patients treated with anxiolytics and controls, which may be explained by a lack of power due to the small sample size and large individual variation. Both patient groups (users of hypnotics and anxiolytics) displayed increased reaction times in a number of neuropsychological tasks. In line with findings for SDLP in hypnotic users, these impairments were most prominent in patients who used these drugs for less than 3 years. Clinical relevance seemed less present in patients using hypnotics for more than 3 years.

The clinical relevance of the effects of long-term benzodiazepines use on driving ability and neurocognitive performance was determined by comparing the average difference in performance between patients and the controls with the change in performance in subjects who were under the influence of a BAC of $0.5 \mathrm{mg} / \mathrm{ml}$, the legal limit for driving under the influence of alcohol in many countries. Previous studies employing the on-the-road highway driving test have demonstrated an average increase in mean SDLP of $2.5 \mathrm{~cm}$ in drivers operating with a BAC level of $0.5 \mathrm{mg} / \mathrm{ml}$ (Jongen et al., 2017). In the present study, the mean increase in SDLP in patients using anxiolytic or hypnotic benzodiazepines was $1.48 \mathrm{~cm}$ and $1.70 \mathrm{~cm}$ respectively, relative to healthy controls. The $95 \%$ CI of these mean differences included the alcohol criterion in both groups, as well as zero in case of the anxiolytic users. As mentioned above, driving performance of anxiolytic users was inconsistent. Some individuals showed marked increments in SDLP whereas others did not. Overall, no conclusion can be drawn for this group from these data.

Driving impairment observed in hypnotic users is of clinical relevance, because it exceeds the level of impairment associated with the legal limit of alcohol in traffic. This is in line with 


\section{Chapter 3}

results from epidemiological studies showing increased risk of traffic accidents associated with the use of hypnotics (Gustavsen et al., 2008; Hansen, Boudreau, Ebel, Grossman, \& Sullivan, 2015; Orriols et al., 2011). Interestingly, however, severe impairment was present only in patients who used hypnotics less than 3 years, whereas no relevant impairment, as measured by SDLP, was found in those who had been using hypnotics longer than 3 years. The mean difference in SDLP between controls and hypnotic LT3- users was $+4.56 \mathrm{~cm}$ which is equivalent to a BAC > $0.8 \mathrm{mg} / \mathrm{ml}$ (Louwerens et al., 1987). For LT3+ users the mean differences was only $0.70 \mathrm{~cm}$, and the $95 \% \mathrm{CI}$ remained below the alcohol criterion, indicating no relevant impairment of driving. The latter finding is in line with that from a previous driving study in insomnia patients who frequently used hypnotics (Leufkens, Ramaekers, de Weerd, Riedel, \& Vermeeren, 2014). Duration of use in these patients was on average 7.7 years, and their SDLP did not differ from those of a group of normal sleepers. The difference in impairment between the LT3- and LT3+ groups in our study corresponds with gradually decreasing accident risk found in epidemiological studies following benzodiazepine treatment (Neutel, 1995; Verster, Veldhuijzen, \& Volkerts, 2005). Although development of physiological tolerance may explain the mitigation in impairment, other factors may also play a role, such as improvements in underlying conditions, reduction in co-medication, and behavioural tolerance (i.e. learning to minimize unwanted drug effects on performance by cognitive or behavioural adaptations).

Users of hypnotics and anxiolytics also demonstrated increments of reaction times as compared to controls on a number of neurocognitive tasks that exceeded the alcohol criterion of clinical relevance. In line with the results of the driving test, results of cognitive tests were mostly inconclusive for users of anxiolytics, and showed clinically relevant impairment in users of hypnotics. Similar to driving impairment, psychomotor impairment in hypnotic users was most severe in patients who had been using these drugs less than 3 years.

Contrary to the absence of driving impairment, patients who used hypnotics longer than 3 years showed relevant impairment in some tests (i.e. the PVT, DSST, and DT). This finding seems in line with recent reviews (Crowe \& Stranks, 2017; van der Sluiszen, Vermeeren, Jongen, Vinckenbosch, \& Ramaekers, 2017) concluding that long-term treatment with benzodiazepines can be associated with deleterious neuropsychological effects. Impairment was even found to persist following benzodiazepine withdrawal (Crowe \& Stranks, 2017). The question remains what the consequences of this impairment are for driving. From the alcohol calibration of our tests, we can conclude that the impairment found in some neurocognitive tests after 3 years of hypnotic use is comparable to, or larger than, the effects found for alcohol at a BAC of 
$0.5 \mathrm{mg} / \mathrm{ml}$. It can be concluded that impairment may be moderate, but the evidence that patients who have been using hypnotics more than three years are severely impaired is weak. Therefore, the current classification, and the associated general prohibition to drive when using these drugs, may be too strict for this group of patients. For shorter use of hypnotics, our data support the current classification as category III. For anxiolytics there is no evidence to support a change in the current classification.

Several limitations may be present in this study. First, there may be a selection bias, in so far as probably only patients who estimated themselves as fit-to-drive volunteered for the study. However, these patients may be representative for the target population, i.e. long-term users who are active car drivers. Patients who do not feel fit-to-drive are less likely to drive in real life. Second, it should be noted that the statistical power to detect clinically relevant impairment was much less in anxiolytic users $(n=12)$ and hypnotic LT3- users $(n=9)$, due to the low sample size in both groups. Yet, differences from controls were relatively large in the LT3group and therefore still achieved statistical significance. Third, the anxiolytic and hypnotic users in the present study formed a heterogeneous sample due to the diversity in benzodiazepines, daily dosages, time since last dosage and co-medication. Such factors may generate variability in performance between patients and hinder the interpretation of underlying mechanisms. However, it does reflect the diversity in the population of long-term users of benzodiazepines who drive a car. Fourth, subdivision of benzodiazepine use below and above 3 years was a legislative measure as adopted in The Netherlands. Strict conclusions based on this somewhat arbitrary subdivision should therefore be avoided. Nonetheless, future studies could explore the time needed to build op tolerance to the impairing effects of daily antidepressant usage and handle treatment duration as a continues variable over time.

Overall, the results show that impairing effects of benzodiazepine hypnotics on driving performance may mitigate over time following long-term use of 3 years, although forms of neurocognitive impairment may remain. This supports the idea to take duration of treatment into account when evaluating the impact of hypnotics on individual drivers. The implication would be that classification systems that grade effects of drugs on driving should allow for differential classification of hypnotics in relation to treatment duration. The results do not support differential grading for benzodiazepine anxiolytics. 
Chapter 3

\section{Acknowledgements}

Authors would like to thank A. van Oers, I. Brauers, H. Brauers, C. Steins, J. Jongen, S. Coleman, F.R.J. Vinckenbosch (Maastricht University), J. Jansen, R. Enkelaar, Z. Kösem, J. Zwart, W. Langendroff, S. Timmermans, S. van Kreel, D. Bervoets and S. de Klerk (University of Utrecht), B. de Kruijk, E. Flier and M. Janmaat and J.H. van Dijken (University of Groningen) for their assistance in carrying out the study. C. van Leeuwen, MD. (Maastricht University), N. Bouwmeester, MD. (University of Utrecht), and P.P. de Deyn, MD. (University of Groningen), for their medical supervision.

\section{Declaration of Interest}

JC Verster has received grants from Janssen, Nutricia, Red Bull, Sequential, Takeda, and acted as a consultant / advisor for 82Labs, Canadian Beverage Association, Centraal Bureau Drogisterij bedrijven, Clinilabs, Coleman Frost, Danone, Deenox, Eisai, Janssen, Jazz, Purdue, Red Bull, Sanofi-Aventis, Sen-Jam Pharmaceutical, Sepracor, Takeda, Transcept, Trimbos Institute, Vital Bevrages and ZBiotics. A Vermeeren and JG Ramaekers have received funding over the last 4 years from pharmaceutical companies (Eisai, Jazz, Merck and Transcept).

\section{Funding}

This study was financially supported by the Dutch Ministry of Infrastructure and Water Management. 


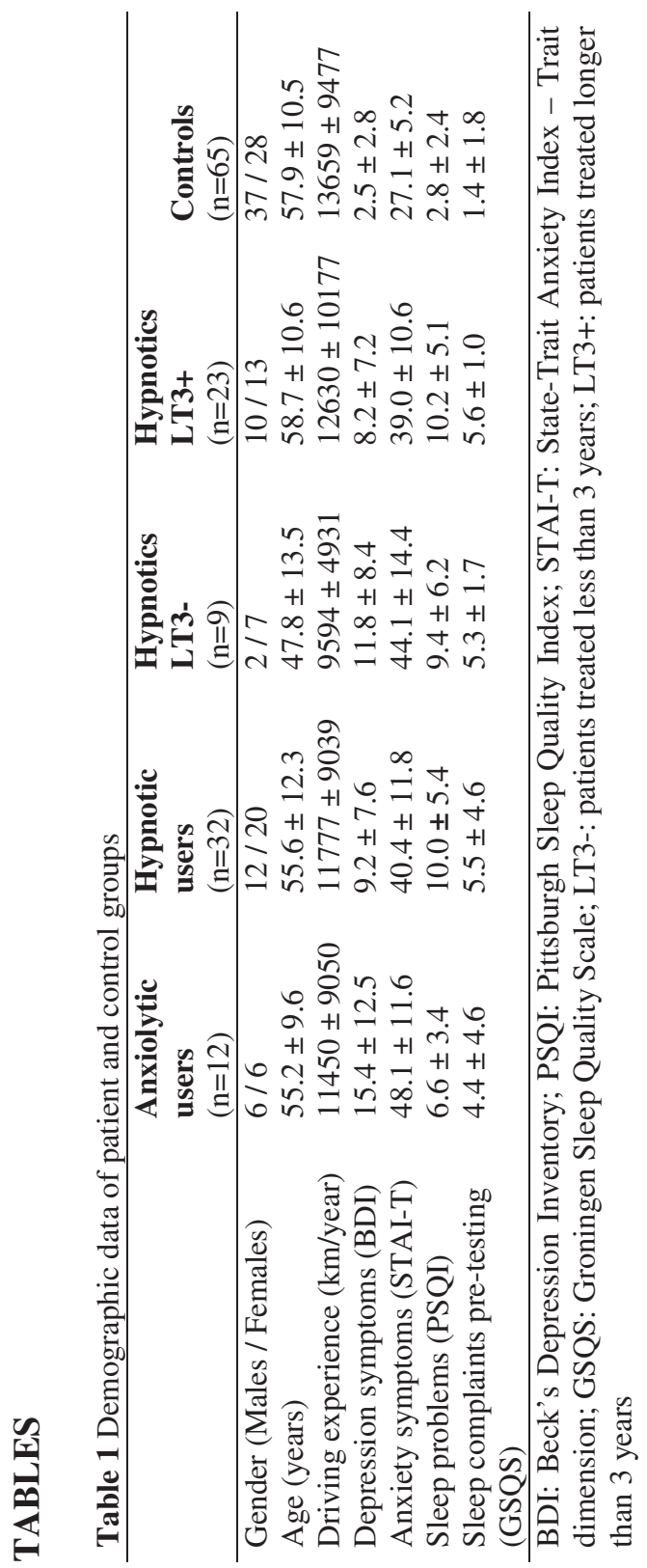




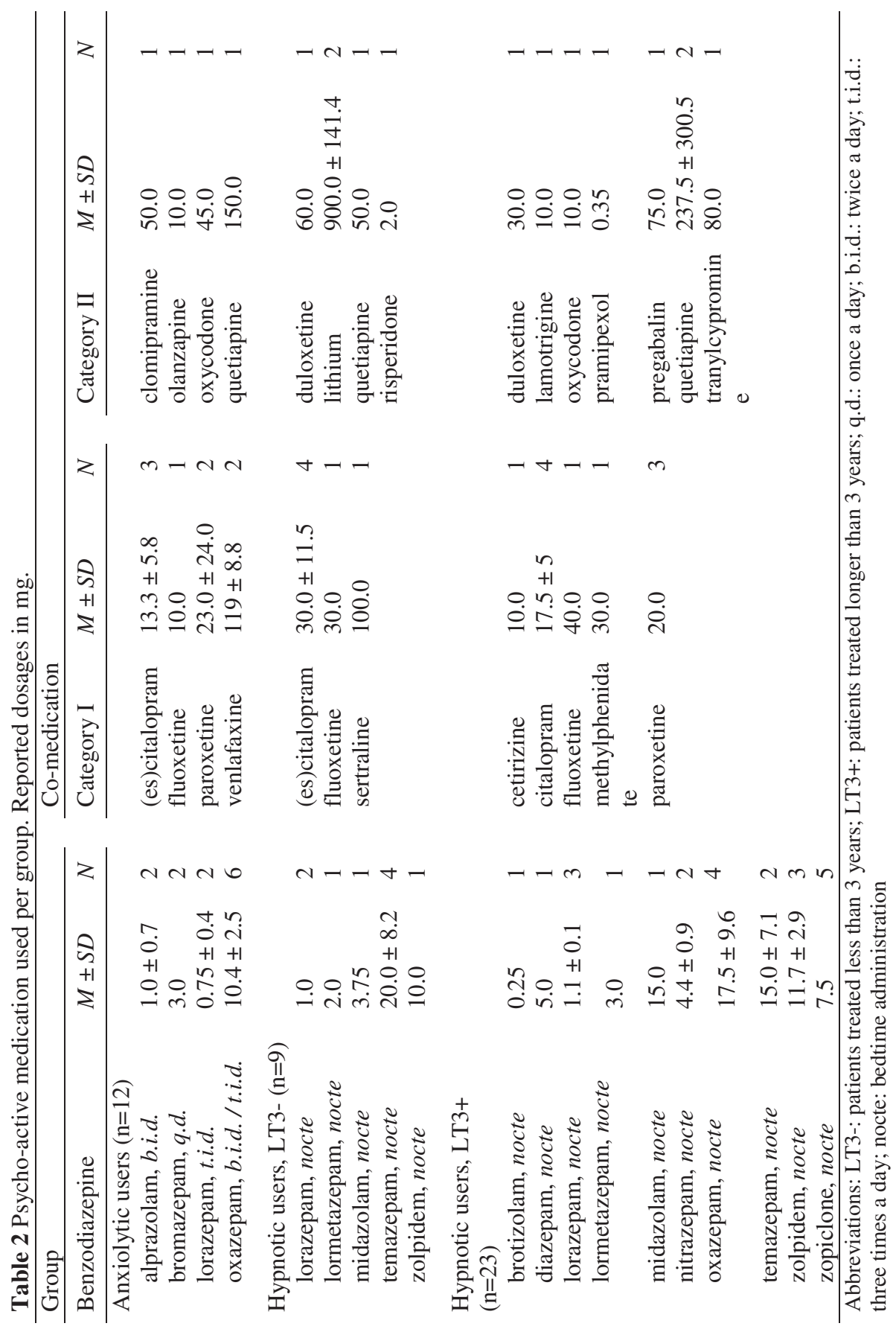


Driving performance of long-term benzodiazepine users

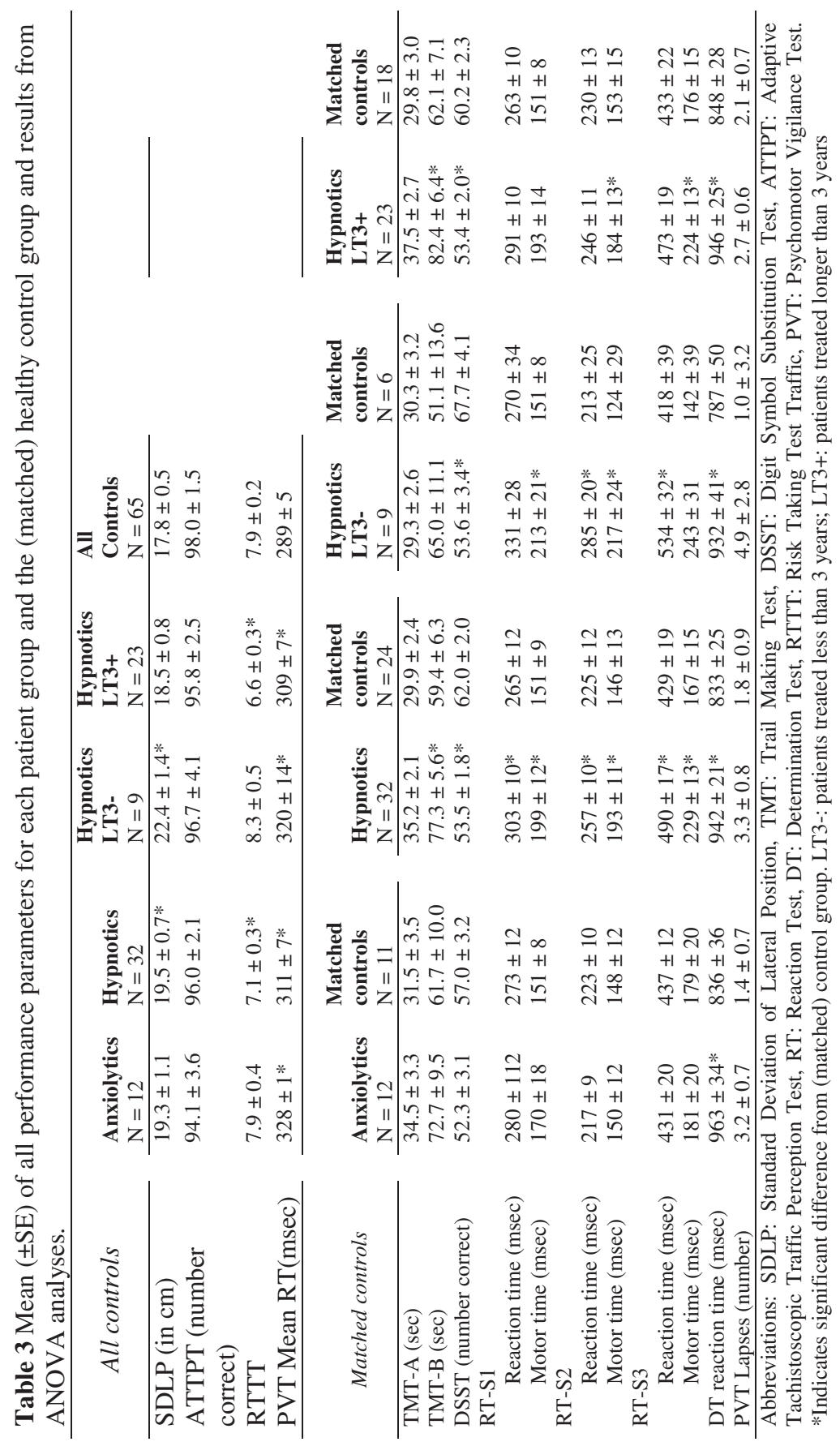


Chapter 3

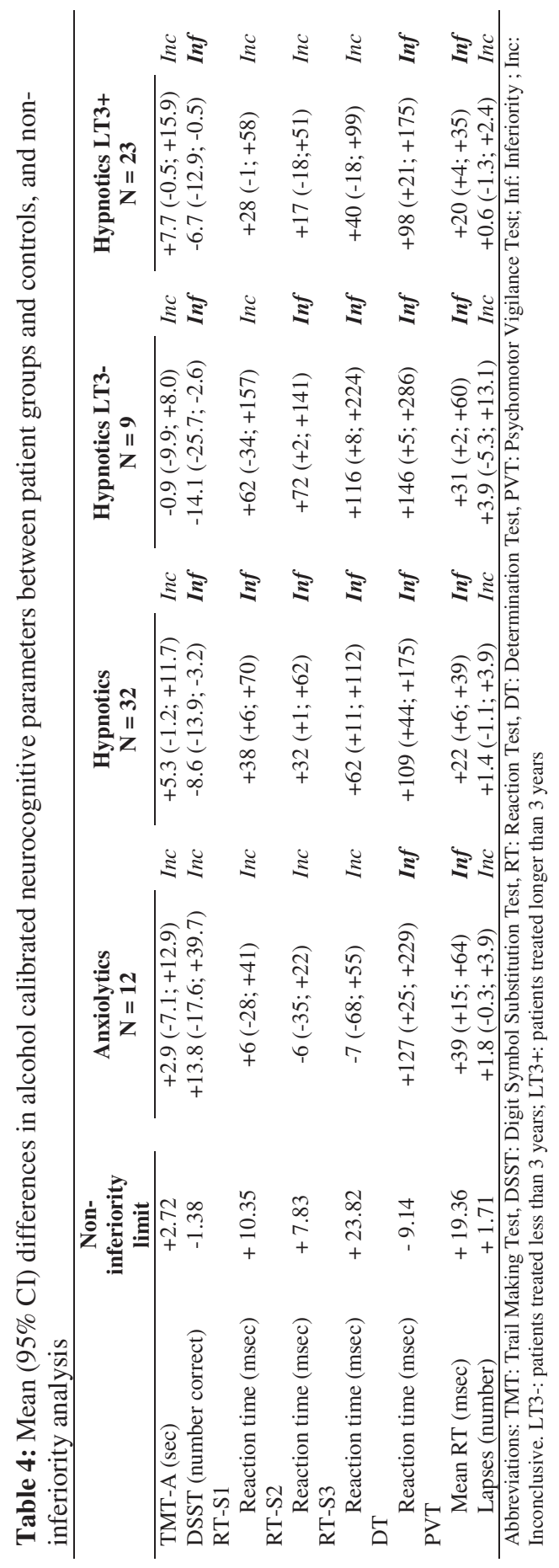




\section{FIGURES}

Figure 1: Standard highway driving test. Left: Volunteers drive a specially instrumented vehicle for about 1 hour over a $100 \mathrm{~km}$ primary highway circuit, accompanied by a licensed driving instructor having access to dual controls. The volunteer's task is to drive with a steady lateral position between the delineated boundaries of the slower (right) traffic lane, while maintaining a constant speed of $95 \mathrm{~km} / \mathrm{h}$. The lateral position of the car relative to the middle line, between the left and right traffic lane, is continuously measured by means of a camera that is mounted on the roof of the car. Right: schematic drawing of the highway driving test. The standard deviation of lateral position (SDLP) is an index of road tracking error or "weaving". Drugs that induce sleepiness or sedation cause loss of vehicle control, leading to increased road tracking error.

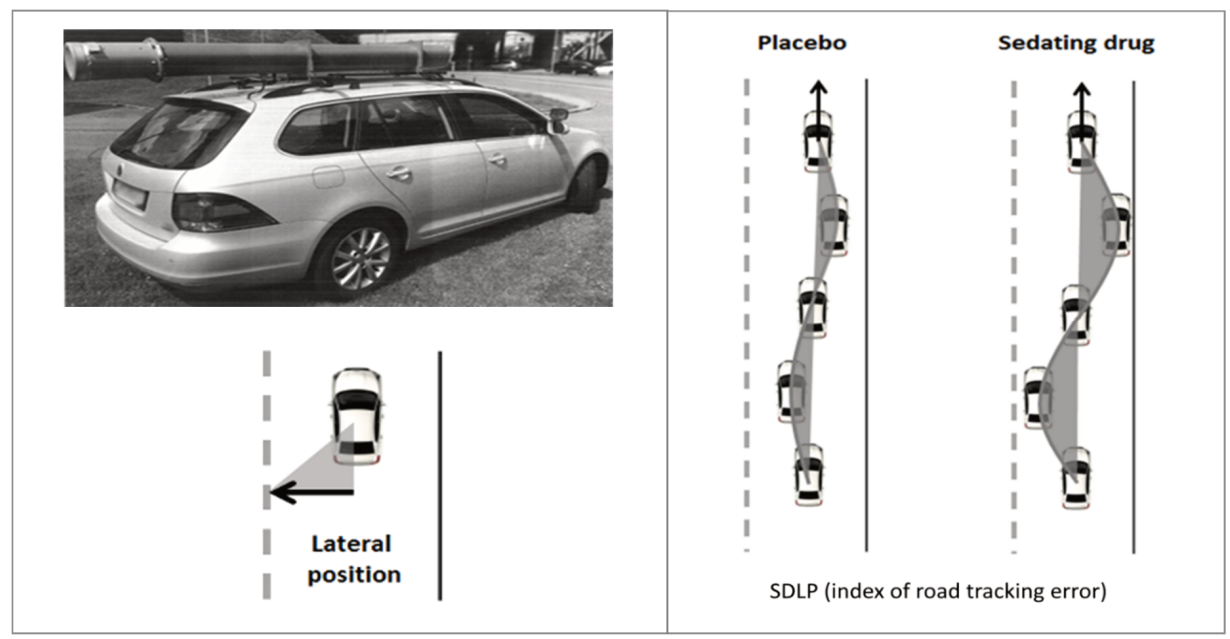


Chapter 3

Figure 2: Schedule of a testing day. Time (in hours) is displayed relative from start. TMT: Trail Making Test, DSST: Digit Symbol Substitution Test, ATTPT: Adaptive Tachistoscopic Traffic Perception Test, RT: Reaction Test, DT: Determination Test, RTTT: Risk Taking Test Traffic, PVT: Psychomotor Vigilance Test.

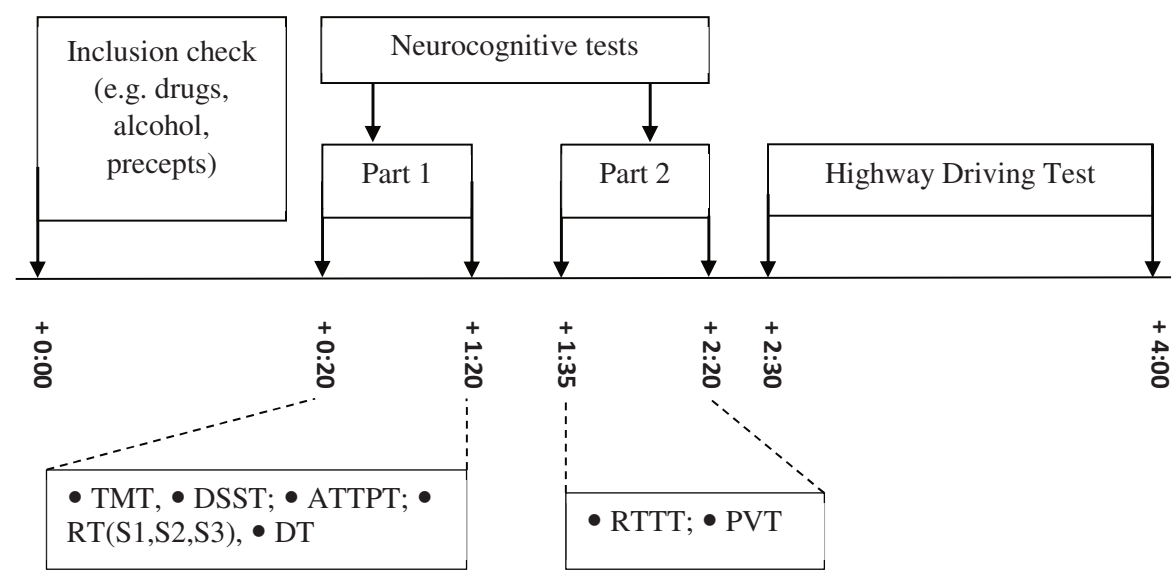


Figure 3: Hypothetical example of the qualification of clinical relevance of performance differences between patients and controls. The dotted line indicates the change in performance after alcohol intake (relative to placebo). A (drug induced) change in performance will be classifcied as inferior when the $95 \%$ CI includes the alcohol criterium but not zero (A Inferiority). Non-inferiority is concluded when the 95\% CI does not include the alcohol criterium (B - Non-inferiortiy). If the $95 \%$ CI includes the alcohol criterion as well as zero, the qualification of clinical relevance is undecided ( $\mathrm{C}$ - Inconclusive).

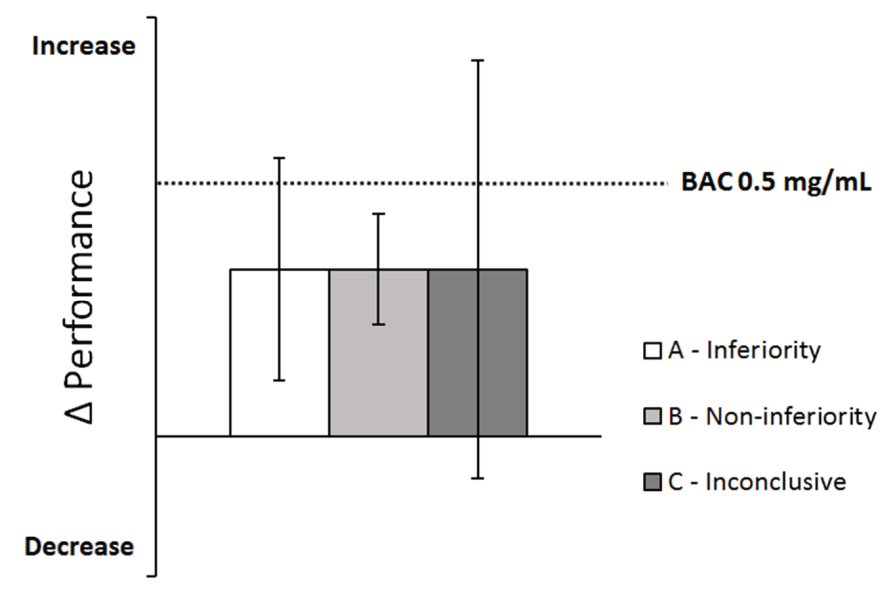


Chapter 3
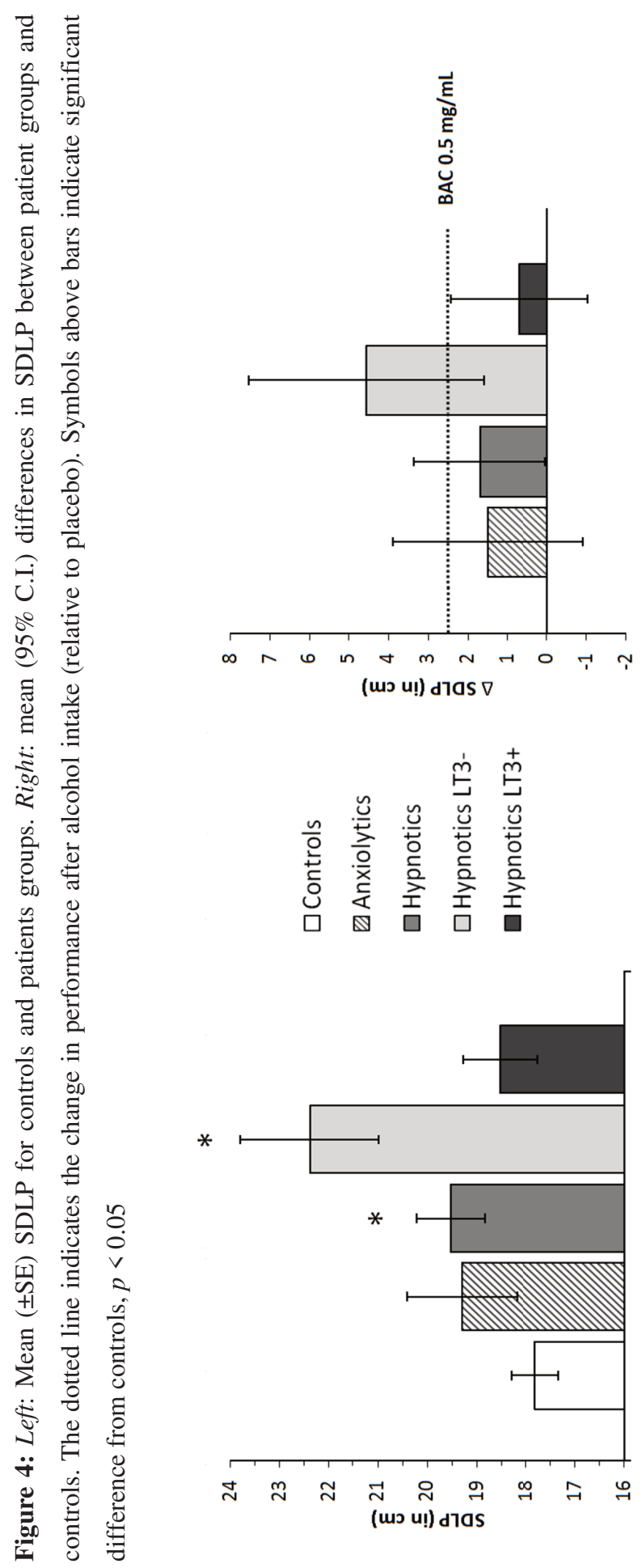


\section{REFERENCES}

Barker, M. J., Greenwood, K. M., Jackson, M., \& Crowe, S. F. (2004). Cognitive effects of long-term benzodiazepine use. CNS drugs, 18(1), 37-48.

Basner, M., \& Dinges, D. F. (2011). Maximizing sensitivity of the psychomotor vigilance test (PVT) to sleep loss. Sleep, 34(5), 581-591.

Beck, A. T., Steer, R. A., \& Carbin, M. G. (1988). Psychometric properties of the Beck Depression Inventory: Twenty-five years of evaluation. Clinical psychology review, 8(1), 77-100.

Blomberg, R. D., Peck, R. C., Moskowitz, H., Burns, M., \& Fiorentino, D. (2009). The long beach/fort lauderdale relative risk study. Journal of safety research, 40(4), 285-292.

Borkenstein, R. F., Crowther, R., \& Shumate, R. (1974). The role of the drinking driver in traffic accidents (The Grand Rapids Study). Blutalkohol, 11(Suppl.), 1-131.

Buysse, D. J., Reynolds III, C. F., Monk, T. H., Berman, S. R., \& Kupfer, D. J. (1989). The Pittsburgh Sleep Quality Index: a new instrument for psychiatric practice and research. Psychiatry research, 28(2), 193-213.

Cloos, J.-M., \& Ferreira, V. (2009). Current use of benzodiazepines in anxiety disorders. Current Opinion in Psychiatry, 22(1), 90-95.

Crowe, S.F., \& Stranks, E.K. (2017). The residual medium and long-term cognitive effects of benzodiazepine use: an updated meta-analysis. Archives of Clinical Neuropsychology, 33(7), 901-911.

Dassanayake, T., Michie, P., Carter, G., \& Jones, A. (2011). Effects of benzodiazepines, antidepressants and opioids on driving. Drug safety, 34(2), 125-156.

de Gier, J. J., Alvarez, F. J., Mercier-Guyon, C., \& Verstraete, A. G. (2009). Prescribing and dispensing guidelines for medicinal drugs affecting driving performance. In J. Verster, S. Pandi-Perumal, J. Ramaekers, \& J. de Gier (Eds.), Drugs, Driving and Traffic Safety (pp. 121-134). Basel Birkaeuser Berlag AG.

Dinges, D. F., \& Powell, J. W. (1985). Microcomputer analyses of performance on a portable, simple visual RT task during sustained operations. Behavior Research Methods, Instruments, \& Computers, 17(6), 652-655.

Faul, F., Erdfelder, E., Lang, A.-G., \& Buchner, A. (2007). G* Power 3: A flexible statistical power analysis program for the social, behavioral, and biomedical sciences. Behavior research methods, 39(2), 175-191.

Ghoneim, M., Mewaldt, S., Berie, J., \& Hinrichs, J. (1981). Memory and performance effects of single and 3-week administration of diazepam. Psychopharmacology, 73(2), 147151.

Gustavsen, I., Bramness, J. G., Skurtveit, S., Engeland, A., Neutel, I., \& Mørland, J. (2008). Road traffic accident risk related to prescriptions of the hypnotics zopiclone, zolpidem, flunitrazepam and nitrazepam. Sleep medicine, 9(8), 818-822.

Hansen, R. N., Boudreau, D. M., Ebel, B. E., Grossman, D. C., \& Sullivan, S. D. (2015). Sedative hypnotic medication use and the risk of motor vehicle crash. American journal of public health, 105(8), e64-e69.

Hemmelgarn, B., Suissa, S., Huang, A., Jean-Francois, B., \& Pinard, G. (1997). Benzodiazepine use and the risk of motor vehicle crash in the elderly. Jama, 278(1), 27-31. 
Hergovich, A., Bognar, B., Arendasy, M., \& Sommer, M. (2005). Manual Vienna Risk-taking Test Traffic (WRBTV). Mödling: SCHUHFRIED GmbH.

Jongen, S., Perrier, J., Vuurman, E. F. P. M., Ramaekers, J. G., \& Vermeeren, A. (2015).

Sensitivity and validity of psychometric tests for assessing driving impairment: effects of sleep deprivation. PloS one, 10, e0117045-e0117045.

Jongen, S., Vermeeren, A., van der Sluiszen, N. N. J. J. M., Schumacher, M. B., Theunissen, E. L., Kuypers, K. P. C., Vuurman, E.F.P.M. and Ramaekers, J. G. (2017). A pooled analysis of highway driving studies in actual traffic measuring standard deviation of lateral position (i.e. "weaving") while driving at a blood alcohol concentration of 0.5 g/L. Psychopharmacology, 234(5), 837 - 844. doi:10.1007/s00213-016-4519-z

Jongen, S., Vuurman, E. F. P. M., Ramaekers, J. G., \& Vermeeren, A. (2014). Alcohol calibration of tests measuring skills related to car driving. Psychopharmacology, 231(12), 2435-2447.

Koster, E.S., Blom, L., Philbert, D., Rump, W., \& Bouvy, M.L. (2014). The Utrecht Pharmacy Practice network for Education and Research: a network of community and hospital pharmacies in the Netherlands. International journal of clinical pharmacy, 36(4), 669674.

Leufkens, T.R.M., Lund, J., \& Vermeeren, A. (2009). Highway driving performance and cognitive functioning the morning after bedtime and middle-of-the-night use of gaboxadol, zopiclone and zolpidem. Journal of sleep research, 18(4), 387-396.

Leufkens, T.R.M., Ramaekers, J., de Weerd, A., Riedel, W., \& Vermeeren, A. (2014). On-theroad driving performance and driving-related skills in older untreated insomnia patients and chronic users of hypnotics. Psychopharmacology, 231(14), 2851-2865.

Louwerens, J. W., Gloerich, A. B. M., DeVries, G., Brookhuis, K. A., \& O'Hanlon, J. F. (1987). The relationship between drivers' blood alcohol concentration (BAC) and actual driving performance during high speed travel. In: Noordzij PC, Roszbach R. (eds). Alcohol Drugs Traffic Safety - T86. Elsevier, Amsterdam, 183 - 186.

Ministry of Infrastructure and Water Management. (2000). Regeling eisen geschiktheid (REG 2000) (http://wetten.overheid.nl/BWBR0011362/), .

Mulder-Hajonides van der Meulen, W., Wijnberg, J., Hollander, J., De Diana, I., \& van den Hoofdakker, R. (1980). Measurement of subjective sleep quality. Eur Sleep Res Soc Abstr.

Morin, A. K., Jarvis, C. I., \& Lynch, A. M. (2007). Therapeutic Options for Sleep-Maintenance and Sleep-Onset Insomnia. Pharmacotherapy: The Journal of Human Pharmacology and Drug Therapy, 27(1), 89-110.

Neutel, I. (1995). Risk of traffic accident injury after a prescription for a benzodiazepine. Annals of epidemiology, 5(3), 239-244.

Neutel, I. (1998). Benzodiazepine-related traffic accidents in young and elderly drivers. Human Psychopharmacology: Clinical and Experimental, 13(S2), S115-S123.

Neuwirth, W., \& Benesch, M. (2007). Manual DT: Determination Test, Version 33.00. Mödling: SCHUHFRIED GmbH.

O'Hanlon, J. F. (1984). Driving performance under the influence of drugs: rationale for, and application of, a new test. British Journal of Clinical Pharmacology, 18(S1), 121S129S. doi:10.1111/j.1365-2125.1984.tb02590.x 
O’Hanlon, J. F., Vermeeren, A., Uiterwijk, M., Van Veggel, L., \& Swijgman, H. F. (1995). Anxiolytics' effects on the actual driving performance of patients and healthy volunteers in a standardized test. Neuropsychobiology, 31(2), 81-88.

Orriols, L., Philip, P., Moore, N., Castot, A., Gadegbeku, B., Delorme, B., Mallaret, M. and Lagarde, E. (2011). Benzodiazepine-like hypnotics and the associated risk of road traffic accidents. Clinical Pharmacology \& Therapeutics, 89(4), 595-601.

Pomara, N., Tun, H., DaSilva, D., Hernando, R., Deptula, D., \& Greenblatt, D. J. (1998). The acute and chronic performance effects of alprazolam and lorazepam in the elderly: relationship to duration of treatment and self-rated sedation. Psychopharmacology bulletin, 34(2), 139-154.

Prieler, J. (2008). Manual RT: Reaction Test, Version 31. Mödling: SCHUHFRIED GmbH.

Ramaekers, J. (2017). Drugs and driving research in medicinal drug development. Trends in pharmacological sciences, 38(4), 319-321.

Ravera, S., Monteiro, S. P., de Gier, J. J., Van der Linden, T., Gómez-Talegón, T., \& Álvarez, F. J. (2012). A European approach to categorizing medicines for fitness to drive: outcomes of the DRUID project. British Journal of Clinical Pharmacology, 74(6), 920931.

Reitan, R. M. (1958). Validity of the Trail Making Test as an indicator of organic brain damage. Perceptual and motor skills, 8(3), 271-276.

Roth, T., Eklov, S., Drake, C., \& Verster, J. (2014). Meta-analysis of on-the-road experimental studies of hypnotics: effects of time after intake, dose, and half-life. Traffic injury prevention, 15(5), 439-445.

Schuhfried, G. (2009). Manual ATAVT: The Adaptive Tachistoscopic Traffic Perception Test, Version 22. Mödling: SCHUHFRIED GmbH.

Smink, B. E., Egberts, A. C., Lusthof, K. J., Uges, D. R., \& De Gier, J. J. (2010). The relationship between benzodiazepine use and traffic accidents. CNS drugs, 24(8), 639653.

Spielberger, C. D., Gorsuch, R. L., \& Lushene, R. E. (1970). STAI: Manual for the State-Trait Anxiety Inventory (Self Evaluation Questionnaire). Palo Alto California: Consulting Psychologist, 22, 1-24.

van der Sluiszen, N. N. J. J. M., Vermeeren, A., Jongen, S., Vinckenbosch, F., \& Ramaekers, J. G. (2017). Influence of Long-Term Benzodiazepine use on Neurocognitive Skills Related to Driving Performance in Patient Populations: A Review. Pharmacopsychiatry, 50(05), 189-196. doi:http://dx.doi.org/10.1055/s-0043-112755

van Laar, M., Volkerts, E. R., \& van Willigenburg, A. (1992). Therapeutic effects and effects on actual driving performance of chronically administered buspirone and diazepam in anxious outpatients. Journal of clinical psychopharmacology, 12(2), 86-95.

Vermeeren, A. (2004). Residual effects of hypnotics. CNS drugs, 18(5), 297-328.

Vermeeren, A., Leufkens, T., \& Verster, J. (2009). Effects of anxiolytics on driving. In Drugs, driving and traffic safety (pp. 289-305): Springer.

Verster, J.C. \& Roth, T. (2011). Standard operation procedures for conducting the on-the-road driving test, and measurement of the standard deviation of lateral position (SDLP). International journal of general medicine, 4, 359. 
Chapter 3

Verster, J.C., Veldhuijzen, D., Patat, A., Olivier, B., \& Volkerts, E. (2006). Hypnotics and driving safety: meta-analyses of randomized controlled trials applying the on-the-road driving test. Current drug safety, 1(1), 63-71.

Verster, J.C., Veldhuijzen, D., \& Volkerts, E. (2004). Residual effects of sleep medication on driving ability. Sleep Medicine Reviews, 8(4), 309-325.

Verster, J.C., Veldhuijzen, D., \& Volkerts, E. (2005). Is it Safe to Drive a Car when Treated with Anxiolytics? Evidence from onthe-Road Driving Studies During Normal Traffic. Current Psychiatry Reviews, 1(2), 215-225.

Verster, J.C., van de Loo, A. J. A. E., Vermeeren, A., van der Sluiszen, N. N. J. J. M., Brookhuis, K. A., Veldstra, J. L., van Dijken, J.H. and Ramaekers, J. G. (2016). Beïnvloeding van de rijvaardigheid bij langdurig gebruik van ICADTS-categorie III geneesmiddelen. Retrieved from: https://www.rijksoverheid.nl/documenten/rapporten/ 2016/12/01/beinvloeding-van-de-rijvaardigheid-bij-langdurig-gebruik-van-icadtscategorie-iii-geneesmiddelen.

Wechsler, D. (1958). The measurement and appraisal of adult intelligence. (4th ed.). Baltimore, MD, US: Williams \& Wilkins Co. 




\section{CHAPTER 4}

Driving performance of depressed patients who are untreated or receive long-term antidepressant (SSRI/SNRI) treatment

\section{Published as}

van der Sluiszen, N.N.J.J.M., Wingen, M., Vermeeren, A., Vinckenbosch F.R.J., Jongen, S. and Ramaekers, J.G. (2017). Driving performance of depressed patients who are untreated or receive long-term antidepressant (SSRI/SNRI) treatment. Pharmacopsychiatry, 50(5), 182-188, DOI: 10.1055/s-0043-111600. 
Chapter 4

\begin{abstract}
Introduction: Depression is a mental disorder likely to affect everyday functions. The present study aimed to assess actual driving performance of depressed patients who were without specific antidepressant treatment or received long-term antidepressant treatment.
\end{abstract}

Methods: A standardized on-the-road driving test was used to assess standard deviation of lateral position (SDLP) in three patient groups, receiving either: no antidepressant treatment (with or without benzodiazepine medication) or treatment with selective serotonin/noradrenalin reuptake inhibitors for a period of 6 - 52 weeks. Depression severity was assessed using Becks Depression Inventory and the Hamilton Depression Rating Scale. Performance of patient groups was compared to healthy controls.

Results: Mean SDLP of untreated and treated patients were significantly higher as compared to SDLP of healthy controls. Driving impairment in the long-term treated group was significantly less as compared to the untreated groups. SDLP was positively correlated to severity of depression across all groups.

Discussion: It is concluded that symptoms of depression are a major cause of driving impairment. Reductions in severity of depression through antidepressant treatment reduce severity of driving impairment. 


\section{INTRODUCTION}

Depression is a mental disorder with a global prevalence of $4.7 \%$ [1] and is characterised by cognitive-, affective- and executive impairment [2]. Symptoms of depression such as lethargy and sleep disturbances can be expected to detrimentally affect daily functioning, including operating a vehicle [3].

Pharmacological treatment of depression often includes treatment with selective serotonin reuptake inhibitors (SSRIs) or serotonin and norepinephrine reuptake inhibitors (SNRIs). The effects of SSRIs and SNRIs on driving performance have been systematically assessed in a range of placebo controlled experimental studies using a standardized on-the-road driving test in healthy volunteers [4]. Overall, these studies showed that these treatments do not affect standard deviation of lateral position (SDLP), a measure of road tracking error, in single dose or repeated dose (up to 3 weeks) administration. These data suggest that monotherapy treatment with SSRIs and SNRIs do not compromise driving performance and can be safely used by patients when operating a motor vehicle [4].

Studies on SSRIs and SNRIs effects on driving performance in depressed patients have however, provided mixed results. Experimental studies using the on-the-road driving test demonstrated that 6 weeks of fluoxetine treatment did not alter SDLP as compared to baseline performance [5]. Brunnauer and colleagues showed that before onset of treatment with antidepressants, about $65 \%$ of patients suffering from depression did not reach the threshold criterion for fitness to drive. Yet, after 14 days of treatment with reboxetine patients significantly improved in driving ability as assessed with neuropsychological tests measuring skills related to driving [6]. Similar results were obtained with venlafaxine-treated patients suffering from depression. Patients showed significant improvement in driving ability after 14 days of treatment, compared to before treatment onset [7]. Wingen and colleagues demonstrated that on-the-road driving performance of depressed patients receiving SSRIs and SNRIs was significantly worse as compared to matched controls [8]. Epidemiological studies have suggested that long-term treatment with SSRIs may slightly increase crash risk $[9,10]$ or do not affect crash risk at all $[11,12]$. It has been suggested that crash risk during SSRI treatment may be related to (residual) symptoms of depression, co-medication (e.g. benzodiazepines to treat sleep complaints) or withdrawal symptoms in patients that do not use their medication as prescribed $[8,13]$. 


\section{Chapter 4}

The present study aimed to determine the role of (residual) symptoms of depression on driving impairment in depressed patients. Driving data from untreated depressed patients (either with or without benzodiazepine medication) [5] was combined with data from patients receiving SSRI/SNRI treatment and compared with healthy controls [8] which were previously collected in two separate studies. In both studies, driving performance was assessed using a standardized on-the-road highway driving test following identical operating procedures and outcome measures (i.e. SDLP), as well as severity of depression rated by means of Becks Depression Inventory (BDI) and the Hamilton Depression Rating Scale (HDRS). It was expected that driving impairment observed in (un)treated patients was positively correlated to severity of depression.

\section{METHODS}

\section{Design and Participants}

The current analysis entails between-group comparisons of driving performance of depressed patients who are untreated (with or without benzodiazepine medication), depressed patients receiving long-term treatment with a SSRI or SNRI and a group of healthy controls. All data were retrieved from historical datasets that were collected in two separate studies. Data from the latter two groups were obtained from Wingen et al [8], whereas data on the untreated depressed patient groups were retrieved from Ramaekers et al [5]. All patients $(n=24)$ and controls $(n=24)$ from Wingen et al were included. Patients had a primary diagnosis of unipolar disorder with an active depressive episode by a psychiatrist or physician according to the DSMIV criteria and received daily antidepressant treatment during a period ranging from 6 - 52 weeks. From the latter study, all untreated patients $(n=41)$ were included. Patients had a diagnosis of major depression by a psychiatrist according to the DSM-III-R criteria with a score $\geq 17$ on the HDRS and did not engage in structural analytical or behavioural psychotherapy that could influence the depressive illness during the study. Untreated patients received either chronic ( $>3$ months) benzodiazepine medication $(n=31)$, or no treatment $(n=10)$.

\section{On-the-road driving test}

In the standardized highway driving test [14] participants drive a specially instrumented car over a $100 \mathrm{~km}$ (61 miles) primary highway circuit accompanied by a licensed driving instructor having access to dual controls. The participant's task is to maintain a constant speed of $95 \mathrm{~km} / \mathrm{h}$ (58 miles per hour) and a steady lateral position between the delineated boundaries of the slower 
right traffic lane. The vehicle's speed and lateral position relative to the left lane delineation is continuously recorded. These signals are digitally sampled at $4 \mathrm{~Hz}$ and edited off-line to remove data recorded during overtaking manoeuvres or disturbances caused by roadway or traffic situations. The remaining data yields the standard deviation of lateral position and speed for each successive 5-km segment and, as the square root of pooled variance over all segments, for the test as a whole. The primary outcome variable is the Standard Deviation of Lateral Position (SDLP, in $\mathrm{cm}$ ) which is a measure of road tracking error, or 'weaving'. The clinical relevance of performance changes in the on-the-road driving test have previously been determined by establishing the relationship between blood alcohol concentration (BAC) and SDLP [15]. A mean increase in SDLP of $2.5 \mathrm{~cm}$ was previously found at a BAC of $0.5 \mathrm{mg} / \mathrm{ml}$ as compared to placebo [16] and from that point onwards associated with a significantly higher risk of traffic accidents [17]. The highway driving test has been used in more than 100 studies and has proven sensitive to many sedating drugs and alcohol in blood concentrations as low as $0.35 \mathrm{mg} / \mathrm{ml}$ $[18,19]$.

\section{Beck's Depression Inventory}

The Beck's Depression Inventory (BDI) [20] is a self-report questionnaire that consists of 21 questions determining depression severity. The questions are answered on a scale of 0 to 3 . A score greater than 14 suggest minimal depression.

\section{Hamilton Depression Rating Scale}

The Hamilton Depression Rating Scale (HDRS) [21] is a clinical rating scale that quantitatively measures the severity of depressive symptoms. In both studies [5,8] a trained clinician administered the interview.

\section{Statistical analysis}

For the total sample of 89 participants, a power calculation for analysis of variance (ANOVA) resulted in a power of $99.9 \%$ to detect a clinically relevant difference of $2.5 \mathrm{~cm}$ in SDLP between groups, assuming 4 groups, an alpha of 0.05 , an effect size of 0.58 , and a betweensubjects SD of $4.3 \mathrm{~cm}[16]$.

The outcome variable(s) of the driving test (SDLP) and questionnaires (HDRS, BDI) were analysed by comparing the three patient groups to the performance of healthy controls. In addition, untreated patients (with or without benzodiazepine medication) were compared to 
Chapter 4

long-term treated patients. To assess the relationship between depressive symptomology and driving performance, a correlation analysis between BDI / HDRS scores and SDLP was conducted for all groups together.

The SDLP, HDRS and BDI scores for each group were checked for normality with the use of the Shapiro-Wilk test [22]. If all groups had a normal distribution, univariate ANOVA with LSD correction was used. However, if one of the groups had a non-normal distribution, the Kruskal-Wallis H test [23] in combination with the Mann-Whitney U test [24] was used.

Non-inferiority analyses were used to evaluate the SDLP effects between patient groups and healthy controls in relation to a non-inferiority limit of $2.5 \mathrm{~cm}$, which is associated with a BAC of $0.5 \mathrm{mg} / \mathrm{ml}$ and considered clinically relevant. For SDLP, non-inferiority between groups was concluded if the upper limit of the $95 \%$ confidence interval (e.g. upper limit of the $90 \%$ C.I.) of the mean difference in SDLP between patient groups and healthy controls exceeds $2.5 \mathrm{~cm}$.

All statistical analyses were conducted by using the Statistical Package for the Social Sciences for Windows (version 24.0.0.0., SPSS Inc, Chicago, IL, USA).

\section{RESULTS}

\section{Missing data}

From Wingen et al [8], the BDI scores of 2 healthy controls were missing.

\section{Participant sample}

Table 1 gives a summary of the participant sample.

\section{Tests of assumptions}

According to the Shapiro-Wilk test, the HDRS and BDI scores between groups were nonnormally distributed (for at least one group). Therefore, the overall group effects on HDRS and BDI scores were analysed with the Kruskal-Wallis H test. Comparisons between two groups were done with the Mann-Whitney U test. SDLP scores were analysed with univariate ANOVA, including LSD.

\section{Driving performance}

Mean $( \pm$ SE) SDLP scores are shown in Table 2. ANOVA showed a significant effect of Group $\left(\mathrm{F}_{3,85}=11.83, \mathrm{p}<0.001\right)$ on SDLP. Mean $(95 \% \mathrm{CI})$ increases in SDLP of untreated depressed 
patients with benzodiazepines, untreated depressed patient and long-term treated patient, as compared to healthy controls were: $+6.28 \mathrm{~cm}(+4.06 ;+8.51),+5.56 \mathrm{~cm}(+2.48 ;+8.64)$ and $+2.48 \mathrm{~cm}(+0.12 ;+4.84)$, respectively. Contrast analysis showed that increments in mean SDLP of untreated patients, with or without benzodiazepine medication, and long-term treated patients were significant compared to healthy controls ( $\mathrm{p}<0.001, \mathrm{p}=0.001$ and $\mathrm{p}=0.040$, respectively). Across patient groups, untreated patients with or without benzodiazepines performed significantly worse compared to long-term treated patients $(\triangle \operatorname{SDLP}+3.80 \mathrm{~cm}, \mathrm{p}=0.001$; $\Delta \mathrm{SDLP}+3.08 \mathrm{~cm}, \mathrm{p}=0.050$, respectively). The difference in mean SDLP between both untreated patient groups was non-significant. Non-inferiority testing revealed that in all patient groups, the upper limit of the mean difference in SDLP exceeded the $2.5 \mathrm{~cm}$ criteria (see figure 1).

\section{Ratings of depression}

An overview of HDRS and BDI scores is given in Table 2. There was a significant difference in HDRS and BDI scores between groups (HDRS: $\chi^{2}(3)=68.18$, $<<0.001$, mean rank of 68.24 for untreated depression with benzodiazepine medication, 63.60 for untreated depression, 38.75 for long-term treatment and 13.48 for healthy controls; BDI: $\chi^{2}(3)=46.33$, p<0.001, mean rank of 61.85 for untreated depression with benzodiazepine medication, 49.85 for untreated depression, 45.58 for long-term treatment and 14.45 for healthy controls). The Mann-Whitney $\mathrm{U}$ test showed a significant increase in BDI $(\mathrm{p}<0.001)$ and HDRS $(\mathrm{p}<0.001)$ scores between healthy controls and all patient groups. Across patient groups, untreated patients with benzodiazepine medication had significantly higher HDRS and BDI scores compared to longterm treated patients $(\mathrm{p}<0.001)$. Untreated patients, however, only had significantly higher HDRS scores compared to long-term treated patients ( $\mathrm{p}<0.001)$. The HDRS and BDI scores of both untreated patient groups did not significantly differ from each other.

\section{Correlation analysis}

There was a significant correlation (2-tailed) between clinically rate HDRS scores and SDLP $(\mathrm{r}=0.55, \mathrm{n}=89, \mathrm{p}<0.001)$, as well as self-reported BDI scores and SDLP $(\mathrm{r}=0.42, \mathrm{n}=87$, $\mathrm{p}<0.001$ ), across all groups. Correlations between SDLP and either HDRS scores or BDI scores, were non-significant in each group separately. An overview of the correlation between individual SDLP and HDRS scores across all groups is given in Figure 2. 
Chapter 4

\section{DISCUSSION}

The current study examined the effects of depression on driving performance of patients who received no antidepressant treatment and patients who received long-term SSRI and SNRI treatment. Results indicated significant increments in mean SDLP in untreated (with or without benzodiazepine medication) as well as long-term treated depressed patients, compared to healthy controls. Mean SDLP and symptoms of depression were significantly higher in both untreated patient groups as compared to long-term treated patients. SDLP was positively correlated to symptoms of depression across all groups.

Mean increments in SDLP were approximately $6 \mathrm{~cm}$ in both untreated groups whereas an increment of $2.5 \mathrm{~cm}$ was observed in the long-term treated group. The clinical relevance of performance changes in the on-the-road driving test is often determined by comparison to SDLP changes under the influence of alcohol because the latter is well known to increase crash risk of drivers [15,16]. It has been demonstrated that an average increase in SDLP of $+2.5 \mathrm{~cm}$ and $+4.2 \mathrm{~cm}$, is comparable to driving under the influence of a blood alcohol concentration (BAC) of $0.5 \mathrm{mg} / \mathrm{ml}$ and $0.8 \mathrm{mg} / \mathrm{ml}$, respectively. The mean increase in SDLP observed in both untreated depressed patients groups (with or without benzodiazepine medication) was higher than a SDLP increase seen at a BAC $>0.8 \mathrm{mg} / \mathrm{ml}$. Depressed patients receiving antidepressant treatment displayed a mean SDLP increase of $+2.5 \mathrm{~cm}$ compared to healthy controls. This is comparable to the increase in SDLP that has previously been observed when driving at a BAC of $0.5 \mathrm{mg} / \mathrm{ml}$. Therefore, driving impairment observed in untreated as well as treated patients should be interpreted as highly relevant for traffic safety.

Non-inferiority analyses furthermore revealed wide confidence intervals around the mean increments in SDLP in all patients groups. The upper limit of the 95\% CI around the mean change in SDLP in both untreated patient groups approximated an increase of $9 \mathrm{~cm}$. The latter is estimated to be comparable to driving under the influence of a BAC of $1.5 \mathrm{mg} / \mathrm{ml}$ [16]. The upper limit of the $95 \%$ CI around the mean increase in SDLP of long-term treated patients included the SDLP criterion level for a BAC of $0.8 \mathrm{mg} / \mathrm{ml}$. Wide confidence intervals indicate large inter-individual differences in patient groups and that the degree of driving impairment observed in depressed patients ranges from moderate to very severe.

The association between driving impairment and depression symptomatology was also apparent from the moderate, positive correlations that were observed between SDLP and ratings of depression such as HDRS $(r=.55)$ and BDI $(r=.42)$. These findings are in line with previous 
meta-analyses that reported positive associations between depression severity and cognitive impairment $[25,26]$. Between group comparisons showed signficantly lower SDLP and HDRS scores in treated patients as compared to untreated patients (with or without benzodiazepine medication). SDLP and HDRS scores did not significantly differ between the two untreated patient groups. It was estimated that depression severity explained about $30 \%$ of the variance in SDLP across all groups.

Other factors may have contributed to the inter-individual variance in driving impairment among depressed patients. In one of the untreated groups, patients received chronic benzodiazepine medication that that may have caused driving impairment in some individuals. Mean SDLP in both untreated groups receiving either chronic benzodiazepines or no medication were comparable. The notion that both untreated groups showed comparable performance is in line with previous experimental and epidemiological research indicating tolerance development for benzodiazepines. Repeated dosing of diazepam in anxious patients resulted in significant driving impairment up to 4 weeks after treatment initiation [27]. After 4 weeks, driving performance was no longer significantly different from baseline. Similarly, epidemiological data has shown that the overall risk of traffic accident involvement decreases when benzodiazepines are taken over a two month time window [28]. Likewise, it has been demonstrated that repeated users of benzodiazepines have a lower risk of traffic accidents compared to new users [29]. Both untreated groups, however, showed inferior performance in comparison to healthy controls. Given the development of tolerance for benzodiazepines, the absence of specific antidepressant treatment and comparable HDRS scores in both untreated groups, the observed driving impairment is likely to be the result of depressive symptomology.

The use of medication was checked in the study by Wingen et al. [8] and Ramaekers et al. [5] prior to study enrolment. Assessment was based on the participant's medical background and self-reported medication use. After study enrolment, participants agreed to adhere to their own presciption. It is, however, possible that participants deviated from their medication use or dosing regimen, since medication compliance was not checked during study enrolment. Patients receiving SSRI or SNRI treatment would not be expected to suffer from treatment induced impairment since experimental driving studies in healthy volunteers as well as patients demonstrated that these compounds do not affect driving performance after single doses and after weeks of administration [4]. Yet, patients who use these antidepressants irregularly have been reported to suffer from withdrawal symptoms as well [30]. It cannot be excluded that some 
Chapter 4

depressed patients in the long-term treated group deviated from daily use and developed symptoms of withdrawal that may have affected their driving ability.

Demographic differences between groups may have also increased variability in driving performance. The healthy control group was originally matched to the long-term treated depressed patient group in the study by Wingen et al [8], but not to the untreated groups that were selected from another study [5]. Descriptive analysis for age and gender showed no significant difference between both untreated groups and healthy controls, indicating that these factors did not play a role in potential between-group differences. Yet, indications of driving experience were lacking in the study by Ramaekers et al [5] and therefore could not be compared to Wingen et al [8]. In addition, the highway circuit used in both studies differed from each other, which might have influenced road tracking performance. However, in a recent pooled-analysis that incorporated nine studies measuring alcohol effects on SDLP as measured in the on-the-road driving test [16], it was concluded that effects of alcohol were robust across all studies and independent from the highway circuit. This serves to indicate that the difference in highway circuit is unlikely to have influenced current results.

In summary, untreated depressed patients showed major driving impairment, whereas longterm treated depressed patients showed moderate driving impairment. Depression severity was positively correlated to SDLP. It is concluded that symptoms of depression are a major cause of driving impairment. Reductions in severity of depression through antidepressant treatment reduce severity of driving impairment. 
Driving performance and long-term SSRI/SNRI treatment

\section{TABLES \& FIGURES}

Table 1: Participant characteristics for untreated depressed patients (with or without benzodiazepine medication), long-term treated depressed patients and healthy controls group. The mean $( \pm \mathrm{SD})$ of Age, Driving experience, BDI and HDRS are reported. Mean medication dose with range is reported, if applicable.

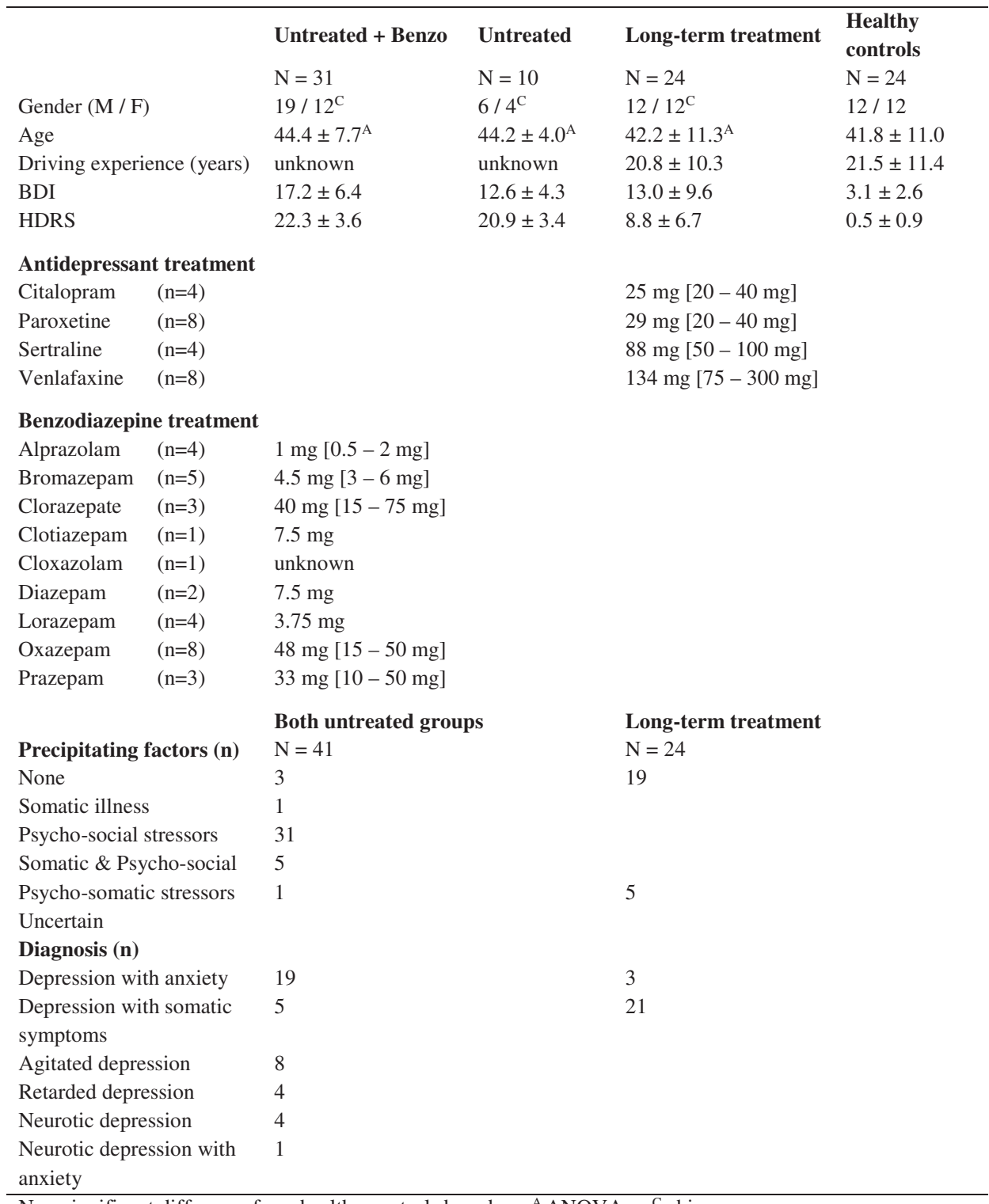

Non-significant difference from healthy controls based on: ${ }^{\mathrm{A}} \mathrm{ANOVA}$ or ${ }^{\mathrm{C}}$ chi-square 
Chapter 4

ํㅜㅇ

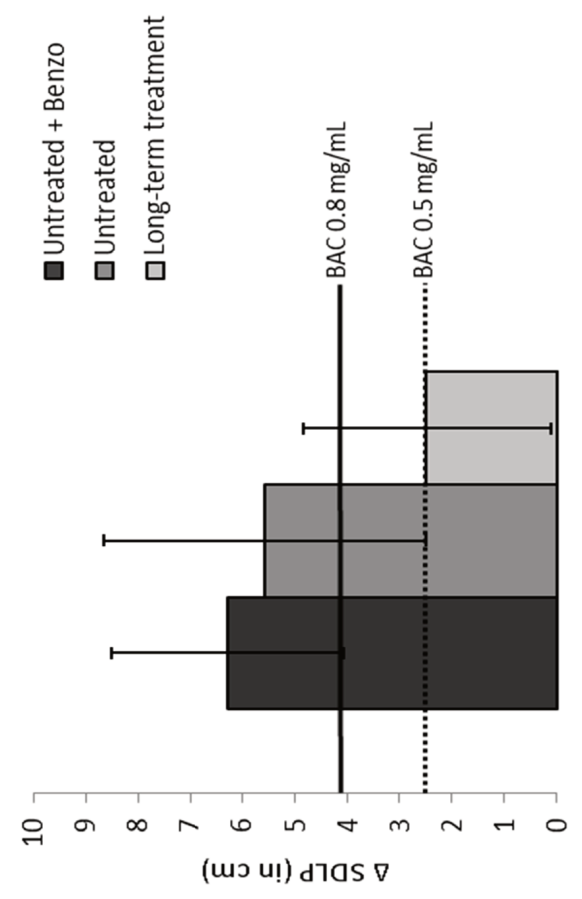

ü

ถ้

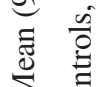

$\sum_{0} 0$

.

ڤิ

ธิ

50 8

के อ

可

ज

至 :

च

$\sum^{\infty} \frac{0}{\tilde{c}}$

范

$\ddot{-}$ है

苛
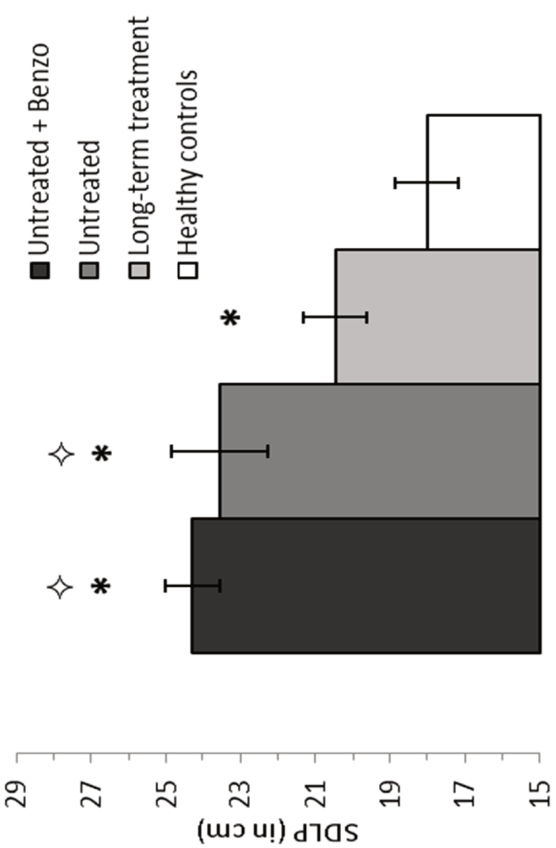
Figure 2: Correlation between individual driving performances $(n=89)$ as indicated by standard deviation of lateral position (SDLP) and depression severity as indicated by the hamilton depression rating scale (HDRS).

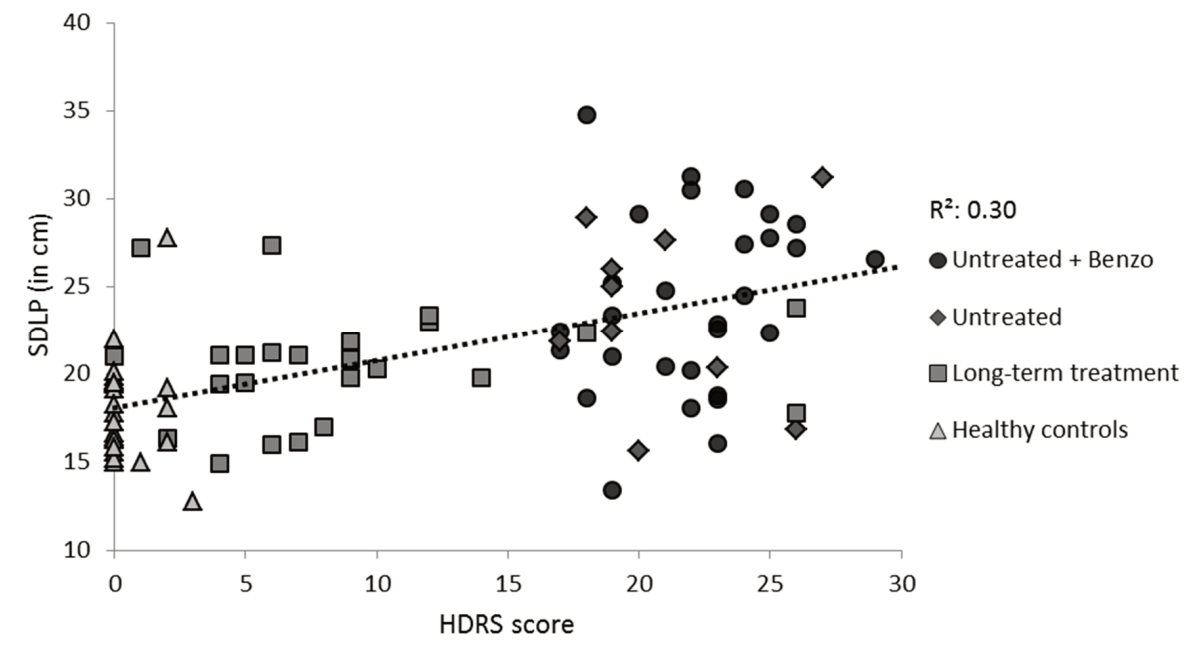




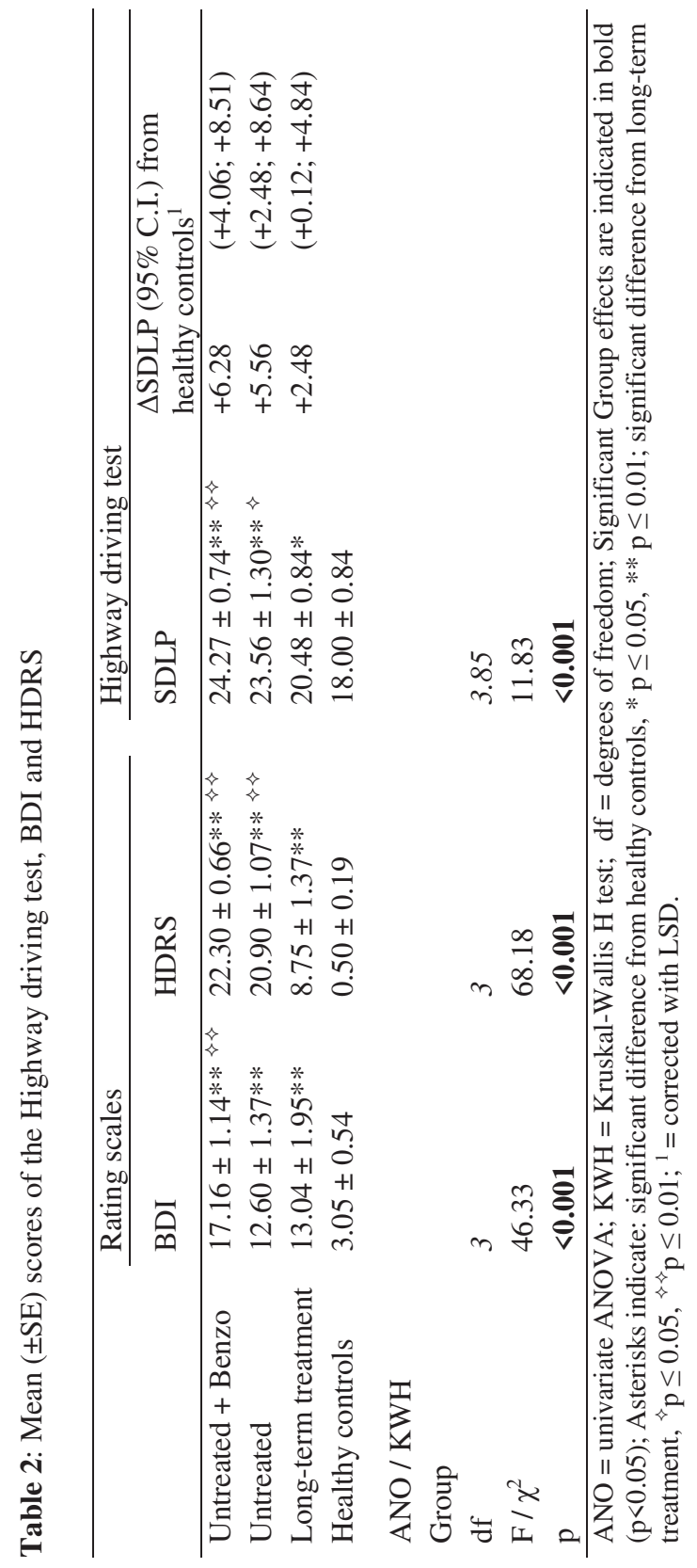


Driving performance and long-term SSRI/SNRI treatment

\section{REFERENCES}

1. Ferrari A, Somerville A, Baxter A et al. Global variation in the prevalence and incidence of major depressive disorder: a systematic review of the epidemiological literature. Psychol Med 2013; 43: 471-481

2. Marazziti D, Consoli G, Picchetti $\mathrm{M}$ et al. Cognitive impairment in major depression. Eur J Pharmacol 2010; 626: 83-86

3. Ramaekers J, Muntjewerff N, Van Veggel L et al. Effects of nocturnal doses of mirtazapine and mianserin on sleep and on daytime psychomotor and driving performance in young, healthy volunteers. Hum Psychopharmacol 1998; 13: S87-S97

4. Ramaekers JG. Antidepressants and driver impairment: empirical evidence from a standard on-the-road test. J Clin Psychiatry 2003; 64: 20-29

5. Ramaekers JG, Ansseau M, Muntjewerff $\mathrm{N}$ et al. Considering the P450 cytochrome system as determining combined effects of antidepressants and benzodiazepines on actual driving performance of depressed outpatients. Int Clin Psychopharmacol 1997; 12: $159-169$

6. Brunnauer A, Laux G, David I et al. The impact of reboxetine and mirtazapine on driving simulator performance and psychomotor function in depressed patients. J Clin Psychiatry 2008; 69: 1,478-1886

7. Brunnauer A, Buschert V, Fric M et al. Driving performance and psychomotor function in depressed patients treated with agomelatine or venlafaxine. Pharmacopsychiatry 2015; 48: 65-71

8. Wingen M, Ramaekers JG, Schmitt JA. Driving impairment in depressed patients receiving long-term antidepressant treatment. Psychopharmacol 2006; 188: 84-91

9. Meuleners LB, Duke J, Lee AH et al. Psychoactive Medications and Crash Involvement Requiring Hospitalization for Older Drivers: A Population-Based Study. J Am Geriatr Soc 2011; 59: 1575-1580

10. Ravera S, van Rein N, De Gier JJ et al. Road traffic accidents and psychotropic medication use in the Netherlands: a case-control study. Br J Clin Pharmacol 2011; 72: 505-513

11. Barbone F, McMahon A, Davey P. Use of benzodiazepines increased road traffic accidents whereas use of tricyclic antidepressants and SSRIs did not. Lancet 1998; 24: 1331-1336

12. Rapoport MJ, Zagorski B, Seitz D et al. At-fault motor vehicle crash risk in elderly patients treated with antidepressants. Am J Geriatr Psychiatry 2011; 19: 998-1006

13. Ravera S, Ramaekers JG, de Gier JJ. Are selective serotonin reuptake inhibitors safe for drivers? What is the evidence? Clin Ther 2012; 34: 1070-1083

14. O'Hanlon JF. Driving performance under the influence of drugs: rationale for, and application of, a new test. Br J Clin Pharmacol 1984; 18: 121S-129S

15. Louwerens JW, Gloerich ABM, DeVries G et al. The relationship between drivers' blood alcohol concentration (BAC) and actual driving performance during high speed travel. In: Noordzij PC, Roszbach R (eds) Alcohol Drugs Traffic Safety - T86 Elsevier, Amsterdam 1987, DOI: 183 - 186

16. Jongen S, Vermeeren A, van der Sluiszen NNJJM et al. A pooled analysis of highway driving studies in actual traffic measuring standard deviation of lateral position (i.e. 
Chapter 4

"weaving") while driving at a blood alcohol concentration of $0.5 \mathrm{~g} / \mathrm{L}$. Psychopharmacol 2017, DOI: 10.1007/s00213-016-4519-Z

17. Borkenstein RF, Crowther R, Shumate R. The role of the drinking driver in traffic accidents (The Grand Rapids Study). Blutalkohol 1974; 11: 1-131

18. Vermeeren A, Ramaekers J, O'Hanlon J. Effects of emedastine and cetirizine, alone and with alcohol, on actual driving of males and females. J Psychopharmacol 2002; 16: 57 64

19. Vuurman E, Muntjewerff N, Uiterwijk M et al. Effects of mefloquine alone and with alcohol on psychomotor and driving performance. Eur J Clin Pharmacol 1996; 50: 475482

20. Beck AT, Steer RA, Carbin MG. Psychometric properties of the Beck Depression Inventory: Twenty-five years of evaluation. Clin Psychol Rev 1988; 8: 77-100

21. Hamilton M. Development of a rating scale for primary depressive illness. Br J Soc Clin Psychol 1967; 6: 278-296

22. Shapiro SS, Wilk M. An analysis of variance test for the exponential distribution (complete samples). Technometrics 1972; 14: 355-370

23. Kruskal WH. Errata for Kruskal-Wallis (1952). J Am Stat Assoc 1953; 48: 907-911

24. Mann HB, Whitney DR. On a test of whether one of two random variables is stochastically larger than the other. Ann Math Stat 1947, DOI: 50-60

25. McDermott LM, Ebmeier KP. A meta-analysis of depression severity and cognitive function. J Affect Disord 2009; 119: 1-8

26. Snyder HR. Major depressive disorder is associated with broad impairments on neuropsychological measures of executive function: a meta-analysis and review. Psychol Bull 2013; 139: 81

27. van Laar M, Volkerts ER, van Willigenburg A. Therapeutic effects and effects on actual driving performance of chronically administered buspirone and diazepam in anxious outpatients. J Clin Psychopharmacol 1992; 12: 86-95

28. Neutel I. Risk of traffic accident injury after a prescription for a benzodiazepine. Ann Epidemiol 1995; 5: 239-244

29. Neutel I. Benzodiazepine-related traffic accidents in young and elderly drivers. Hum Psychopharmacol 1998; 13: S115-S123

30. Nielsen M, Hansen EH, Gøtzsche PC. What is the difference between dependence and withdrawal reactions? A comparison of benzodiazepines and selective serotonin reuptake inhibitors. Addict 2012; 107: 900-908 




\section{CHAPTER 5}

On-the-road driving

performance and

neurocognition of

patients with long-term

antidepressant treatment

In revision as

van der Sluiszen, N.N.J.J.M., Vermeeren, A., van Dijken, J.H.,

van de Loo, A.J.A.E., Veldstra, JL., de Waard, D., Verster, J.C., Brookhuis, K.A. and Ramaekers, J.G. Driving performance and neurocognitive skills of long-term users of sedating antidepressants. Human Psychopharmacology: Clinical and Experimental. 
Chapter 5

\begin{abstract}
Objective: To assess driving performance and neurocognition of patients using sedating antidepressants for at least six months in comparison to healthy controls.

Methods: Thirty-eight long-term users of amitriptyline $(n=13)$ and mirtazapine $(n=25)$ were compared to 65 healthy controls. Driving performance was assessed using a one hour standardized highway driving test in actual traffic, with road-tracking error (SDLP) being the primary measure. Secondary measures included neurocognitive tasks related to driving. Performance differences between groups were compared to those of blood alcohol concentrations of $0.5 \mathrm{mg} / \mathrm{ml}$ to determine clinical relevance.
\end{abstract}

Results: Compared to controls, mean increase in SDLP of all antidepressant users was neither significant, nor clinically relevant $(+0.75 \mathrm{~cm}, 95 \% \mathrm{CI}:-0.83 \mathrm{~cm} ;+2.33 \mathrm{~cm})$. However, patients treated less than 3 years $(n=20)$ did show a significant and clinically relevant increase in SDLP $(+2.05 \mathrm{~cm})$. No significant effects were observed on neurocognitive tasks for any patient group, although large individual differences were present. Most results from neurocognitive tests were inconclusive, while a few parameters confirmed non-inferiority for patients treated longer than 3 years.

Conclusion: The impairing effects of antidepressant treatment on driving performance and neurocognition mitigate over time following long-term use of 3 years. 


\section{INTRODUCTION}

Despite the availability of non-sedating antidepressants, older generation antidepressants are still frequently prescribed for the treatment of depression (Arroll et al., 2005) and neuropathic pain (Nikolaus \& Zeyfang, 2004). Among this older generation are the tricyclic and tetracyclic antidepressants, such as amitriptyline and mirtazapine. These drugs are known to cause psychomotor- and cognitive impairments (Darowski, Chambers, \& Chambers, 2009) that interfere with daily activities such as operating a vehicle (Dassanayake, Michie, Carter, \& Jones, 2011; Verster \& Ramaekers, 2009).

Epidemiological studies showed that tri- and tetracyclic antidepressant use is associated with an increased relative risk of 1.4- 2.3 of becoming involved in a traffic accident (Bramness, Skurtveit, Neutel, Mørland, \& Engeland, 2008; Chang et al., 2013; Leveille et al., 1994; Ray, Fought, \& Decker, 1992). Experimental studies in patients confirm that these drugs can produce significant driving impairment after treatment initiation, but also indicated that such impairment may decrease over two weeks of treatment, possibly due to tolerance (Brunnauer et al., 2008; Veldhuijzen et al., 2006). Furthermore, chronically treated patients with either clomipramine or imipramine showed minor forms of impairment in the domain of psychomotor performance and memory when compared to healthy controls (Gorenstein, De Carvalho, Artes, Moreno, \& Marcourakis, 2006).

Experimental studies have systematically assessed the clinical relevance of the effects of antidepressants on driving behaviour by means of comparison to alcohol, given its well documented dose dependent association with crash risk (Blomberg, Peck, Moskowitz, Burns, \& Fiorentino, 2009; Borkenstein, Crowther, \& Shumate, 1974). These studies focussed on driving performance after single and repeated doses of a range of antidepressants (Ramaekers, 2003). Results showed that tricyclic antidepressants, such as amitriptyline, produce moderate to severe impairment of driving performance equivalent to driving under the influence of a blood alcohol concentration (BAC) of $0.5 \mathrm{mg} / \mathrm{ml}$ or more during the first days of treatment as compared to placebo. However, driving impairment was virtually absent after one week of repeated dosing, likely due to tolerance development. For tetracyclic antidepressants, such as mirtazapine, clinically relevant driving impairment was observed at the onset of a nocturnal treatment regimen. This mitigated over 3 weeks of repeated dosing, but never fully disappeared, suggesting that tolerance was incomplete. 


\section{Chapter 5}

Data from experimental studies on the effects of antidepressants on driving performance and neurocognition have also been used for classifying fitness to drive of patients receiving antidepressant treatment. These classification systems (de Gier, Alvarez, Mercier-Guyon, \& Verstraete, 2009; Ravera et al., 2012) use a graded level warning system that expresses druginduced impairment in BAC equivalents. Classifications that are commonly used to define drug-related impairment on driving are: no/minor influence (category 0/I, BAC $<0.5 \mathrm{mg} / \mathrm{ml}$ ), moderate influence (category II, $0.5 \mathrm{mg} / \mathrm{ml} \leq \mathrm{BAC} \leq 0.8 \mathrm{mg} / \mathrm{ml}$ ), and severe influence (category III, BAC $>0.8 \mathrm{mg} / \mathrm{ml}$ ). Patients who use category III antidepressants are advised not to operate a vehicle, given that driving related performance may be impaired for approximately 24 hours after intake (Gómez-Talegón, Fierro, Carmen Del Río, \& Álvarez, 2011). A limitation of existing drug categorisation systems is the lack of information regarding the effects of longterm drug usage on driving performance. Mirtazapine and amitriptyline are placed in category III mainly because of their acute effects on driving performance even though acute impairments may dissipate over time after prolonged use. Therefore, the classification of these antidepressants in category III may be too conservative for drivers receiving long-term treatment, limiting their mobility unnecessarily.

The objective of the present study was to evaluate driving performance of patients receiving long-term treatment with category III antidepressants, as compared to that of a group of normative healthy controls. Long-term usage was defined as longer than 6 months. The secondary objective was to evaluate driving performance separately for patients who had been using antidepressant for less than 3 years, and those whose use exceeded 3 years. The criterion of 3 years was based on Dutch laws, stating that antidepressant users are unfit to drive when treated for less than 3 years, but can request an individual driver fitness evaluation after more than 3 years of stable usage (Ministry of Infrastructure and Water Management, 2000). Driving performance was assessed by a standardized highway driving test in actual traffic and various neurocognitive tests related to driving. The present data were collected as part of a larger study on the long-term effects of benzodiazepines and antidepressants on driving performance. Data on long-term benzodiazepine use and driving are published separately (van der Sluiszen et al., 2019). 


\section{METHODS}

\section{Design}

The study was designed as a multicentre trial (Universities of Maastricht, Utrecht, and Groningen) in the Netherlands and compared the driving and neurocognitive performance of long-term users of antidepressants to that of healthy controls. To explore the potential difference in impairment before and after 3 years of use, patients were divided into two groups based on duration of treatment, i.e. long-term use between 6 months - 3 years (LT3-) and long-term use $>3$ years $(\mathrm{LT} 3+)$.

\section{Participants}

Patients were recruited via patient organisations, hospitals, practitioners affiliated with UPPER (Koster, Blom, Philbert, Rump, \& Bouvy, 2014) and regional advertisements. Healthy controls were recruited via flyers and advertisements in local newspapers. Participants were informed about the study's goal, procedures and potential hazards. The study was approved by the Medical Ethics Committees of Maastricht University and the Maastricht Academic Hospital and was conducted in agreement with the code of ethics on human experimentation established by the Declaration of Helsinki (1964), amended in Edinburgh (2000), Seoul (2008) and Fortaleza (2013). Written informed consent was obtained from each participant before enrolment. Participants received a financial compensation for their participation in the study.

\section{Patients}

Thirty-eight patients with long-term antidepressant treatment were recruited. All patients used category III antidepressants (amitriptyline, $\mathrm{n}=13$; mirtazapine, $\mathrm{n}=25$ ) that are expected to severely affect fitness to drive. Initial screening was based on a medical history questionnaire evaluated by a clinician. The following inclusion criteria had to be met: use of a category III antidepressant over a period of at least six months with a frequency of at least 2 times a week ( $\approx 90$ days a year), possession of a valid driver's licence for at least three years, driving an average of $3000 \mathrm{~km}$ per year, normal or corrected to normal vision, body mass index (BMI) between 17 and $35 \mathrm{~kg} / \mathrm{m}^{2}$. Although Dutch law deems category III antidepressant users who have been treated for less than 3 years unfit to drive, many of them drive a motor vehicle simply because they are unaware of this legal provision and because this provision is not actively enforced by the Dutch government. Patients were excluded if they used concomitant medication classified as ICADTS cat. III. Concomitant medication classified as ICADTS cat. 0/I was 


\section{Chapter 5}

allowed, whereas ICADTS cat. II was evaluated by a clinician on individual basis. Additional exclusion criteria were: alcohol use $>21$ glasses per week, smoking $>20$ cigarettes a day, use of illegal drugs.

Before test days, patients took their medication as usual, i.e. in the evening or morning before testing. Patients' usual dosing regime was established at screening and monitored by self-report on the practice and test day.

\section{Controls}

Sixty-five controls formed a normative group with comparable age, gender distribution and years of driving experience as patients. Inclusion criteria were: a valid driver's licence for at least three years, driving an average of $3000 \mathrm{~km}$ per year; normal or corrected to normal vision; BMI between 19 and $29 \mathrm{~kg} / \mathrm{m}^{2}$. Exclusion criteria were: diagnosed with a neurological disorder or sleeping disorder; alcohol use $>21$ glasses per week; smoking $>10$ cigarettes a day; illegal drug use and psychoactive medication (e.g.: antidepressants, benzodiazepines, anti-epileptics, anticonvulsants, antihistamines, opioids).

\section{On-the-road driving test}

In the standardized on-the-road highway driving test (figure 1) (O'Hanlon, 1984; Ramaekers, 2017; Verster \& Roth, 2011) participants drive a specially instrumented car over a $100 \mathrm{~km}$ primary highway circuit accompanied by a licensed driving instructor having access to dual controls. The participant's task is to maintain a constant speed of $95 \mathrm{~km} / \mathrm{h}$ and a steady lateral position between the delineated boundaries of the slower right-hand traffic lane. The vehicle's speed and lateral position relative to the left lane delineation is continuously recorded. These signals are digitally sampled at $4 \mathrm{~Hz}$ and pre-processed off-line to mark data recorded during overtaking manoeuvres or disturbances caused by roadway or traffic situations. The preprocessed dataset is used to calculate the mean and variance of lateral position of clean (unmarked) data, for each successive 5-km segment and, as the square root of pooled variance over all segments, for the test as a whole. The primary outcome variable is the Standard Deviation of Lateral Position (SDLP, in $\mathrm{cm}$ ) which is a measure of road tracking error, or 'weaving'.

Drug-induced impairments in the standardized high-way driving test have been compared to that of a well-known benchmark drug (i.e. alcohol) that is known to jeopardize traffic safety and shows a clear exponential dose-dependent relationship with accident crash risk (Blomberg 
et al., 2009; Borkenstein et al., 1974). The clinical relevance of performance changes in the highway driving test have previously been determined by establishing the relationship between blood alcohol concentration (BAC) and SDLP (Louwerens, Gloerich, DeVries, Brookhuis, \& O'Hanlon, 1987). A recent meta-analysis of nine alcohol-calibration studies revealed that a mean increment in SDLP of $2.5 \mathrm{~cm}$ was observed during the standardized highway driving test at a BAC of $0.5 \mathrm{mg} / \mathrm{ml}$ and has been defined as the minimal cut-off value to present clinical relevance (Jongen et al., 2017). The highway driving test has been used in more than 100 studies and has proven sensitivity to alcohol, antidepressants and many other sedating drugs (Ramaekers, 2017; Roth, Eklov, Drake, \& Verster, 2014; Vermeeren, 2004).

\section{Neurocognitive tests}

Trailmaking Test (TMT)

The TMT is a paper and pencil test measuring selective and divided attention, as well as executive functions (Reitan, 1958). The test comprises two parts. In part A, the task of the participant is to connect, as fast as possible, 25 circles that contain the numbers 1 to 25 , by means of connecting the circles in ascending order. In part B the 25 circles contain letters (A to L) and numbers (1 to 13). Participants are required to connect the 25 circles as fast as possible in an alternately ascending fashion (i.e. 1-A-2-B-3-C, and so on). The maximum time allowed for part $\mathrm{A}$ is 5 minutes, and for part $\mathrm{B}$ it is 6 minutes. The primary outcome measure for part $\mathrm{A}$ and $\mathrm{B}$ is the time (in seconds) needed to complete each task.

\section{Digit Symbol Substitution Test (DSST)}

The DSST is a paper and pencil test measuring executive attention and processing speed (Wechsler, 1958). Participants are presented with rows of digits and have to respond by writing the corresponding symbol in a blank space, according to a key presented at the top of the paper. The primary outcome measure is the number of correctly filled-in symbols in 90 seconds.

\section{Adaptive Tachistoscopic Traffic Perception Test (ATTPT)}

The ATTPT of the Vienna Test System assesses visual orientation ability, visual observational ability, speed of perception and skills in obtaining an overview (Schuhfried, 2009). Participants are briefly presented with pictures of traffic situations on a computer screen. After each picture participants are required to indicate the contents of the picture, by choosing from five answer options (i.e. cars, cyclists, pedestrians, traffic signs and / or traffic lights). Pictures are presented 


\section{Chapter 5}

adaptively, meaning that the difficulty of the pictures is adapted to the abilities of the participant (i.e. participants who perform poorly receive pictures containing less complex traffic situations; vice versa for participants whom perform well). The primary outcome is the number of correct answers. Time to complete the task is 10 minutes.

\section{Reaction Test (RT)}

The RT of the Vienna Test System assesses reaction time and motor time in response to simple and complex visual or acoustic signals (Prieler, 2008). Before the start of the test, participants are instructed to lay their index finger on a pressure-sensitive key (i.e. rest key). During the test, participants are required to press a target key, with their index finger, whenever a target stimulus is presented. After pressing the target key, they must return their index finger immediately to the rest key. By means of using a rest key and target key, it is possible to distinct between reaction time (time between the presentation of the target stimulus and the moment the index finger is removed from the rest key) and motor time (the time between releasing the rest key and pressing the target key). The current experiment uses three versions of the reaction test, namely: S1, in which participants have to respond whenever a yellow circle is shown on screen; $\mathrm{S} 2$, in which participants have to respond whenever they hear a tone; and S3, in which participants have to respond whenever they see a yellow circle on screen and a hear a tone in combination, all other stimuli combinations are to be ignored. Time to complete all three versions of this task is 10 minutes. Outcome measures for each test are reaction time and motor time.

\section{Determination Test $(D T)$}

The DT of the Vienna Test System measures reactive stress tolerance, divided attention and mental flexibility (Neuwirth \& Benesch, 2007). Participants are presented with visual stimuli of varying colour and sounds with a different pitch, in a serial order. For each stimulus, a predefined button has to be pressed. The presentation of stimuli is adaptive to the reaction speed of the participant, meaning that the inter-stimulus-interval is shortened when participants make correct and fast responses, and is slowed down when participants make mistakes or respond slowly. During the task, participants are presented with the following stimuli and have to press the following corresponding buttons: a) visual coloured circles (white, yellow, red, green and blue), each presented colour has a matching coloured key on the keyboard; b) auditory signals (low pitch \& high pitch), each auditory signal has its own response key on the keyboard; C) motor signals (displayed as a white rectangle on the left or right side of the bottom of the 
screen), each motor signal required the participant to press a left or right foot pedal, depending on the position of the white rectangle on screen. The outcome measure is the average reaction time of all responses made.

\section{Risk-Taking Test Traffic (RTTT)}

The RTTT measures risk-taking behaviour in potentially dangerous driving situation (Hergovich, Bognar, Arendasy, \& Sommer, 2005). Participants are presented with 24 items (i.e. video clips) that show diverse driving situations, which are described in words before they are shown on-screen. Each driving situation is shown twice. During the first time, participants observe the entire driving situation. During the second time, participants are required to press a key on the keyboard, indicating the distance from the potential hazard at which the driving manoeuvre that has just been described becomes critical or dangerous (i.e. the point at which the participant would no longer perform the manoeuvre). The first of the 24 items serves as a practice item. Time to complete the task is approximately 15 minutes. The variable "willingness to take risk in driving situations" is measured by obtaining the distance between the moment of a potential hazard, measured in hundreds of a second, and the moment the participant presses the key indicating the potential hazard becomes critical or potentially dangerous. This distance is a measure of subjectively accepted level of risk. Higher scores indicate higher levels of subjectively accepted risk.

\section{Psychomotor Vigilance Test (PVT)}

The PVT is based on a simple visual reaction time test (Dinges \& Powell, 1985). It measures the ability to sustain attention over a period of approximately $10 \mathrm{~min}$. Participants are required to respond to a visual stimulus presented at a variable interval $(2-10 \mathrm{sec})$ by pressing a button with the dominant hand. The visual stimulus is the presentation of a counter that starts running from 0 to $60 \mathrm{~s}$ at 1-ms intervals. Participants are required to respond to this visual counter as soon as they perceive it on screen by pressing the corresponding button. If a response is made the counter stops, stays on screen for $500 \mathrm{~ms}$ as visual feedback for the participant, and disappears. During this period, a variable interval is presented and afterwards the next counter appears on screen. This cycle repeats until 100 stimuli have been presented on screen. If a response has not been made within $60 \mathrm{~s}$, the clock resets and the counter restarts. Primary outcome measures are mean response speed and number of lapses (defined as responses with RT $\geq 500 \mathrm{~ms}$ ) (Basner \& Dinges, 2011). Performance on the PVT has been calibrated for doseeffects of alcohol (Jongen, Vuurman, Ramaekers, \& Vermeeren, 2014). 


\section{Chapter 5}

\section{Questionnaires}

Beck's Depression Inventory (BDI)

The BDI (Beck, Steer, \& Carbin, 1988) is a 21-item self-report questionnaire measuring depression related symptomology. Answer options for each question range from 0 to 3 . The obtained total score for the BDI serves as an indicator for the presence of depression related symptoms, ranging from 0 to 63 . Higher scores indicate the presence of more symptoms of depression.

\section{State-Trait anxiety index - Trait (STAI-T)}

The STAI-T (Spielberger, Gorsuch, \& Lushene, 1970) is the Trait dimension of the 40-item self-reported STAI questionnaire. The STAI-T contains 20-questions that measure trait anxiety (i.e. how individuals feel in general). Answer options for each questions range from 1 to 4, with total scores ranging from 20 to 80 . Higher total scores indicate more anxiety related symptoms.

\section{Pittsburgh Sleep Quality Index (PSQI)}

The PSQI (Buysse, Reynolds III, Monk, Berman, \& Kupfer, 1989) is a self-report questionnaire that assesses the quality and patterns of sleep over the last month, by rating the following seven domains: subjective sleep quality, sleep latency, sleep duration, habitual sleep efficiency, sleep disturbance, use of medication and daytime disturbance. A summary score ranging from 0 to 21 can be derived, with higher scores indicating poorer sleep quality. A summary score $\geq 5$ indicates a poor sleeper.

\section{Groningen Sleep Quality Scale (GSQS)}

The GSQS (Mulder-Hajonides van der Meulen, Wijnberg, Hollander, De Diana, \& van den Hoofdakker, 1980) is a 14-item self-report scale that assess subjective quality of sleep during the previous night. Summary scores range from 0 to 14 , with higher scores indicating poorer sleep quality. A total score $\geq 6$ indicates disturbed sleep.

\section{Procedures}

All volunteers completed a practice and a test session on two separate days, with an interval of one week between both days. Volunteers started at $8: 30 \mathrm{~h}, 10: 30 \mathrm{~h}$ or $12: 30 \mathrm{~h}$ based on individual convenience, but the starting time was kept constant on practice and test days. On day 1 (practice day), volunteers filled out three questionnaires (BDI, PSQI, STAI-T), and were 
familiarized with the test procedures. Volunteers were individually trained to perform the driving test and all neurocognitive tests. On day 2 (test day), volunteers first completed the GSQS, followed by the first part of the neurocognitive test battery (TMT, DSST, ATTPT, RT, DT). After a 15-minute break, participants completed the second cognitive test battery (RTTT, PVT). Finally, volunteers were transported to the start of the highway to start the one-hour driving test. In total, the test day lasted approximately 4:00 hours (table 1).

\section{Statistical analysis}

Statistical power to detect a clinically relevant mean difference in SDLP of $2.5 \mathrm{~cm}$ between patients and controls was as follows: all antidepressant users vs controls, $\beta=0.88$; antidepressants LT3- users vs. controls, $\beta=0.73$; antidepressant LT3+ users vs controls, $\beta=$ 0.70. Assumptions for these power calculations are: an alpha of 0.05 and a between-subject SD of $4.3 \mathrm{~cm}$ (Jongen et al., 2017).

Matching variables (age, gender, driving experience) were included as covariates in an ANCOVA model. If none of the matching variables showed a significant influence on groupcomparisons with SDLP or a neurocognitive parameter, patient performance was compared to that of the entire group of controls $(n=65)$. Alternatively, if one (or more) matched variables did show a significant influence on a between-group comparison, only individually matched controls were included. The determination of the influence of matching variables was performed for SDLP and each neurocognitive parameter separately.

Next, non-inferiority analyses were used to determine whether the $95 \%$ confidence interval (CI) of performance differences between patients exceeded the criterion level of clinical relevance, i.e. an equivalent performance change as seen at a BAC of $0.5 \mathrm{mg} / \mathrm{ml}$. When evaluating the 95\% CI of differences between groups, three interpretations are possible (Figure 2). Patients' performance was considered not impaired (i.e. non-inferior) when the upper limit of the 95\% $\mathrm{CI}$ of the difference from controls was below the alcohol criterion for impairment. Patients' performance was considered impaired (i.e. inferior) when the lower limit of the $95 \%$ CI of the difference from controls was above zero and the upper limit exceeded the alcohol criterion for impairment. When the $95 \%$ CI of the difference from controls included both zero and the alcohol criterion for impairment, the results were considered inconclusive. The non-inferiority limit for the on-the-road driving test (figure 3) was obtained from Jongen et al. (Jongen et al., 2017). 


\section{Chapter 5}

Clinical relevance of impairment of neurocognitive performance was also based on direct comparison with impairing the effects of alcohol at a BAC of $0.5 \mathrm{mg} / \mathrm{ml}$. In a separate study (Verster et al., 2016) an alcohol-calibration was performed to determine which neurocognitive parameters were able to detect impairment at a BAC of $0.5 \mathrm{mg} / \mathrm{ml}$. Results of the calibration study showed that the only parameters sensitive for the impairing effects of alcohol were: TMTA, DSST, RT-S1, RT-S2, RT-S3, DT and PVT. Consequently, these are the only parameters that provided non-inferiority limits for the present study. The clinical relevance of results will only be discussed for these parameters.

All statistical analyses were conducted by using the IBM Statistical Package for the Social Sciences for Windows (version 24, IBM Corp., Armonk, N.Y., USA). Power calculations were performed using G*Power version 3.1 (Faul, Erdfelder, Lang, \& Buchner, 2007).

\section{RESULTS}

\section{Group characteristics}

Table 2 gives a demographic summary of the patient group $(n=38)$, patient subgroups (LT3-, $\mathrm{n}=20$; LT3,$+ \mathrm{n}=18)$ and the control group $(\mathrm{n}=65)$. As expected, significant differences between patients and controls were found for the $\operatorname{BDI}\left(F_{1,101}=42.72, p<0.01\right)$, STAI $\left(F_{1,101}=\right.$ $42.07, p<0.01)$, PSQI $\left(F_{1,101}=23.72, p<0.01\right)$, GSQS $\left(F_{1,101}=11.78, p<0.01\right)$. Patients showed more symptomology related to anxiety, depression and sleep problems.

Table 3 describes antidepressant usage for each patient (sub)group and gives an overview of the reported psycho-active co-medication. Patients took their medication at least once a day. The most frequently reported co-medication were second generation antidepressants (SSRIs / SNRIs), which have minor effects on driving performance (category I). In addition, three patients reported usage of category II co-medication.

\section{Matching of controls}

Analyses showed no significant effect of age, gender or driving experience in the ANCOVA for either SDLP, ATTPT, RTTT and PVT mean reaction time. For these parameters, the entire control group was used as a reference for comparison with the patient groups. For the remaining parameters, matched healthy controls were used for each patient (sub)group. 


\section{Highway driving test}

Data of the highway driving test were missing for one person in the control group due to problems with the recording system.

Mean $( \pm \mathrm{SE})$ scores for SDLP of both groups are shown in Figure 3. Mean SDLP of all patients did not differ significantly from controls $\left(F_{1,100}=0.89, p=0.35\right)$. The upper limit of the $95 \%$ $\mathrm{CI}$ of the difference between both groups $(+0.75 \mathrm{~cm}, 95 \% \mathrm{CI}:-0.83 \mathrm{~cm} ;+2.33 \mathrm{~cm})$ did not exceed the $+2.5 \mathrm{~cm}$ criterion, indicating non-inferiority. Further analysis showed a significant difference between LT3- patients and controls $\left(F_{1,82}=4.40, p=0.04\right)$, but not between LT3+ patients and controls $\left(F_{1,80}=0.46, p=0.50\right)$. Mean $(95 \% \mathrm{CI})$ difference in SDLP between LT3patients and controls was $+2.05 \mathrm{~cm}(+0.11 \mathrm{~cm} ;+4.00 \mathrm{~cm})$ and $-0.69 \mathrm{~cm}(-2.74 \mathrm{~cm} ;+1.35 \mathrm{~cm})$ for LT3+ patients. Non-inferiority testing revealed that only for LT3- patients, the lower and upper limit of the mean difference in overall SDLP exceed zero and the +2.5 criterion respectively, indicating clinically relevant impairment.

\section{Neurocognitive performance}

Table 4 shows the mean $( \pm$ SE) of for all performance parameters for each patient (sub)group and healthy controls. Comparisons between patients using antidepressants and controls showed no significant performance difference between both groups. Table 5 shows an overview of the 95\% CI of mean changes between patients and (matched) controls on alcohol sensitive parameters only, including inferiority limits and analyses. The 95\% CI of mean changes of all alcohol sensitive parameters included zero and exceeded the BAC $0.5 \mathrm{mg} / \mathrm{ml}$ criterion, indicating inconclusive results.

Subsequent analyses based on treatment duration showed no significant performance difference between the normative control group and the LT3- or LT3+ patient groups, respectively. Similar to the results for the group as a whole, non-inferiority analysis of alcohol sensitive parameters showed that the $95 \%$ CIs of the difference between LT3- patients and controls on all alcohol sensitive parameters included zero and the alcohol criterion indicating inconclusive results. For the LT3+ patient subgroup, non-inferiority was observed for the parameters of the RT-S2, RTS3 and the PVT (mean RT + Lapses). 


\section{Chapter 5}

\section{DISCUSSION}

The current study aimed to compare the driving performance of long-term users of sedating antidepressants to that of a normative control group consisting of healthy volunteers. The goal was to evaluate whether the classification of the investigated antidepressants in category III may be too conservative for drivers who use their medication for a prolonged time. Overall, mean SDLP of patients did not differ significantly from the normative control group. Significant increments in SDLP were however found for patients who had been treated for less than 3 years, but not for patients treated for longer than 3 years. Furthermore, patients showed no significant differences in neurocognitive performance in comparison to normative controls, although individual differences were present as evidenced by a wide $95 \% \mathrm{CI}$ around mean differences between patients and controls.

The clinical relevance of the effects of prolonged antidepressant usage on driving- and neurocognitive performance was determined by comparing the average difference in performance between patients and the controls with the change in performance in subjects who were under the influence of a BAC of $0.5 \mathrm{mg} / \mathrm{ml}$, which is the legal limit in the Netherlands. A meta-analysis of nine alcohol-calibration studies employing the on-the-road highway driving test demonstrated an average increase in mean SDLP of $2.5 \mathrm{~cm}$ for drivers operating a vehicle with a BAC level of $0.5 \mathrm{mg} / \mathrm{ml}$ (Jongen et al., 2017). In the present study, the mean increase in SDLP of all patients treated with antidepressants was $0.75 \mathrm{~cm}$, relative to healthy controls. The 95\% CI of this mean difference included zero and did not include the alcohol criterion. This indicates that on-the-road driving impairment is non-inferior for the group as a whole, given that the level of impairment associated with the legal limit of alcohol in traffic was not reached.

However, clinically relevant driving impairment was found in patients who used these drugs less than 3 years. The mean $(95 \%$ CI) difference in SDLP between controls and LT3- patients was $+2.05 \mathrm{~cm}(+0.11 \mathrm{~cm} ;+4.00 \mathrm{~cm})$ which includes the BAC $0.5 \mathrm{mg} / \mathrm{ml}$ criterion of clinical relevance. For LT3+ patients the mean and $95 \%$ CI remained below the alcohol criterion. This suggests mitigation of driving-related impairment over time, which corresponds with a decreasing accident risk found in epidemiological studies following long-term antidepressant treatment (Barbone, McMahon, \& Davey, 1998; Rapoport et al., 2011). Possible factors that may contribute to the mitigation of impairment over time as seen in the on-the-road driving test are physiological tolerance, improvements in clinical symptomatology (van der Sluiszen, et al., 
2017) and behavioural tolerance (i.e. learning to minimize the unwanted drug effects on performance by means of cognitive- or behavioural adaptation).

Several neurocognitive tests where administrated which conceptually measure skills related to driving performance (Kay \& Logan, 2011). The performance of patients on these neurocognitive tasks showed no significant differences when compared to normative controls. However, the $95 \%$ CIs of the mean differences in performance between patients and controls on all neurocognitive task also included the alcohol criterion, suggesting large inter-individual variations. Mean differences for these parameters should therefore be regarded as inconclusive in terms of clinical relevance. Furthermore, for patients treated longer than 3 years noninferiority was observed for 4 neurocognitive tests. This supports the notion that treatment duration plays a role in the observed impairment in long-term treated patients.

The present study may hold several limitations. First, patients were included into the study based upon their category III antidepressant usage and gave self-reported reasons (such as depression or pain) for their prescription. As such, the exact underlying clinical indication remained unknown. This lack of information makes direct comparison with prior research about long-term antidepressant treatment difficult, given the possibility of disorder heterogeneity. Nonetheless, the present study primarily aimed to include a representative group of drivers with long-term category III antidepressant treatment. Second, patients in the present study showed underlying diversity due to differences in daily dosages and reported co-medication. Although such factors limit the interpretation of underlying mechanisms, it does reflects the characteristics of the population of long-term antidepressant users who operate a vehicle. Third, there may be a selection bias, in so far as probably only patients who estimated themselves as fit-to-drive volunteered for the study. However, these patients may be representative for the target population, i.e. long-term users who are active car drivers. Patients who do not feel fitto-drive are less likely to drive in real-life. Fourth, the division of treatment duration into subgroups was based on a practical and legislative measure as adopted in the Netherlands. Nonetheless, future studies could explore the time needed to build op tolerance to the impairing effects of daily antidepressant usage and handle treatment duration as a continues variable over time. Fifth, the current study did not include the collection of blood samples to monitor drug levels. Monitoring driving related impairment as a function of drug levels and/or treatment duration may indicate a time-point at which the development of tolerance mitigates the magnitude of performance impairment below the level of clinical relevant impairment (van der Sluiszen, Vermeeren, Jongen, Vinckenbosch, \& Ramaekers, 2017). 


\section{Chapter 5}

In summary, antidepressant users who were treated for less than 3 years showed clinically relevant impairment during the on-the-road driving test, but this was absent in the subgroup of patient treated for longer than 3 years. The lack of clinically relevant impairment in patients treated longer than 3 years was further supported by results from neurocognitive tests, although most outcomes of the neurocognitive tests remained inconclusive. These findings support the idea that duration of treatment can be taken into account when evaluating the impact of longterm medication usage on individual drivers. The implication would be that classification systems grading the effects of drugs on driving should allow for differential classification of drug effects on driving in relation to treatment duration.

\section{Acknowledgements}

Authors would like to thank A. van Oers, I. Brauers, H. Brauers, C. Steins, J. Jongen, S. Coleman, F.R.J. Vinckenbosch (Maastricht University), J. Jansen, R. Enkelaar, Z. Kösem, J. Zwart, W. Langendroff, S. Timmermans, S. van Kreel, D. Bervoets and S. de Klerk (University of Utrecht), B. de Kruijk, E. Flier and M. Janmaat (University of Groningen) for their assistance in carrying out the study. Furthermore, the authors would like to thank C. van Leeuwen, MD. (Maastricht University), N. Bouwmeester, MD. (University of Utrecht), and P.P. de Deyn, MD. (University of Groningen), for their medical supervision.

\section{Declaration of Interest}

J.C. Verster has received grants from Janssen, Nutricia, Red Bull, Sequential, Takeda, and acted as a consultant / advisor for 82Labs, Canadian Beverage Association, Centraal Bureau Drogisterij bedrijven, Clinilabs, Coleman Frost, Danone, Deenox, Eisai, Janssen, Jazz, Purdue, Red Bull, Sanofi-Aventis, Sen-Jam Pharmaceutical, Sepracor, Takeda, Transcept, Trimbos Institute, Vital Bevrages and ZBiotics. A. Vermeeren and J.G. Ramaekers have received funding over the last 4 years from pharmaceutical companies (Eisai, Jazz, Merck and Transcept).

\section{Funding}

This study was financially supported by the Dutch Ministry of Infrastructure and Water management. 


\section{FIGURES \& TABLES}

Figure 1: Schematic drawing of the highway driving test. The standard deviation of lateral position (SDLP) is an index of road tracking error or "weaving". Drugs that induce sleepiness or sedation cause loss of vehicle control, leading to increased road tracking error. Figure and description taken with permission from van der Sluiszen et al., 2019.
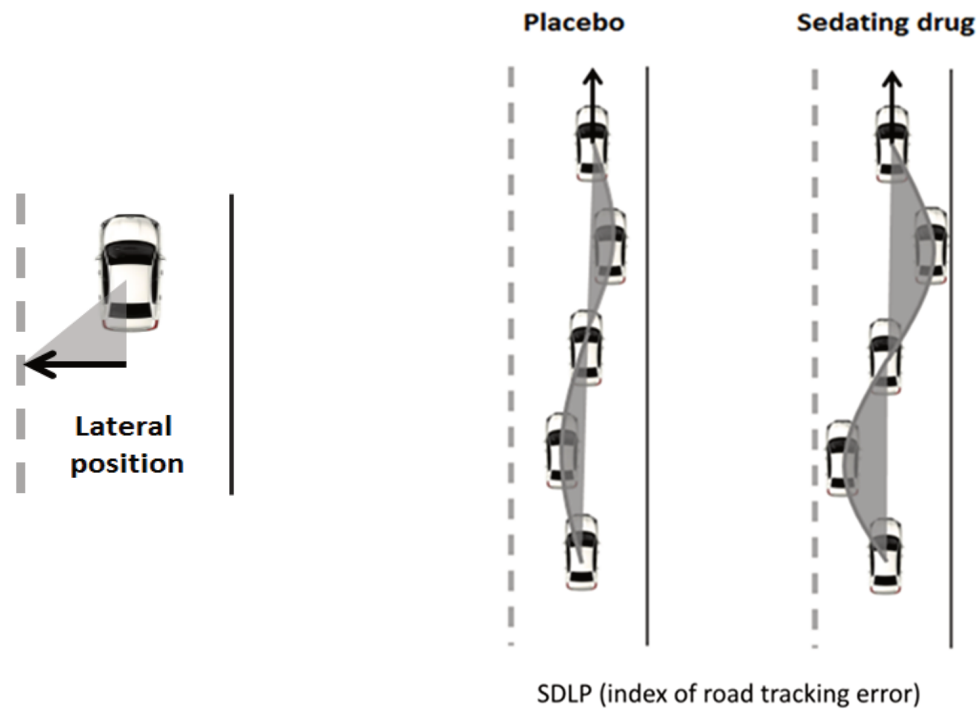
Chapter 5

Figure 2: Hypothetical example of the qualification of clinical relevance of performance differences between patients and controls. The dotted line indicates the change in performance after alcohol intake (relative to placebo). A (drug induced) change in performance will be classifcied as inferior when the 95\% CI includes the alcohol criterium but not zero (A Inferiority). Non-inferiority is concluded when the $95 \%$ CI does not include the alcohol criterium (B - Non-inferiortiy). If the $95 \%$ CI includes the alcohol criterion as well as zero, the qualification of clinical relevance is undecided ( $\mathrm{C}$ - Inconclusive). Figure and description taken with permission from van der Sluiszen et al., 2019.

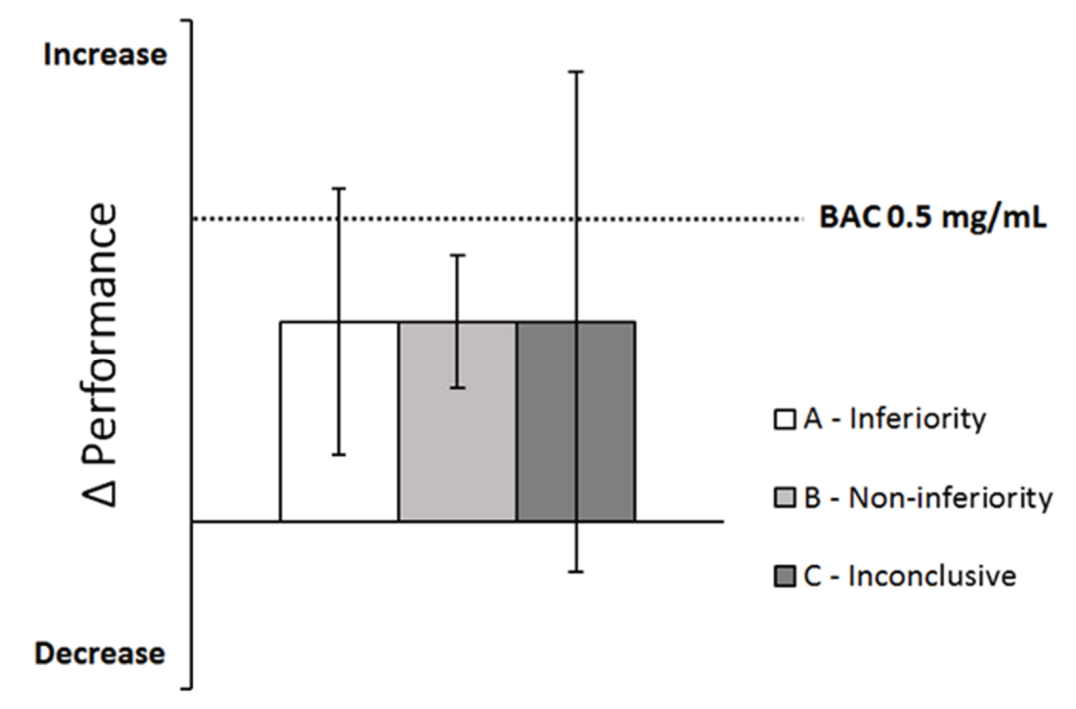


Driving performance of long-term antidepressant users
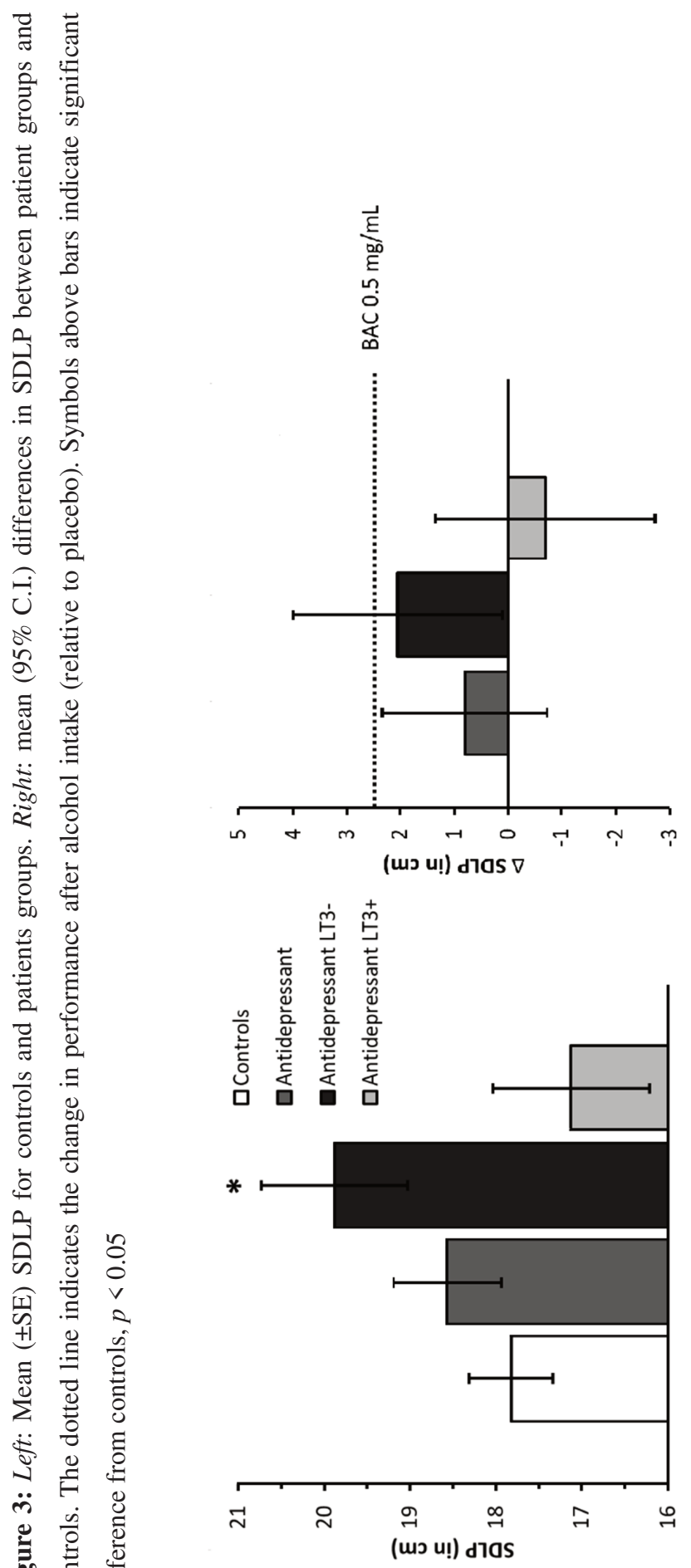
Chapter 5

Table 1: Overview testing day. Time (in hours) is displayed relative from start

\begin{tabular}{cl}
\hline $\begin{array}{c}\text { Time } \\
\text { (h:min) }\end{array}$ & Event \\
\hline$+0: 00$ & $\begin{array}{c}\text { Inclusion check } \\
\text { Alcohol, Drugs, Precepts, Questionnaires }\end{array}$ \\
$+0: 20$ & $\begin{array}{c}\text { Neurocognitive tests }- \text { Part I } \\
\text { TMT; DSST; ATTPT; RT-SI,-S2,-S3; DT }\end{array}$ \\
$+1: 20$ & Break \\
& Standardized meal and refreshment \\
$+1: 35$ & Neurocognitive tests - Part II \\
$+2: 20$ & Transport to highway \\
$+2: 30$ & Start Highway driving test \\
$+3: 30$ & End Highway driving test, transport to lab \\
$+4: 00$ & End testing day \\
\hline TMT: Trail Making Test, DSST: Digit Symbol Substitution Test, ATTPT: Adaptive \\
Tachistoscopic Traffic Perception Test, RT: Reaction Test, DT: Determination Test, \\
RTTT: Risk Taking Test Traffic, PVT: Psychomotor Vigilance Test
\end{tabular}




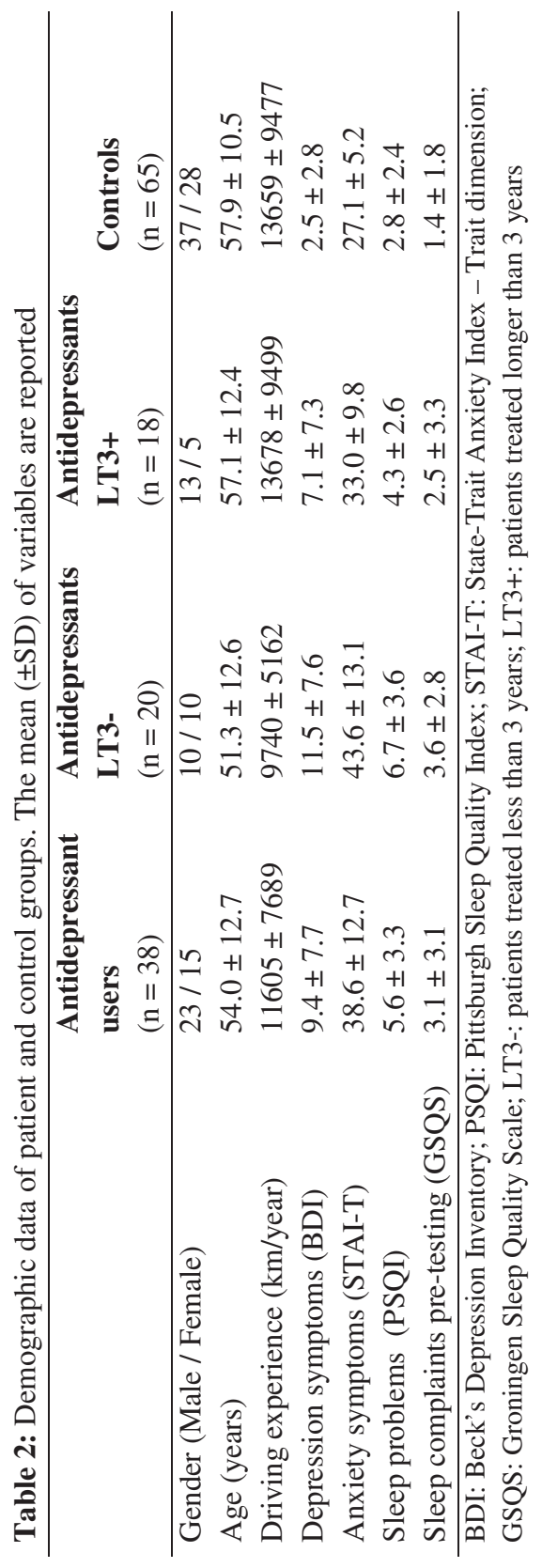




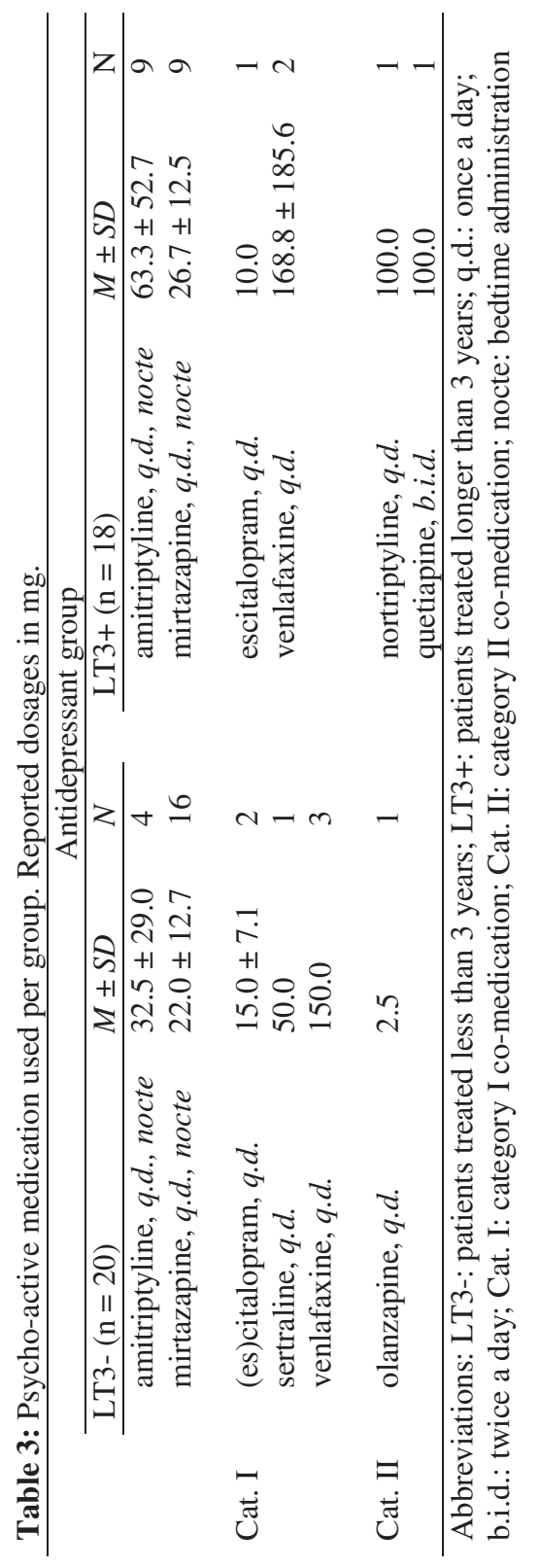


Driving performance of long-term antidepressant users

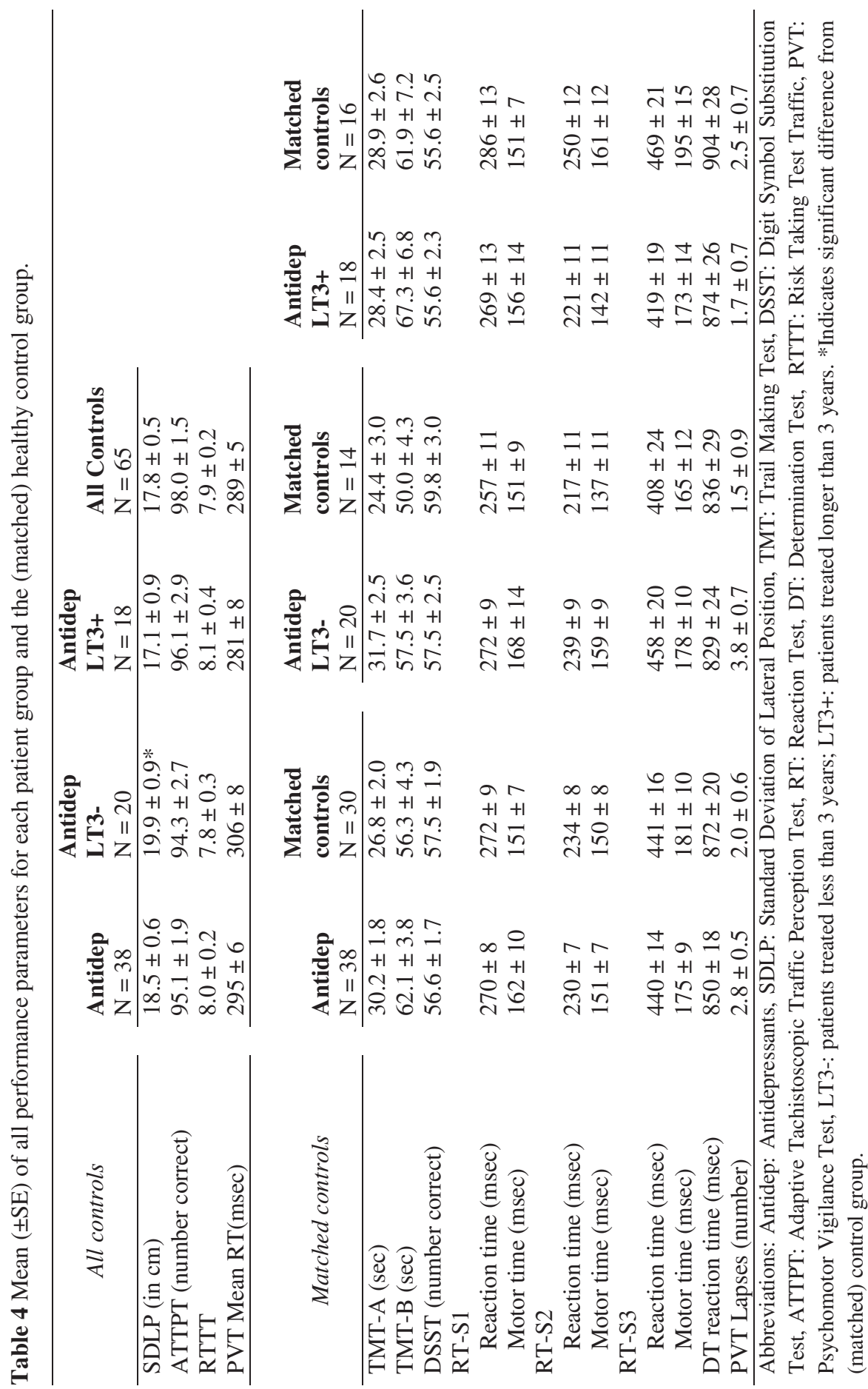


Chapter 5

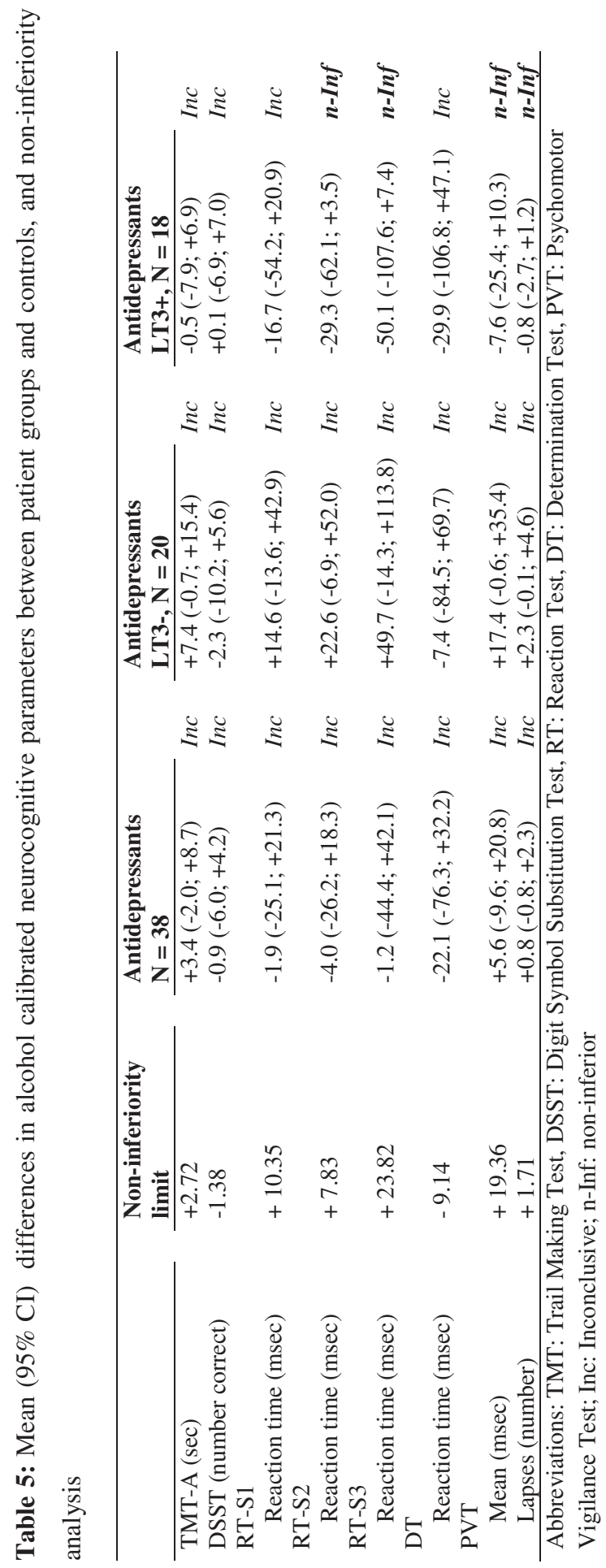


Driving performance of long-term antidepressant users

\section{REFERENCES}

Arroll, B., Macgillivray, S., Ogston, S., Reid, I., Sullivan, F., Williams, B., \& Crombie, I. (2005). Efficacy and tolerability of tricyclic antidepressants and SSRIs compared with placebo for treatment of depression in primary care: a meta-analysis. The Annals of Family Medicine, 3(5), 449-456.

Barbone, F., McMahon, A., \& Davey, P. (1998). Use of benzodiazepines increased road traffic accidents whereas use of tricyclic antidepressants and SSRIs did not. Lancet, 24, 13311336.

Basner, M., \& Dinges, D. F. (2011). Maximizing sensitivity of the psychomotor vigilance test (PVT) to sleep loss. Sleep, 34(5), 581-591.

Beck, A. T., Steer, R. A., \& Carbin, M. G. (1988). Psychometric properties of the Beck Depression Inventory: Twenty-five years of evaluation. Clinical psychology review, 8(1), 77-100.

Blomberg, R. D., Peck, R. C., Moskowitz, H., Burns, M., \& Fiorentino, D. (2009). The long beach/fort lauderdale relative risk study. Journal of safety research, 40(4), 285-292.

Borkenstein, R. F., Crowther, R., \& Shumate, R. (1974). The role of the drinking driver in traffic accidents (The Grand Rapids Study). Blutalkohol, 11(Suppl.), 1-131.

Bramness, J. G., Skurtveit, S., Neutel, C. I., Mørland, J., \& Engeland, A. (2008). Minor increase in risk of road traffic accidents after prescriptions of antidepressants: a study of population registry data in Norway. The Journal of clinical psychiatry, 69(7), 1,4781103.

Brunnauer, A., Laux, G., David, I., Fric, M., Hermisson, I., \& Möller, H.-J. (2008). The impact of reboxetine and mirtazapine on driving simulator performance and psychomotor function in depressed patients. The Journal of clinical psychiatry, 69(12), 1,478-1886.

Buysse, D. J., Reynolds III, C. F., Monk, T. H., Berman, S. R., \& Kupfer, D. J. (1989). The Pittsburgh Sleep Quality Index: a new instrument for psychiatric practice and research. Psychiatry research, 28(2), 193-213.

Chang, C. M., Wu, E. C. H., Chen, C. Y., Wu, K. Y., Liang, H. Y., Chau, Y. L., . . Tsai, H. J. (2013). Psychotropic drugs and risk of motor vehicle accidents: a population-based case-control study. British Journal of Clinical Pharmacology, 75(4), 1125-1133.

Darowski, A., Chambers, S.-A. C., \& Chambers, D. J. (2009). Antidepressants and falls in the elderly. Drugs \& aging, 26(5), 381-394.

Dassanayake, T., Michie, P., Carter, G., \& Jones, A. (2011). Effects of benzodiazepines, antidepressants and opioids on driving. Drug safety, 34(2), 125-156.

de Gier, J. J., Alvarez, F. J., Mercier-Guyon, C., \& Verstraete, A. G. (2009). Prescribing and dispensing guidelines for medicinal drugs affecting driving performance. In J. Verster, S. Pandi-Perumal, J. Ramaekers, \& J. de Gier (Eds.), Drugs, Driving and Traffic Safety (pp. 121-134). Basel Birkaeuser Berlag AG.

Dinges, D. F., \& Powell, J. W. (1985). Microcomputer analyses of performance on a portable, simple visual RT task during sustained operations. Behavior Research Methods, Instruments, \& Computers, 17(6), 652-655. 
Faul, F., Erdfelder, E., Lang, A.-G., \& Buchner, A. (2007). G* Power 3: A flexible statistical power analysis program for the social, behavioral, and biomedical sciences. Behavior research methods, 39(2), 175-191.

Gómez-Talegón, T., Fierro, I., Carmen Del Río, M., \& Álvarez, F. J. (2011). Classification of medicinal drugs and driving: coordination and synthesis report. Retrieved from (http://www.bast.de/Druid/EN/deliverales-

list/downloads/Deliverable_4_4_1.html?nn=613800)

Gorenstein, C., De Carvalho, S. C., Artes, R., Moreno, R. A., \& Marcourakis, T. (2006). Cognitive performance in depressed patients after chronic use of antidepressants. Psychopharmacology, 185(1), 84-92.

Hergovich, A., Bognar, B., Arendasy, M., \& Sommer, M. (2005). Manual Vienna Risk-taking Test Traffic (WRBTV). Mödling: SCHUHFRIED GmbH.

Jongen, S., Vermeeren, A., van der Sluiszen, N. N. J. J. M., Schumacher, M. B., Theunissen, E. L., Kuypers, K. P. C., . . Ramaekers, J. G. (2017). A pooled analysis of highway driving studies in actual traffic measuring standard deviation of lateral position (i.e. "weaving") while driving at a blood alcohol concentration of $0.5 \mathrm{~g} / \mathrm{L}$. Psychopharmacology, 234(5), 837 - 844. doi:10.1007/s00213-016-4519-z

Jongen, S., Vuurman, E. F. P. M., Ramaekers, J. G., \& Vermeeren, A. (2014). Alcohol calibration of tests measuring skills related to car driving. Psychopharmacology, 231(12), 2435-2447.

Kay, G. G., \& Logan, B. K. (2011). Drugged driving expert panel report: a consensus protocol for assessing the potential of drugs to impair driving. Retrieved from

Koster, E. S., Blom, L., Philbert, D., Rump, W., \& Bouvy, M. L. (2014). The Utrecht Pharmacy Practice network for Education and Research: a network of community and hospital pharmacies in the Netherlands. International journal of clinical pharmacy, 36(4), 669674.

Leveille, S. G., Büchner, D. M., Koepsell, T. D., McCloskey, L. W., Wolf, M. E., \& Wagner, E. H. (1994). Psychoactive medications and injurious motor vehicle collisions involving older drivers. Epidemiology, 5(6), 591-598.

Louwerens, J. W., Gloerich, A. B. M., DeVries, G., Brookhuis, K. A., \& O’Hanlon, J. F. (1987). The relationship between drivers' blood alcohol concentration (BAC) and actual driving performance during high speed travel. In: Noordzij PC, Roszbach R. (eds). Alcohol Drugs Traffic Safety - T86. Elsevier, Amsterdam, 183 - 186.

Ministry of Infrastructure and Water Management. (2000). Regeling eisen geschiktheid (REG 2000). Retrieved from http://wetten.overheid.nl/BWBR0011362/

Mulder-Hajonides van der Meulen, W., Wijnberg, J., Hollander, J., De Diana, I., \& van den Hoofdakker, R. (1980). Measurement of subjective sleep quality. Eur Sleep Res Soc Abstr.

Neuwirth, W., \& Benesch, M. (2007). Manual DT: Determination Test, Version 33.00. Mödling: SCHUHFRIED GmbH.

Nikolaus, T., \& Zeyfang, A. (2004). Pharmacological treatments for persistent non-malignant pain in older persons. Drugs \& aging, 21(1), 19-41. 
O'Hanlon, J. F. (1984). Driving performance under the influence of drugs: rationale for, and application of, a new test. British Journal of Clinical Pharmacology, 18(S1), 121S129S. doi:10.1111/j.1365-2125.1984.tb02590.x

Prieler, J. (2008). Manual RT: Reaction Test, Version 31. Mödling: SCHUHFRIED GmbH.

Ramaekers, J. (2003). Antidepressants and driver impairment: empirical evidence from a standard on-the-road test. The Journal of clinical psychiatry, 64(1), 20-29.

Ramaekers, J. (2017). Drugs and driving research in medicinal drug development. Trends in pharmacological sciences, 38(4), 319-321.

Rapoport, M. J., Zagorski, B., Seitz, D., Herrmann, N., Molnar, F., \& Redelmeier, D. A. (2011). At-fault motor vehicle crash risk in elderly patients treated with antidepressants. The American Journal of Geriatric Psychiatry, 19(12), 998-1006.

Ravera, S., Monteiro, S. P., de Gier, J. J., Van der Linden, T., Gómez-Talegón, T., \& Álvarez, F. J. (2012). A European approach to categorizing medicines for fitness to drive: outcomes of the DRUID project. British Journal of Clinical Pharmacology, 74(6), 920931.

Ray, W. A., Fought, R. L., \& Decker, M. D. (1992). Psychoactive drugs and the risk of injurious motor vehicle crashes in elderly drivers. American journal of epidemiology, 136(7), 873-883.

Reitan, R. M. (1958). Validity of the Trail Making Test as an indicator of organic brain damage. Perceptual and motor skills, 8(3), 271-276.

Roth, T., Eklov, S., Drake, C., \& Verster, J. (2014). Meta-analysis of on-the-road experimental studies of hypnotics: effects of time after intake, dose, and half-life. Traffic injury prevention, 15(5), 439-445.

Schuhfried, G. (2009). Manual ATAVT: The Adaptive Tachistoscopic Traffic Perception Test, Version 22. Mödling: SCHUHFRIED GmbH.

Spielberger, C. D., Gorsuch, R., \& Lushene, R. (1970). STAI Manual for the State-Trait Anxiety Inventory (Self Evaluation Questionnaire). Consulting Psychologist, 22, 1-24.

van der Sluiszen, N. N. J. J. M., Vermeeren, A., Jongen, S., Vinckenbosch, F. R. J., \& Ramaekers, J. G. (2017). Influence of Long-Term Benzodiazepine use on Neurocognitive Skills Related to Driving Performance in Patient Populations: A Review. Pharmacopsychiatry, 50(05), 189-196. doi:10.1055/s-0043-112755

van der Sluiszen, N. N. J. J. M., Vermeeren, A., Verster, J. C., van de Loo, A. J. A. E., van Dijken, J. H., Veldstra, J. L., . . . Ramaekers, J. G. (2019). Driving performance and neurocognitive skills of long-term users of benzodiazepine anxiolytics and hypnotics. Human Psychopharmacology: Clinical and Experimental, 34(6). doi:10.1002/hup.2715 van der Sluiszen, N. N. J. J. M., Wingen, M., Vermeeren, A., Vinckenbosch, F. R. J., Jongen, S., \& Ramaekers, J. (2017). Driving performance of depressed patients who are untreated or receive long-term antidepressant (SSRI/SNRI) treatment. Pharmacopsychiatry, 50(05), 182-188. doi:10.1055/s-0043-111600

Veldhuijzen, D. S., van Wijck, A. J., Verster, J. C., Kenemans, J. L., Kalkman, C. J., Olivier, B., \& Volkerts, E. R. (2006). Acute and subchronic effects of amitriptyline $25 \mathrm{mg}$ on actual driving in chronic neuropathic pain patients. Journal of Psychopharmacology, 20(6), 782-788.

Vermeeren, A. (2004). Residual effects of hypnotics. CNS drugs, 18(5), 297-328. 
Chapter 5

Verster, J. C., \& Ramaekers, J. G. (2009). Antidepressants and traffic safety. In Drugs, driving and traffic safety (pp. 307-313): Springer.

Verster, J. C., \& Roth, T. (2011). Standard operation procedures for conducting the on-the-road driving test, and measurement of the standard deviation of lateral position (SDLP). International journal of general medicine, 4, 359.

Verster, J. C., van de Loo, A. J. A. E., Vermeeren, A., van der Sluiszen, N. N. J. J. M., Brookhuis, K. A., Veldstra, J. L., . . Ramaekers, J. G. (2016). Beïnvloeding van de rijvaardigheid bij langdurig gebruik van ICADTS-categorie III geneesmiddelen. Retrieved from https://www.rijksoverheid.nl/documenten/rapporten/2016/12/01/beinvloeding-van-derijvaardigheid-bij-langdurig-gebruik-van-icadts-categorie-iii-geneesmiddelen

Wechsler, D. (1958). The measurement and appraisal of adult intelligence (4th ed.). Baltimore, MD, US: Williams \& Wilkins Co. 




\section{CHAPTER 6}

On-the-road driving

performance of patients

with central disorders

of hypersomnolence

on stable treatment

\section{In revision as}

van der Sluiszen, N.N.J.J.M.*, Urbanus, B.*, Lammers, G.J., Overeem, S., Ramaekers. J.G. and Vermeeren, A. On-the-road driving performance of patients with central disorders of hypersomnolence. Traffic Injury Prevention. 
Chapter 6

\begin{abstract}
Excessive Daytime Sleepiness is a core symptom of narcolepsy and idiopathic hypersomnia, which impairs driving performance. Adequate treatment improves daytime alertness, but it is unclear whether driving performance completely normalizes. This study compares driving performance of patients with narcolepsy and idiopathic hypersomnia on stable treatment to that of healthy controls. Patients diagnosed with narcolepsy type 1 (NT1, n=33), narcolepsy type 2 $(\mathrm{NT} 2, \mathrm{n}=7)$, or idiopathic hypersomnia $(\mathrm{IH}, \mathrm{n}=6)$ performed a standardized one-hour on-theroad driving test, measuring standard deviation of lateral position (SDLP). Results showed that mean SDLP in patients did not differ significantly from controls, but the 95\%CI of the mean difference $(+1.02 \mathrm{~cm})$ was wide $(-0.72$ to $+2.76 \mathrm{~cm})$. Analysis of subgroups, however, showed that mean SDLP in NT1 patients was significantly increased by $1.90 \mathrm{~cm}$ as compared to controls, indicating impairment. Moreover, four NT1 patients requested to stop the test prematurely due to self-reported somnolence, and two NT1 patients were stopped by the driving instructor for similar complaints. No significant impairment was found in NT2 and IH patients, but groups were small and individual variation was large. In conclusion, driving performance of patients with narcolepsy and idiopathic hypersomnia on stable treatment varies widely. Driving performance of NT1 patients may still be impaired despite stable treatment. In clinical practice, determination of fitness to drive for these patients should be based on an individual assessment.
\end{abstract}


Driving performance and central disorders of hypersomnolence

\section{INTRODUCTION}

Adequate alertness is crucial for safely operating a vehicle. Several studies have shown that sleepiness while driving is one of the major causes of car accidents (Higgins et al., 2017; Sagberg, Jackson, Krüger, Muzet, \& Williams, 2004). Severe daytime sleepiness is the most common and disturbing complaint of patients with narcolepsy type 1 (NT1), narcolepsy type 2 (NT2) and idiopathic hypersomnia (IH). Without adequate treatment, sleepiness and associated vigilance impairments in these patients may lead to impaired performance during the waking state, and thus, be potentially dangerous for traffic safety.

The current international classification of sleep disorders distinguishes two types of narcolepsy. Type 1 (NT1) is characterised by excessive daytime sleepiness (EDS), disturbed nocturnal sleep, and the REM sleep related symptoms cataplexy (i.e. sudden loss of muscle tone evoked by strong emotions), hypnagogic hallucinations and sleep paralysis. Its hallmark is hypocretin deficiency that can be measured in CSF. Type 2 (NT2) presents with similar symptomatology except for cataplexy. Hypocretin measurement, if performed, must show a normal concentration. In patients with IH, excessive sleepiness manifests without evidence of REM sleep dysregulation nor hypocretin deficiency. Symptomatic management of narcolepsy and IH consists of a combination of behavioural- (e.g. the adoption of regular sleep schedules and planned daytime naps) and pharmacological treatments (Kornum et al., 2017). Stimulants are used as first-line treatment for daytime sleepiness. Sodium oxybate and antidepressants are primarily prescribed for treatment of cataplexy, but sodium oxybate can also improve other core symptoms of narcolepsy including sleepiness.

Patients with narcolepsy and $\mathrm{IH}$ are indeed known to have impaired driving performance. Driving simulator studies consistently show poor driving performance in these patients (Findley, Suratt, \& Dinges, 1999; George, Boudreau, \& Smiley, 1996; Kotterba et al., 2004; Philip et al., 2013). Clinical trials have shown, however, that pharmacological treatment of daytime sleepiness can significantly improve patients' daytime performance (Dauvilliers et al., 2013; Philip et al., 2014; van Schie et al., 2016). Nonetheless, studies found that patients' performance remained inferior compared to healthy controls, despite treatment (Philip et al., 2014; van Schie et al., 2016). This limited improvement may be related to the relatively short duration of treatment in clinical trials, and the restriction to certain types of medication. Patients' performance might improve further with stable and optimized long-term treatment. Pizza and colleagues compared frequency of self-reported car crashes between patients with 
Chapter 6

narcolepsy or IH and healthy controls, and found that crash risk was significantly increased in both treated and untreated patients (Pizza et al., 2015). However, crash risk of patients treated for at least 5 years was not different from healthy controls, suggesting that stable long-term treatment protected patients from driving risk.

This raises the question as to whether driving performance of narcolepsy and IH patients on stable treatment is comparable to that of the general population. The present study aimed to determine whether actual on-the-road driving performance of these patients is inferior to that of healthy controls. Patients with NT1, NT2 or IH presenting to sleep clinics for the evaluation of their fitness to drive to allow continuation of their license were invited for this study. Their performance was assessed using a standardized highway driving test (O'Hanlon, 1984; Ramaekers, 2017) and compared to that of a normative group of healthy controls who completed the same test, using identical procedures, equipment and test environment (van der Sluiszen et al., 2019).

\section{METHODS}

\section{Design and participants}

The current analysis compares driving performance of a group of patients with narcolepsy and idiopathic hypersomnia on stable treatment with that of a group of healthy controls. Forty-six patients (29 male, 17 female) were recruited via the Stichting Epilepsie Instelling Nederland (SEIN, Hoofddorp, The Netherlands) and Sleep Medicine Center Kempenhaeghe (Heeze, The Netherlands). The included patient sample was part of a large group of 96 patients who were evaluated for their fitness to drive between June 2015 and January 2017. Patients had to meet the following inclusion criteria: Diagnosis of NT1, NT2 or IH according to ICSD-3 criteria (American Academy of Sleep Medicine, 2014), stable treatment (no changes in treatment of hypersomnolence for at least 6 weeks), age between 18 - 75 years, and possession of a valid driver's licence. Patients were not restricted with regard to napping, smoking, drinking, foodor caffeine intake, given that the study aimed evaluate patients' performance in their everyday lives.

Thirty-one healthy subjects (20 male, 11 female) formed a control group. Their data were retrieved from a normative dataset collected in a previous study using the same driving test and procedures (van der Sluiszen et al., 2019). Control subjects had a valid driving license for at least 3 years and drove at least $3000 \mathrm{~km}$ per year. Exclusion criteria were: drinking more than 
21 units of alcohol per week; smoking more than 10 cigarettes a day; history of drug or alcohol abuse; presence of a significant medical-, neurological-, psychiatric- or sleep-disorder and the use of CNS-active medication that may affect driving.

The Medical Ethics Committee of Maastricht University and academic hospital Maastricht approved the study (www.toetsingonline.nl, NL50579.068.14). The study was conducted in agreement with the code of ethics on human experimentation established by the Declaration of Helsinki (1964) and subsequent amendments. All participants signed an informed consent form before enrolment.

\section{Highway driving test}

Driving performance was assessed using a standardized on-the-road highway driving test, which assesses standard deviation of lateral position (SDLP in $\mathrm{cm}$ ) as a measure of driver vehicle control (O'Hanlon, 1984; Ramaekers, 2017). In this test, participants drive a specially instrumented car for about 1 hour over a 100-km (61-mile) primary highway circuit (road E25) between the Dutch cities of Maastricht and Kelpen-Oler, accompanied by a licensed driving instructor having access to dual controls (brakes and accelerator). The participants' task is to drive with a steady lateral position between the delineated boundaries of the slower (right) traffic lane, while maintaining a constant speed of $95 \mathrm{~km} / \mathrm{h}$ (58 mph). Participants may deviate from those instructions only to pass a slower vehicle, and to leave and re-enter the highway at the turnaround point. Participants are instructed beforehand to terminate the test by stopping the car on the road shoulder if they have doubts about their competence to continue safely. If, however, they fail to do this and the driving instructor judges their performance to become unsafe, the participants can be ordered to stop the vehicle.

During the drive, the vehicle's speed and lateral distance relative to the left lane-line are continuously recorded via a camera mounted on top of the vehicle. These signals are captured at a rate of $4 \mathrm{~Hz}$ and stored on an on-board computer disk file for later pre-processing and analysis. Data pre-processing consists of off-line visual inspection of all data by trained processors to mark data segments that reveal signal loss or disturbances, such as overtaking manoeuvres and the turn-around point. The pre-processed dataset is then used to calculate means and standard deviations of lateral position, for each successive 5-km segment and for the test as a whole. The primary outcome variable is the Standard Deviation of Lateral Position (SDLP, in $\mathrm{cm}$ ) which is a measure of road tracking error, or 'weaving'. SDLP scores of prematurely terminated tests are calculated from the data collected until termination of each 
Chapter 6

ride. Performance as measured by mean SDLP has repeatedly been found sensitive to effects of alcohol, sleep deprivation and sedating drugs (Jongen, Perrier, Vuurman, Ramaekers, \& Vermeeren, 2015; Ramaekers, 2017; Vermeeren, 2004).

Drug-induced impairments in the highway-driving test have been compared to that of alcohol. Alcohol is a well-known benchmark drug that jeopardize traffic safety and shows a clear exponential dose-dependent relationship with traffic accident risk (Blomberg, Peck, Moskowitz, Burns, \& Fiorentino, 2009; Borkenstein, Crowther, \& Shumate, 1974). The clinical relevance of performance changes in the driving test have previously been determined by establishing the relationship between blood alcohol concentration (BAC) and SDLP (Louwerens, Gloerich, DeVries, Brookhuis, \& O'Hanlon, 1987). Studies have shown that a BAC of $0.5 \mathrm{mg} / \mathrm{ml}$ (the legal limit for driving in most countries) is associated with a mean increment in SDLP of $2.5 \mathrm{~cm}$ (Jongen et al., 2017). Consequently, $2.5 \mathrm{~cm}$ has been defined as the cut-off point for clinically relevant differences in SDLP (the non-inferiority limit).

\section{Karolinska Sleepiness Scale}

The Karolinska Sleepiness Scale (KSS) (Åkerstedt \& Gillberg, 1990) is a subjective rating scale that measures instantaneous sleepiness. The KSS contains nine points and ranges from extremely awake (1), to, very sleepy, great effort to stay awake (9). Higher values on the KSS indicate greater subjective sleepiness. To determine the effects of driving on subjective sleepiness, patients filled out the KSS at the start $\left(\mathrm{KSS}_{\text {start }}\right)$ and end $\left(\mathrm{KSS}_{\text {end }}\right)$ of the highway driving test. The change in $\mathrm{KSS}$ scores $\left(\Delta \mathrm{KSS}=\mathrm{KSS}_{\text {end }}-\mathrm{KSS}_{\text {start }}\right)$ was used to determine the relation between compare changes in subjective sleepiness during the on-the-road driving test with absolute road-tracking error.

\section{Statistical Analysis}

Power calculation revealed that a total sample of 77 participants should permit detection of a clinically relevant mean difference in SDLP of $2.5 \mathrm{~cm}$ between groups with a power of at least $90 \%$, assuming an alpha of 0.05 and a between subjects standard deviation of $4.3 \mathrm{~cm}$ (Jongen et al. 2017).

Univariate ANOVAs were used to compare driving performance between patients and controls. Covariate corrections were added to the ANOVA model if a demographic parameter (i.e. age or driving experience) showed a significant difference between patients and controls, and, the covariate in the ANCOVA model approximated significance $(\mathrm{p} \leq 0.10)$. GLM repeated 
measures were used to evaluate the effects of Time-on-Task and interactions between Timeon-Task and Group. To this end, the $100 \mathrm{~km}$ dataset (20 segments of $5 \mathrm{Km}$ each) was binned into 4 segments of approximately $25 \mathrm{Km}$ each. Time-on-Task effects were determined by comparing SDLP scores of the first and last $25 \mathrm{Km}$-segments, because both represent driving on the same section of the highway (i.e. the same physical lay-out of the road). Individuals with prematurely terminated highway driving tests had no or insufficient data in the last $25 \mathrm{~km}$ segment, and were excluded from Time-on-Task analysis.

To explore performance differences between subgroups of patients, comparative analyses were performed between subgroups of patients based on diagnosis (NT1, NT2 and IH) and treatment. CNS active treatment was classified as use of stimulants only (STI), sodium oxybate only (SBX), a combination (COM), or no CNS active treatment (NO).

To evaluate the clinical relevance of group differences SDLP between patients and control subjects a non-inferiority limit of $2.5 \mathrm{~cm}$ was used. When evaluating the $95 \%$ confidence interval (95\% C.I.) of the mean difference between groups, three interpretations are possible. First, a clinically relevant difference (inferiority) is assumed when the $95 \%$ C.I. lies above zero and when the upper limit of the $95 \%$ C.I. includes the non-inferiority limit of $2.5 \mathrm{~cm}$. Second, a clinically non-relevant difference (non-inferiority) is assumed when the $95 \%$ C.I. lies below the non-inferiority limit. Third, when the $95 \%$ C.I. includes zero and the limit of $2.5 \mathrm{~cm}$, it is concluded that a uniform interpretation of the observed differences is not possible due too large inter-individual differences (inconclusive).

All statistical analyses were conducted by using the IBM Statistical Package for the Social Sciences for Windows, version 24 (IBM Corp., Armonk, N.Y., USA).

\section{RESULTS}

\section{Prematurely terminated driving tests and missing data}

The driving tests of six out of 46 patients (13\%) were terminated prematurely, because the driving instructor or the participant judged that it was unsafe to continue. All six prematurely terminated tests were NT1 patients. Four patients reported sleepiness and requested to stop the test after driving for 45 to 51 minutes. Their SDLP scores were 15.8, 18.7, 19.1, and $24.7 \mathrm{~cm}$. Tests of two patients were stopped by the driving instructor (after driving for 30 and 35 minutes), because the participants was judged to be too drowsy to continue safely. Their SDLP scores were 23.1 and $30.4 \mathrm{~cm}$, respectively. Data from all six patients were excluded from the 


\section{Chapter 6}

Time-on-Task analysis, because of incomplete data in the last $25 \mathrm{Km}$ segment. For one patient (diagnosed with NT1) data of the highway driving test were missing due to failure of writing an output file after the completion of the test. This patient was excluded from all analysis. In summary, 45 patients were included in the SDLP between-group analyses, of which 39 patients were included in the Time-on-Task analyses.

\section{Participant sample}

Of the 45 patients (29 males, 16 females) included in the analyses, 32 were diagnosed with NT1, seven with NT2, and 6 with IH (Table 1). Their mean $( \pm$ SD) age was $41.9( \pm 15.8)$ years, and they drove on average $10258( \pm 10424) \mathrm{km}$ per year. Nineteen patients $(10$ NT1, 5 NT2, 4 $\mathrm{IH}$ ) were on stable treatment with stimulant drugs only (dexamphetamine, methylphenidate, modafinil), five with sodium oxybate only (4 NT1) and sixteen patients (14 NT1) used a combination of stimulants, sodium oxybate and/or antidepressants (clomipramine, mirtazapine, venlafaxine). Five patients (4 NT1) used no medication for their hypersomnolence.

The control group comprised 31 healthy participants ( 20 males, 11 females) with a mean $( \pm S D)$ age of $59.8( \pm 10.8)$ years. Their annual driving experience was on average $12577( \pm 7684)$ $\mathrm{km} /$ year. Controls were older than the patients $\left(F_{1,74}=30.18, \mathrm{p}<0.01\right)$, but driving experience did not differ significantly between groups.

\section{Driving performance}

Mean $( \pm$ SE) SDLP scores were $18.68( \pm 0.56) \mathrm{cm}$ in patients and $17.66( \pm 0.67) \mathrm{cm}$ in healthy controls. The difference $(1.02 \mathrm{~cm})$ was not significant $\left(F_{1,74}=1.37, p=0.25\right)$. The $95 \% \mathrm{CI}$ of the mean difference $(-0.72 \mathrm{~cm}$ to $+2.76 \mathrm{~cm})$ included zero as well as the $2.5 \mathrm{~cm}$ non-inferiority limit, indicating that individual variation was large and that the results should be considered as inconclusive.

To correct for the age difference between groups, univariate analysis of SDLP was repeated with age as a co-variate. Results show no significant effect of age as a co-variate on SDLP ( $p=$ $0.76)$, and the difference between groups remained not significant $(p=0.20)$. Therefore, further analyses of SDLP were performed without age as a covariate.

Mean SDLP scores increased from the first to the last $25 \mathrm{~km}$-segment of the driving test in patients and controls (figure 1). Time-on-task analysis showed a significant effect for Segment $\left(F_{1,68}=36.16, p<0.01\right)$, but no significant interaction between Group and Segment $\left(F_{1,63}=\right.$ 
0.77, $p=0.39)$. On average, the SDLP at the end ( $4^{\text {th }}$ segment) of the highway drive was $+2.30 \mathrm{~cm}$ higher in comparison to the start ( $1^{\text {st }}$ segment $)$.

Mean $( \pm$ SD) SDLP scores for diagnostic subgroups of patients were $19.56 \mathrm{~cm}( \pm 4.08)$ for NT1, $15.70 \mathrm{~cm}( \pm 1.81)$ for NT2, and $17.50 \mathrm{~cm}( \pm 3.23)$ for IH patients (figure 2). Overall analysis showed that there were significant differences between subgroups and controls $\left(F_{3,72}=2.93, p\right.$ $=0.04)$. Simple contrasts revealed that SDLP was significantly increased by $+1.90 \mathrm{~cm}$ in NT1 patients as compared to controls $(\mathrm{p}=0.04)$. The upper limit of the $95 \% \mathrm{CI}$ was above the limit for impairment (figure 2), so this difference should be considered clinically relevant. Mean SDLPs of NT2 and IH patients were not significantly increased compared to controls. For NT2 patients the $95 \%$ CI did not include the limit for impairment, indicating their performance was not inferior to controls. For IH patients, however, the 95\% CI did include the limit for impairment, indicating the results should be considered inconclusive.

Analysis revealed no significant differences between treatment subgroups and controls $\left(F_{4,71}\right.$ $=0.66, p=0.62)$. All confidence intervals of mean differences included zero as well as noninferiority limit, indicating that these results should be considered inconclusive (figure 2).

\section{Subjective sleepiness}

Analysis showed no significant difference between NT1, NT2 and IH patients groups on the $\operatorname{KSS}_{\text {start }}\left(F_{2.42}=0.12, p=0.89\right)$. Mean $( \pm \mathrm{SD}) \mathrm{KSS}_{\text {start }}$ scores were $3.2( \pm 1.5), 2.9( \pm 1.6)$ and 3.2 $( \pm 1.5)$, respectively. Similar non-significant $(p=0.65)$ differences were obtained for sleepiness rating after the driving test. For the three groups, mean $( \pm \mathrm{SD}) \mathrm{KSS}_{\text {end }}$ scores were $4.3( \pm 2.2)$, $3.7( \pm 1.6)$ and $3.7( \pm 2.3)$, respectively. Patients whose driving tests were terminated prematurely had significantly higher sleepiness ratings after the completion of the driving test $(7.3 \pm 1.2)$ as compared to patients who completed the test as scheduled $\left(3.7 \pm 1.8 ; F_{1.43}=23.86\right.$, $\mathrm{p}<0.01)$. Across all patients, there was a significant correlation (2-tailed) between $\triangle$ KSS scores and $\operatorname{SDLP}(\mathrm{r}=0.44, \mathrm{n}=45, \mathrm{p}<0.01$, figure 3$)$.

\section{DISCUSSION}

The current study examined the driving performance of patients' with central disorders of hypersomnolence on stable treatment in comparison to a normative control group. To the best of our knowledge, this is the first study to compare on-the-road driving performance in treated patients with narcolepsy and IH to that of a group of healthy controls. Overall results showed that the $95 \%$ CI around the mean increase in SDLP between all patients and controls included 


\section{Chapter 6}

the non-inferiority limit (i.e. $+2.5 \mathrm{~cm}$ ) and zero. This indicates that inter-individual differences in driving performance were large between patients, and results for the group as a whole should be considered inconclusive. This finding is in line with previous research showing large variation between patients (Findley et al., 1999; Kotterba et al., 2004).

Analyses of subgroups based on diagnosis revealed that mean SDLP of NT2 and IH patients were not significantly different in comparison to normative controls. However, a clinically relevant increment in SDLP was observed for NT1 patients. Moreover, six out of 33 NT1 patients were not able to complete the 1 hour on-the-road driving test, which is notably more than what is commonly observed in other on-the-road driving studies with healthy volunteers (Verster \& Roth, 2012). Results demonstrate that driving performance in NT1 patients is, on average, not completely normalized after stable treatment.

Transferring the current results to the medicolegal discussion of fitness to drive in nonprofessional drivers with NT1 involves a careful weighing between mobility and safety. Appropriate legislation would help patients better integrate in society and contribute to their quality of life. The most extreme position therefore, to disqualify all patients with NT1 to drive, is neither reasonable nor in agreement with current findings. To illustrate, while the driving performance of NT1 patients on group level should be regarded as impaired, a substantial part of this group performed within the boundaries of what is considered "normal" vehicle control. Furthermore, of the NT1 patients with non-completed on-the-road driving tests, the majority requested to stop the test themselves, indicating that these patients choose to act cautiously when participating in actual real-world traffic. The self-awareness of possible driving impairment, combined with the decision to discontinue driving, reflects the adequate use of coping strategies employed by narcolepsy patients (Kotterba, Müller, Steiner, \& Mayer, 2002). Indeed, a recent French cross-sectional study involving a large cohort of narcolepsy patients with long-term treatment (duration $>5$ years) showed that long-term treated patient had a lower crash risk then healthy controls, possibly due to the increased disease insight and awareness of possible driving risk (Pizza et al., 2015).

Nevertheless, the overall unrestored driving performance in treated NT1 indicates a need for appropriate tests to predict fitness to drive. The problem is, however, that most laboratory tests and subjective scales currently available lack sufficient agreement with real driving performance (Jongen et al., 2015; Verster \& Roth, 2012). It is generally believed that the onthe-road driving test provides the best reliable evidence whether driving is safe or not. Ideally, 
fitness to drive of patients with narcolepsy and IH should be evaluated by standardized on-theroad driving assessments, but these tests are costly and cumbersome. Instead, fitness to drive assessments could consist of a combination of objective and subjective tests assessing different cognitive processes involved in driving, such as vigilance and executive aspects of attention, and subjective feelings of sleepiness (Philip et al., 2013; Pizza et al., 2015).

Several aspects of this study may limit the generalisation of the obtained results. First, the included patient groups were pre-selected based of the possession of a valid driver's license in accordance with the Dutch driving license regulations. It is therefore possible that the currently included group fails to grasp the performance of patients whose hypersomnolence is, on average, more severe and lost their driver's licenses. Second, the cross-sectional nature of this study leaves the question unanswered as to whether treatment had a positive effect on driving performance. Due to the specific symptom profile of NT1 (existence of cataplexy), the selected pharmacological treatment is usually different from what is used in NT2 or IH patients. The explorative analyses comparing treatment type showed an absence of significant differences based on this parameter, although large variation in SDLP were present. A suggestion for further research is to explore the facets of patient treatment with a suggested focus on treatment duration as a factor of importance (Pizza et al., 2015).

In conclusion, driving performance of the group as a whole varied widely. NT1 patients showed impaired driving performance compared to controls reflected in increased SDLP and the high frequency of stopped tests, despite stable treatment. No firm conclusions can be drawn for NT2 and IH patients. Therefore, determination of fitness to drive in clinical practice should be based on an individual assessment. The optimization of detecting risky drivers in clinical practice benefits further by the inclusion of sleepiness measures in combination with objective tests that assess vigilance.

\section{Acknowledgement}

Authors would like to thank M. Dingemanse, F.R.J. Vinckenbosch, S. Coleman, C. Steins and J. Jongen for data collection; A. van Oers and I. Brauers for the logistics work and H. Brauers for ensuring the safety of the participants during the highway driving test. 
Chapter 6

\section{TABLES \& FIGURES}

Table 1: Demographic data for patients and healthy controls

\begin{tabular}{lll}
\hline & $\begin{array}{l}\text { Patients } \\
\mathrm{N}=45\end{array}$ & $\begin{array}{l}\text { Controls } \\
\mathrm{N}=31\end{array}$ \\
\hline Gender (male / female) & 29 / 16 & $20 / 11$ \\
Age (M \pm SD in years) & $41.9( \pm 15.8)$ & $59.8( \pm 10.8)$ \\
Diagnosis (NT1 / NT2 / IH) & 32 / 7 / 6 & \\
Treatment (STI / SBX / COM / NO) & 19 / 6 / 15 / 5 & \\
Kilometres driven per year (M \pm SD) & $10258( \pm 10424)$ & $12577( \pm 7684)$ \\
\hline NT1 = narcolepsy type 1; NT2 = narcolepsy type 2; IH = idiopathic hypersomnia; STI \\
$=$ stimulants only; SBX= sodium oxybate only; COM = combination of stimulants, \\
SBX, antidepressants; NO= no CNS active treatment, M = mean; SD = Standard \\
Deviation
\end{tabular}


Figure 1: The mean $\left( \pm\right.$ SE) SDLP from the $1^{\text {st }}$ to $4^{\text {th }}$ segment (i.e. Time-on-Task effect) for both groups seperately

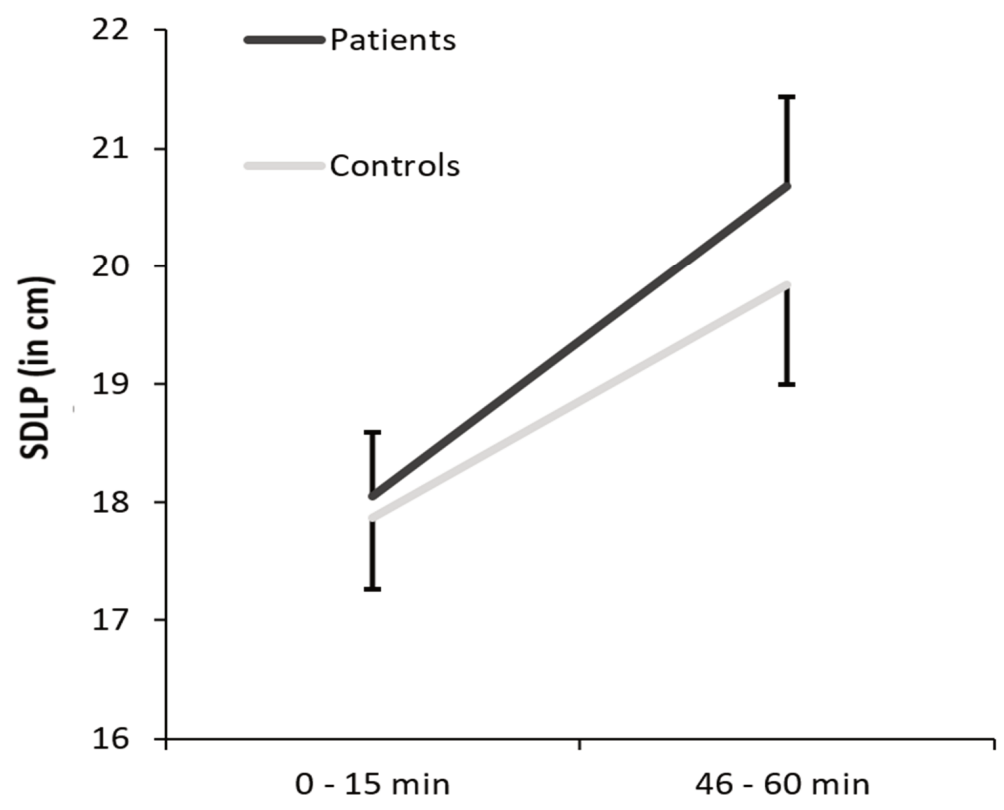


Chapter 6
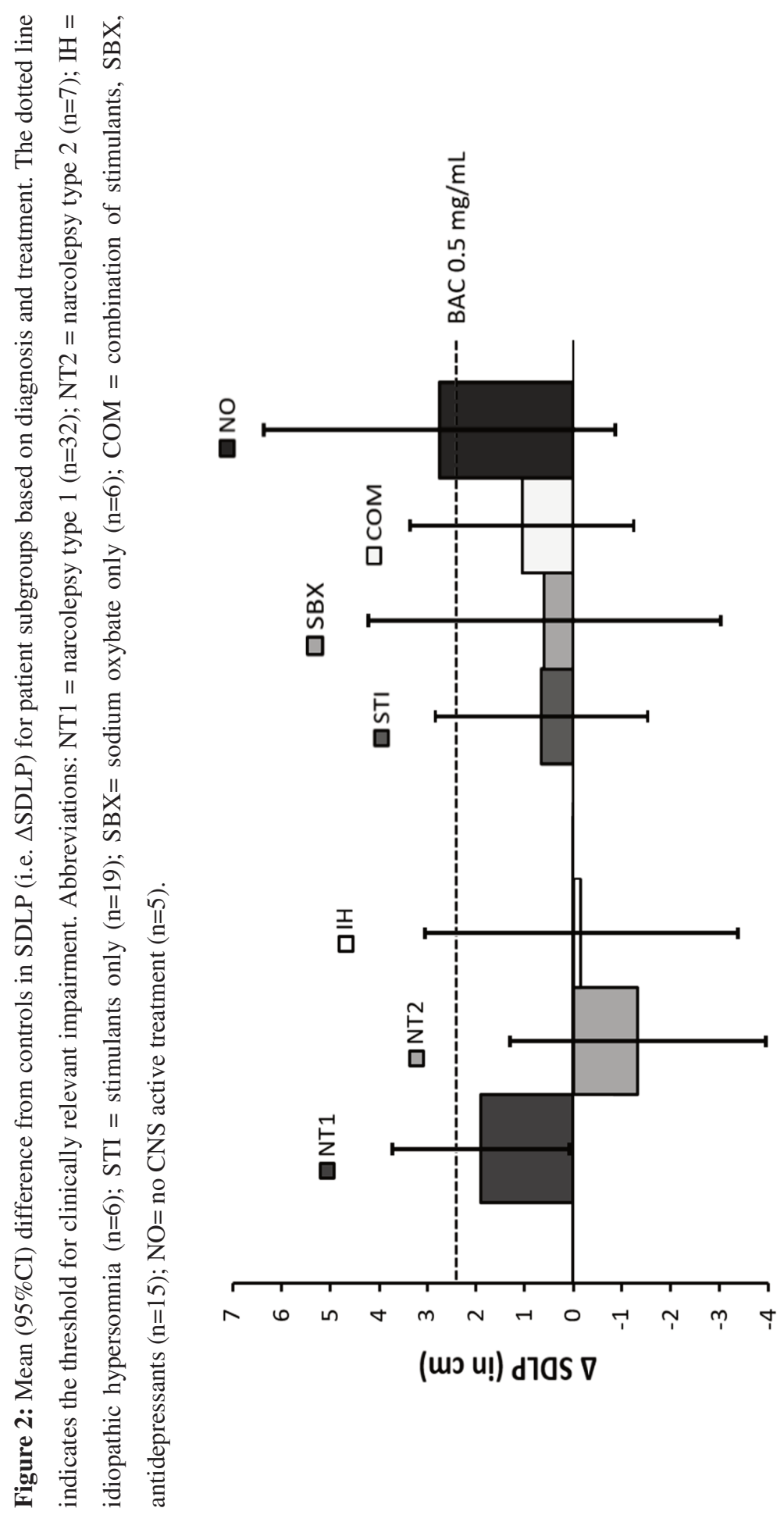
Figure 3: Correlation between individual driving performances $(n=45)$ as indicated by the standard deviation of lateral position (SDLP) and change subjective sleepiness during driving, as indicated by the delta Karolinska Sleepiness Scale ( $\Delta \mathrm{KSS}$ ). Approximately $20 \%$ of the variance in SDLP across patient groups is explained by subjective sleepiness. Abbreviations: NT1 = Narcolepsy with cataplexy; NT2 = narcolepsy without cataplexy; IH = Idiopathic Hypersomnia

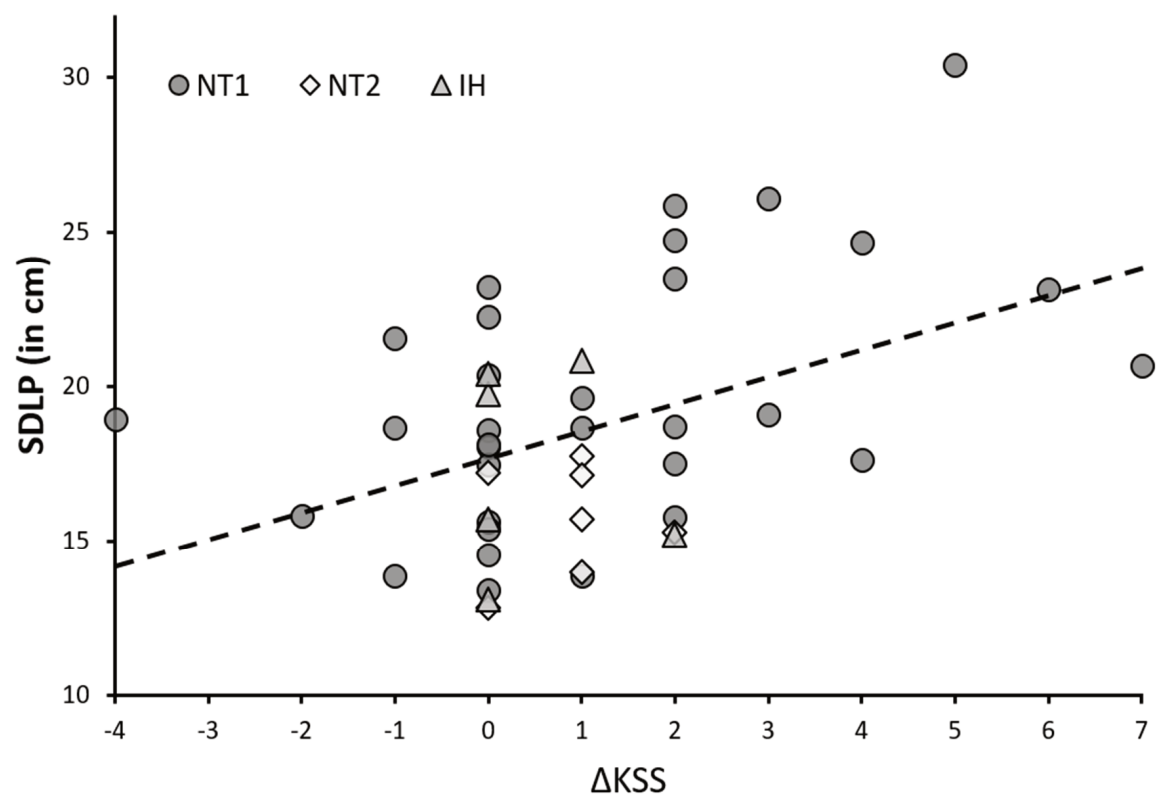


Chapter 6

\section{REFERENCES}

Åkerstedt, T., \& Gillberg, M. (1990). Subjective and objective sleepiness in the active individual. International Journal of Neuroscience, 52(1-2), 29-37.

American Academy of Sleep Medicine. (2014). International classification of sleep disordersthird edition (ICSD-3). AASM Resource Library [online].

Blomberg, R. D., Peck, R. C., Moskowitz, H., Burns, M., \& Fiorentino, D. (2009). The long beach/fort lauderdale relative risk study. Journal of safety research, 40(4), 285-292.

Borkenstein, R. F., Crowther, R., \& Shumate, R. (1974). The role of the drinking driver in traffic accidents (The Grand Rapids Study). Blutalkohol, 11(Suppl.), 1-131.

Dauvilliers, Y., Bassetti, C., Lammers, G. J., Arnulf, I., Mayer, G., Rodenbeck, A., . . . Schwartz, J.-C. (2013). Pitolisant versus placebo or modafinil in patients with narcolepsy: a double-blind, randomised trial. The Lancet Neurology, 12(11), 10681075.

Faul, F., Erdfelder, E., Lang, A.-G., \& Buchner, A. (2007). G* Power 3: A flexible statistical power analysis program for the social, behavioral, and biomedical sciences. Behavior research methods, 39(2), 175-191.

Findley, L. J., Suratt, P. M., \& Dinges, D. F. (1999). Time-on-task decrements in "steer clear" performance of patients with sleep apnea and narcolepsy. Sleep, 22(6), 804-809.

George, C., Boudreau, A., \& Smiley, A. (1996). Comparison of simulated driving performance in narcolepsy and sleep apnea patients. Sleep, 19(9), 711-717.

Higgins, J. S., Michael, J., Austin, R., Åkerstedt, T., Van Dongen, H. P., Watson, N., . . . Rosekind, M. R. (2017). Asleep at the wheel-the road to addressing drowsy driving. Sleep, 40(2), zsx001.

Jongen, S., Perrier, J., Vuurman, E. F. P. M., Ramaekers, J. G., \& Vermeeren, A. (2015). Sensitivity and validity of psychometric tests for assessing driving impairment: effects of sleep deprivation. PloS one, 10, e0117045-e0117045.

Jongen, S., Vermeeren, A., van der Sluiszen, N. N. J. J. M., Schumacher, M. B., Theunissen, E. L., Kuypers, K. P. C., . . Ramaekers, J. G. (2017). A pooled analysis of highway driving studies in actual traffic measuring standard deviation of lateral position (i.e. "weaving") while driving at a blood alcohol concentration of $0.5 \mathrm{~g} / \mathrm{L}$. Psychopharmacology, 234(5), 837 - 844. doi:10.1007/s00213-016-4519-Z

Kornum, B. R., Knudsen, S., Ollila, H. M., Pizza, F., Jennum, P. J., Dauvilliers, Y., \& Overeem, S. (2017). narcolepsy. Nature Reviews Disease Primers, 3, 16100.

Kotterba, S., Mueller, N., Leidag, M., Widdig, W., Rasche, K., Malin, J.-P., . . Orth, M. (2004). Comparison of driving simulator performance and neuropsychological testing in narcolepsy. Clinical neurology and neurosurgery, 106(4), 275-279.

Kotterba, S., Müller, N., Steiner, G., \& Mayer, G. (2002). Fahrverhalten bei NarkolepsieFragebogenanalyse unter Betroffenen: Driving in Narcolepsy-Analysis by Questionnaire Among Patients. Somnologie, 6(1), 26-33.

Louwerens, J. W., Gloerich, A. B. M., DeVries, G., Brookhuis, K. A., \& O’Hanlon, J. F. (1987). The relationship between drivers' blood alcohol concentration (BAC) and actual driving performance during high speed travel. In: Noordzij PC, Roszbach R. (eds). Alcohol Drugs Traffic Safety - T86. Elsevier, Amsterdam, 183 - 186. 
O'Hanlon, J. F. (1984). Driving performance under the influence of drugs: rationale for, and application of, a new test. British Journal of Clinical Pharmacology, 18(S1), 121S129S. doi:10.1111/j.1365-2125.1984.tb02590.x

Philip, P., Chaufton, C., Taillard, J., Capelli, A., Coste, O., Leger, D., . . Sagaspe, P. (2014). Modafinil improves real driving performance in patients with hypersomnia: a randomized double-blind placebo-controlled crossover clinical trial. Sleep, 37(3), 483487.

Philip, P., Chaufton, C., Taillard, J., Sagaspe, P., Leger, D., Raimondi, M., . . Capelli, A. (2013). Maintenance of Wakefulness Test scores and driving performance in sleep disorder patients and controls. International journal of psychophysiology, 89(2), 195202.

Pizza, F., Jaussent, I., Lopez, R., Pesenti, C., Plazzi, G., Drouot, X., . . Dauvilliers, Y. (2015). Car crashes and central disorders of hypersomnolence: a French study. PloS one, 10(6), e0129386.

Ramaekers, J. (2017). Drugs and driving research in medicinal drug development. Trends in pharmacological sciences, 38(4), 319-321.

Sagberg, F., Jackson, P., Krüger, H.-P., Muzet, A., \& Williams, A. (2004). Fatigue, sleepiness and reduced alertness as risk factors in driving: Institute of Transport Economics Oslo.

van der Sluiszen, N. N., Vermeeren, A., Verster, J. C., van de Loo, A. J., van Dijken, J. H., Veldstra, J. L., ... \& Ramaekers, J. G. (2019). Driving performance and neurocognitive skills of long-term users of benzodiazepine anxiolytics and hypnotics. Human Psychopharmacology: Clinical and Experimental, 34(6).

van Schie, M., Werth, E., Lammers, G. J., Overeem, S., Baumann, C., \& Fronczek, R. (2016). Improved vigilance after sodium oxybate treatment in narcolepsy.

Vermeeren, A. (2004). Residual effects of hypnotics. CNS drugs, 18(5), 297-328.

Verster, J., \& Roth, T. (2012). Predicting psychopharmacological drug effects on actual driving performance (SDLP) from psychometric tests measuring driving-related skills. Psychopharmacology, 220(2), 293-301. 



\section{CHAPTER 7}

General discussion 


\section{Chapter 7}

The general discussion serves to address the aims of this dissertation and the extent to which the questions arising from these aims can be answered by the obtained results. The aims, as mentioned in the general introduction, are discussed below in the context of driving performance and neurocognition of long-term treated patients. It is important to determine factors affecting driving performance in patient populations, as well as the implications for drug classification systems that emerge from these results.

\section{Clinical symptomatology}

The results of chapter 4 and 6 indicate that clinical symptomatology has an effect on driving performance of long-term treated patients. Based on the results in these chapters, it can be concluded that symptomatology (e.g. depressive symptoms, sleepiness symptoms) explains a significant proportion of the inter-individual variance in performance as observed in patientsamples. These findings are in line with previous research linking clinical symptomatology to decrements in neurocognitive functioning (McDermott and Ebmeier 2009; Ravera et al. 2012; Snyder 2013). It can be argued that the neurocognitive functions related to driving (e.g. attention, executive functioning) are impaired by the presence of clinical symptomatology. Thus, the possibility arises that reductions in clinical symptomatology may aid in the "recovery" of driving related processes. This may in turn reduce driving impairment that is related to clinical symptomatology.

Examining driving impairment in terms of severity of clinical symptomatology does not necessarily transfer to more diverse patient groups. In chapter 3 and 5, patients with few exclusion criteria performed a range of neurocognitive tests in addition to the most ecologically valid measure of driving performance (i.e. the standardized on-the-road driving test). From these patient samples, it becomes apparent that clinical symptomatology, on average, mainly resides in the "non-clinical spectrum", as indicated by the pre-defined cut-off scores used for the symptomatology questionnaires. Given the rather restricted range of self-reported clinical symptomatology in these patients' samples, it becomes difficult to explain driving related impairment solely due to clinical symptomatology. More likely, multiple factors play a role in the observed impairment of patient samples with few exclusion criteria.

\section{Pharmacological intervention}

It is well known that medicinal drugs can affect driving performance as seen in controlled studies with healthy individuals receiving antidepressants (Ramaekers 2003; Verster and 
Ramaekers 2009) or benzodiazepines (Vermeeren 2004; Vermeeren et al. 2009). From these randomized controlled trials, factors such as received dose, half-life and time after administration explain differences in driving impairment among individuals. The factors provided by studies with healthy controls on performance impairment resulting from pharmacological interventions do not necessarily translate to diverse patient populations (Grabe et al. 1998). In long-term treated patients, pharmacological interventions are individualized and meant to balance symptom reduction and possible side effects, with the goal of maximizing treatment effectiveness and minimizing experienced side effects. As such, patients can receive varying dosages of the same substance, all to suit their individual needs. Restricting a patient's mobility solely based on received medication dosage, without taking individual differences into account, will oversimplify an assessment of driver fitness.

In chapter 3 and 5, the patient samples report a variety of medication (i.e. the primary medication to select them to participate in the study) and co-medication, with the latter being a common observation in patients with pharmacological treatment (Mojtabai and Olfson 2010). In chapter 5, combinations of a category III antidepressant and category II antipsychotic are reported, with the latter either used as an add-on for treatment resistant depression or for the treatment of psychosis. In chapter 3, combinations of category III benzodiazepines with a category II antipsychotic, anti-epileptic, anti-parkinson or monoamine oxidase inhibitor were reported. Interestingly, a large proportion of these reported combinations were from patients who received treatment shorter than 3 years (i.e. LT3- subgroup). Over the past 20 years, attempts have been made to lower the prescription of benzodiazepines by means of changing preferential treatment guidelines towards SSRI's or psychotherapy (Sonnenberg et al. 2012) and by discontinuation of reimbursement of benzodiazepines (Kollen et al. 2012). Exceptions to these general rules were made for patients either non-responsive to multiple SSRI interventions, patients suffering from seizures or patients with multiple psychiatric conditions. It is therefore possible that patients who initiate treatment with benzodiazepines nowadays either have complex psychiatric symptomatology and/or remain unresponsive to alternative treatment options. The investigation of co-medication profiles, besides benzodiazepine administration, may aid in differentiating patients that are fit to drive from those who are not. Further research will be needed to establish a link between medication profiles and expected driving impairment. 


\section{Chapter 7}

\section{Treatment duration}

Results from chapter 3 and 5, combined with the review in chapter 2, provide evidence that the duration of pharmacological treatment plays a role in the observed driving related performance in long-term treated patients. Epidemiological studies confirm the idea that the risk of becoming involved in a traffic accident after treatment initiation reduces over time, but that minor impairment remains (Hansen et al. 2015; Hemmelgarn et al. 1997). From chapter 2, it is evident that forms of tolerance develop over time, when the performance of long-term treated patients is compared to the acute or short-term effects as seen in healthy controls. The development of tolerance is comprised of several components. It contains a combined effect of physiological drug tolerance and behavioural tolerance, with the latter being a behavioural adaptation in learning to minimize unwanted drug effects. Furthermore, reductions in clinical symptomatology may play a role in the overall mitigation of driving related impairment. Although it remains unclear what the contribution is of each individual mechanism (i.e. drug tolerance, reductions in clinical symptomatology), it can be argued that both mechanism are involved in the observation of tolerance development as expressed by treatment duration.

The assessment of performance in patient populations receiving long-term treatment may also include duration of treatment as an explanatory parameter. In chapter 3 and 5, patient subgroups receiving antidepressants and benzodiazepines for longer than 3 years showed an absence of real-world driving impairment, although neurocognitive dimensions related to driving remained impaired. In light of drug tolerance development, it could be possible that a critical point in time after treatment onset mitigates driving related impairment due to the maximal possible contribution of drug tolerance and reductions in clinical symptomatology, both contributing to the overall phenomena of tolerance.

The notion that impairment remains even in patient samples receiving treatment for more than 3 years follows from the underlying aspects of observed tolerance develop in each specific individual. After treatment initiation, the extent to which each aspect of tolerance develops remains dependent on many individual factors, such as genetics (e.g. CYP450 cytochrome expression, brain-receptor sensitivity), and general health factors (e.g. metabolic speed, kidney efficiency). Besides tolerance development, long-term pharmacological treatment may actually be a risk factor itself. For benzodiazepines, previous research shows persistent impairment in the cognitive domain in patients following benzodiazepine withdrawal (Crowe and Stranks 
2017). It is therefore likely that a proportion of patients remain negatively affected with regard to their driving performance, despite receiving long-term treatment.

\section{Implications for Drug Classification Systems}

Scientific evidence forms the fundaments for Drug Classification Systems. Given the high methodological standardization, a comparison can be made between different drug classes with regard to their relative effect on driving performance. The prediction of expected driving impairment of such a system in patient populations remains only partial, given that information relies mainly on the establishment of side-effect profiles in isolation coming from healthy volunteer models. The assumption that such a model is transferable to patients suffering from diverse clinical symptomatology, and treated with a variety of medication, is questionable. Including factors that capture psychological parameters (e.g. disorder) in combination with classification modifiers for treatment duration would aid in classifying the relative expected impact on long-term treated patients.

In conclusion, drug classification systems should be seen as a starting point in determining the relative effect of medication on driving performance. For long-term treated patients, such systems need to be extended with additional parameters that may affect driving performance. As such, a proper translation can be made to the accurate assessment of individual cases in a clinical setting.

\section{Future research perspectives}

Work from this dissertation highlights the components that contribute to patient performance in long-term treated groups. Nonetheless, inter-individual performance differences remain a hurdle to overcome in forming uniform conclusions about the information derived from patient (sub)groups and its subsequent implications. A possible alternative would be to view the performance of patients and controls on a continual scale, instead of relying on strict betweengroup comparisons. An attempt was made in chapter 4, which explained the impact of depressive symptomatology on driving performance as a continuum. This approach is the starting point for more advanced analyses, such as multi-linear regression, explain underlying factors that influence performance differences as primarily seen in patients. Furthermore, multilinear regression sheds light to what extend clinical symptomatology, psychopharmacological intervention and treatment duration play a role in explaining driving performance related impairment. Such a multidimensional regression model could possibly identify patients that are 


\section{Chapter 7}

"at risk" of showing driving related impairment, given a combination of unique contributing factors. A similar approach has been used in a previous project aiming to predict fitness to drive in Alzheimer patients (Piersma et al. 2016).

Another approach is to re-examine the neurocognitive parameters. Neurocognitive tasks, from a conceptual viewpoint, measure skill-dimensions that are related to driving performance (Jongen et al. 2016). The neurocognitive tasks included in chapter 3 and 5 share similar characteristics such as reaction time, attention or executive functioning. The possibility arises to extract latent variables from neurocognitive parameters with overlapping characteristics. An example would be the different aspects of reaction time as measured by the Reaction Test (e.g. RT-S1, RT-S2 and RT-S3) and to create one latent variable "reaction time". Latent variables may give insight in how impairment on 1 out of 3 reaction time tests, translates into impairment in the associated skill (i.e. reaction time). Currently, the feasibility of this approach is explored for the research outcomes and patient population as mentioned in chapter 3 of this dissertation (Vinckenbosch et al. in prep.).

For the future, new methodological and statistical approaches will explain the inter-individual variability seen in patient groups in the field of driving performance.

\section{References}

Crowe SF, Stranks EK (2017) The residual medium and long-term cognitive effects of benzodiazepine use: an updated meta-analysis. Archives of Clinical Neuropsychology 33: 901-911.

Grabe H-J, Wolf T, Grätz S, Laux G (1998) The influence of polypharmacological antidepressive treatment on central nervous information processing of depressed patients: implications for fitness to drive. Neuropsychobiology 37: 200-204.

Hansen RN, Boudreau DM, Ebel BE, Grossman DC, Sullivan SD (2015) Sedative hypnotic medication use and the risk of motor vehicle crash. American journal of public health 105: e64-e69.

Hemmelgarn B, Suissa S, Huang A, Jean-Francois B, Pinard G (1997) Benzodiazepine use and the risk of motor vehicle crash in the elderly. JAMA 278: 27-31.

Jongen S, Vuurman EFPM, Ramaekers JG, Vermeeren A (2016) The sensitivity of laboratory tests assessing driving related skills to dose-related impairment of alcohol: A literature review. Accident Analysis \& Prevention 89: 31-48.

Kollen BJ, van der Veen WJ, Groenhof F, Donker GA, van der Meer K (2012) Discontinuation of reimbursement of benzodiazepines in the Netherlands: does it make a difference? BMC family practice 13: 111.

McDermott LM, Ebmeier KP (2009) A meta-analysis of depression severity and cognitive function. Journal of affective disorders 119: 1-8. 
Mojtabai R, Olfson M (2010) National Trends in Psychotropic Medication Polypharmacy in Office-Based Psychiatry. Archives of General Psychiatry 67: 26-36.

Piersma D, Fuermaier AB, de Waard D, Davidse RJ, de Groot J, Doumen MJ, Bredewoud RA, Claesen R, Lemstra AW, Vermeeren A, Ponds R, Verhey F, Brouwer WH, Tucha O (2016) Prediction of fitness to drive in patients with Alzheimer's dementia. PLoS one 11: e0149566.

Ramaekers J (2003) Antidepressants and driver impairment: empirical evidence from a standard on-the-road test. The Journal of clinical psychiatry 64: 20-29.

Ravera S, Ramaekers JG, de Gier JJ (2012) Are selective serotonin reuptake inhibitors safe for drivers? What is the evidence? Clinical therapeutics 34: 1070-1083.

Sonnenberg CM, Bierman EJ, Deeg DJ, Comijs HC, van Tilburg W, Beekman AT (2012) Tenyear trends in benzodiazepine use in the Dutch population. Social psychiatry and psychiatric epidemiology 47: 293-301.

Snyder HR (2013) Major depressive disorder is associated with broad impairments on neuropsychological measures of executive function: a meta-analysis and review. Psychological bulletin 139: 81.

Vermeeren A (2004) Residual effects of hypnotics. CNS drugs 18: 297-328.

Vermeeren A, Leufkens T, Verster J (2009) Effects of anxiolytics on driving Drugs, driving and traffic safety. Springer, pp 289-305

Verster JC, Ramaekers JG (2009) Antidepressants and traffic safety Drugs, driving and traffic safety. Springer, pp 307-313

Vinckenbosch, F.R.J., Vermeeren, A., Vuurman, E.F.P.M., van der Sluiszen, N.N.J.J.M., Verster, J.C., van de Loo, A.J.A.E., van Dijken, J.H., Veldstra, JL., Brookhuis, K.A., de Waard, D., Ramaekers, J.G. (in preparation). An explorative approach to understanding individual differences in driving performance and neurocognition in long-term benzodiazepine users 

SUMMARY 
Summary

\section{Chapter 1}

\section{General introduction}

The aim of this dissertation was to assess the influence of long-term medication use on driving performance in patient populations. The presented studies outline the potential influence of medication use on actual on-the-road driving performance and neurocognition. Of interest is explaining individual driving performance in light of patients' clinical symptomatology, pharmacological intervention, and duration of treatment.

\section{Chapter 2}

Influence of Long-Term Benzodiazepine use on Neurocognitive Skills Related to Driving Performance in Patient Populations: A Review

The aim of this chapter was to summarize the literature of the past 30 years (1986 - 2016) about the influence of long-term benzodiazepine treatment on driving related performance. In total, 13 studies were selected for this review. Results showed that long-term benzodiazepine users are impairment in the domain of memory and attention, but this is less clear for psychomotor performance. Moreover, long-term users show less impairment after acute benzodiazepine administration in comparison to treatment naïve controls. In conclusion, the chapter suggests that long-term users develop tolerance for the impairing properties of benzodiazepine treatment, but also, that the development of tolerance is incomplete.

\section{Chapter 3}

Driving Performance and Neurocognitive Skills of Long-term Users of Benzodiazepine Anxiolytics and Hypnotics

This chapter present the data of the effects of long-term use of benzodiazepine anxiolytics and hypnotics on driving performance. Performance of patient groups were compared to a group of matched healthy controls. Measures included the one hour standardized highway driving test in actual traffic and several neurocognitive tasks related to driving. Exploratory analyses included the duration of benzodiazepine treatment. Results showed that on-the-road driving performance of long-term users of hypnotics was significantly worse in comparison to controls. Moreover, non-inferiority analyses displayed clinically relevant impairment for patients treated for less than 3 years with hypnotics, but not for patients treated for more than 3 years. Long-term anxiolytic users showed no significant difference compared to controls, although large 
individual differences were present and the included patient sample was relatively small. All patient groups displayed slower reaction times on a number of neurocognitive tasks, however, these differences were most prominent in hypnotic users treated for less than 3 years. It can be concluded that the impairing effects of benzodiazepine hypnotics on driving performance may mitigate over time following long-term usage, although neurocognitive impairments may remain. No overall conclusion could be drawn for the anxiolytic users group.

\section{Chapter 4}

Driving Performance of Depressed Patients who are Untreated or Receive Long-Term Antidepressant (SSRI/SNRI) Treatment

This chapter investigates the driving performance of depressed patient who received either no antidepressant treatment (with or without benzodiazepine medication) or treatment with selective serotonin/noradrenaline reuptake inhibitors for a prolonged period. The performance of patients was primarily compared to a group of healthy controls. Measures included the standardized on-the-road driving test which assesses automated vehicle control and questionnaires assessing clinical symptomatology. Results indicated that driving performance of all patients groups was significantly worse compared to healthy controls. However, the driving impairment observed in long-term treated patients was significantly less than in patients with no antidepressant treatment. Furthermore, severity of depression correlated significantly with driving performance across all groups. It can be concluded that clinical symptomatology plays a role in driving related impairment. As such, antidepressant treatment may mitigate driving impairment in depressed patients.

\section{Chapter 5}

On-the-road driving performance and neurocognition of patients with long-term antidepressant treatment

This chapter presents data of the effects of long-term antidepressant treatment on driving performance and neurocognition. The performance of long-term treated patients was compared to a normative control group consisting of healthy controls. The primary measure was the standard deviation of lateral position and secondary measures included neurocognitive tasks related to driving (e.g. attention, reaction time, and vigilance). Results indicated that long-term users of antidepressants showed comparable performance to a group of normative controls. Subsequent analyses based on duration of treatment revealed a significant and clinically 


\section{Summary}

relevant increase in SDLP for patients treated shorter than 3 years. Patients treated with antidepressants displayed, on average, comparable performance to controls on all neurocognitive tasks, although large individual performance differences were present. It can be concluded that long-term treated patients showed comparable performance to controls in driving performance and neurocognitive functioning. Impairment was primarily observed in patients treated for less than 3 years.

\section{Chapter 6}

On-the-road driving performance of patients with central disorders of hypersomnolence on stable treatment

The aim of this chapter was to assess driving performance of patients with hypersomnolence of central origin. Patients were diagnosed with either narcolepsy (with or without cataplexy) or idiopathic hypersomnia and received stable treatment. The performance of patients groups was primarily compared to a normative control group. Measures included the standardized on-theroad driving test and subjective ratings of sleepiness. Results showed that driving performance of patients did not significantly differ from controls. However, analyses based on diagnoses showed driving related impairment for patients diagnosed with narcolepsy and cataplexy. Sleepiness of patients was positively correlated to driving performance and significantly higher in patients whom were not able to complete the 1-hour driving test. It can be concluded that narcolepsy patients with cataplexy may still be impaired in their driving performance despite stable treatment. Therefore, in clinical practice, the determination of fitness to drive should be based on an individual assessment.

\section{Chapter 7}

\section{General discussion}

The aim of this chapter is to summarize and discuss the results of the studies presented in the previous chapters. Results showed that the observed driving related impairment in long-term treated patients is mitigated by factors such as reductions in clinical symptomatology, tolerance development for their received pharmacological intervention and duration of treatment. These factors seem to play a role in explaining inter-individual variance in patient's performance. Combining the results of aforementioned chapters, provides a rationale for conducting research into predicting fitness to drive (possibly a-priori) of patients in a clinical setting. 




\section{SAMENVATTING}


Samenvatting

\section{Hoofdstuk 1}

Algemene introductie:

Het doel van dit proefschrift is om de invloed van langdurig medicijngebruik op de rijprestaties bij verscheidende patiënt populaties in kaart te brengen. De gepresenteerde studies bieden een beschrijving van de potentiële invloed van medicijngebruik op rijvaardigheid en neurocognitief functioneren. Van belang hierbij is het verklaren van de rijprestaties bij verscheidene patiëntgroepen in het kader van klinische symptomatologie, de farmacologische interventie en de behandelingsduur.

\section{Hoofdstuk 2}

De invloed van lange-termijn benzodiazepine gebruik op neurocognitieve taken gerelateerd aan rijvaardigheid in patient populaties

Het doel van dit hoofdstuk was om een overzicht te verschaffen van de wetenschappelijke literatuur van de afgelopen 30 jaar (1986 - 2016) over de invloed van lange-termijn benzodiazepine gebruik op neurocognitieve taken gerelateerd aan rijvaardigheid. In totaal werden 13 studies geselecteerd voor dit overzicht. De resultaten lieten zien dat langdurige gebruikers van benzodiazepinen een verslechtering van het neurocognitieve domein geheugen en aandacht laten zien, alhoewel dit minder duidelijk is voor psychomotorisch functioneren. Bijkomend laten langdurige gebruikers van benzodiazepinen minder verslechtering op neurocognitieve taken zien na acute benzodiazepine administratie, wanneer zij vergeleken worden met medicatie naïeve controle deelnemers. Er kan worden geconcludeerd dat lange termijn benzodiazepinen gebruikers tolerantie ontwikkelen voor de nadelige eigenschappen van benzodiazepine behandeling, maar ook, dat deze tolerantie ontwikkeling niet volledig is.

\section{Hoofdstuk 3}

Rijvaardigheid en neurocognitieve vaardigheden van lange-termijn gebruikers van benzodiazepinen

Dit hoofdstuk presenteert data over de effecten van langdurige benzodiazepine gebruik op de rijvaardigheid. Vaardigheden van beide patiëntgroepen (anxiolytica \& hypnotica) werden vergeleken met de prestaties van een gezonde controlegroep gematcht op leeftijd, geslacht en rijervaring. Er werden verschillende soorten taken afgenomen, waaronder een gestandaardiseerde rijtest op de snelweg in het verkeer en neurocognitieve taken gerelateerd 
aan rijvaardigheid. Vervolganalyses waren gericht op het in kaart brengen van de invloed van duur van benzodiazepine gebruik op de gemeten prestaties. De gevonden resultaten lieten zien dat de prestaties van langdurige hypnotica gebruikers tijdens de gestandaardiseerde rijtest op de weg significant slechter waren ten opzichte van een controlegroep. De verslechtering in prestaties staat gelijk aan het rijden onder invloed van $>0.5$ promille alcohol, hetgeen alleen waargenomen werd in patiënten die korter werden behandeld dan 3 jaar. Lange-termijn gebruikers van benzodiazepine anxiolytica lieten geen significante verschillen in rijprestaties zien ten opzichte van de controlegroep, alhoewel er kan worden opgemerkt dat de individuele prestaties in deze patiëntengroep zeer ver uit een lagen en de groep een relatief klein aantal deelnemers bevatte. Alle patiëntengroepen lieten een vertraging van het reactievermogen zien op verscheidenen neurocognitieve taken. Deze vertraging was het meest opvallend in gebruikers van hypnotica wiens behandeling korter duurde dan 3 jaar. Er kan worden geconcludeerd dat de belemmerende invloed van benzodiazepine hypnotica op rijvaardigheid geleidelijk afneemt over tijd, alhoewel vormen van neurocognitieve belemmering aanwezig blijven.

\section{Hoofdstuk 4}

Rijvaardigheid van depressieve patiënten die onbehandeld zijn of langdurig behandeld worden met een SSRI of SNRI

Dit hoofdstuk beschrijft een onderzoek naar de rijvaardigheid van een groep depressieve patiënten die geen antidepressivum behandeling kregen (met of zonder benzodiazepine comedicatie), of die langdurig behandeld werden met een selectieve serotonine/noradrenaline heropname remmer (SSRI/SNRI). De prestaties van de verschillende patiëntengroepen werden primair vergeleken met een groep gezonde controle deelnemers. De verscheidene metingen die deze patiënten ondergingen bestonden uit een gestandaardiseerde rijtest op de snelweg in het verkeer en vragenlijsten gericht op het meten van klinische symptomatologie. De resultaten lieten zien dat rijvaardigheid in de verschillende patiëntgroepen significant slechter was in vergelijking met de gezonde controlegroep, maar, deze verslechtering was milder in depressieve patiënten die langdurig behandeld werden met een antidepressivum in vergelijking met de groep die geen antidepressivum behandeling onderging. Verder bleek de ernst van de depressie (uitgedrukt in klinische symptomen) significant samen te hangen met de geobserveerde rijvaardigheid verkregen uit de rit op de snelweg in het verkeer. Er kan worden geconcludeerd dat klinische symptomatologie een rol speelt bij de mate van 
Samenvatting

rijvaardigheidsbelemmering bij patiënten. Mogelijkerwijs kan deze belemmering deels worden opgeheven in depressieve patiënten door een behandeling met een antidepressivum.

\section{Hoofdstuk 5}

Rijvaardigheid en neurocognitieve vaardigheden van patiënten die langdurig behandeld worden met een antidepressivum

Dit hoofdstuk beschrijft een onderzoek naar de invloed van een langdurige antidepressiva behandeling op rijvaardigheid en neurocognitie. De prestaties van langdurig behandelde patiënten werd vergeleken met een gezonde normatieve controlegroep gematcht op leeftijd, geslacht en rijervaring. De primaire uitkomstmaat van het onderzoek betrof de gestandaardiseerde rijtest op de snelweg in het verkeer en verscheidene secundaire maten, waaronder neurocognitieve taken die gerelateerd zijn aan rijvaardigheid (bijv. aandacht, reactievermogen en vigilantie). Resultaten geven weer dat lange-termijn gebruikers van een antidepressivum vergelijkbare prestaties laten zien tot de gezonde controlegroep. Vervolganalyses gebaseerd op duur van het antidepressivum gebruik lieten een significante verslechtering van de rijvaardigheid zien in patiënten die korter dan 3 jaar behandeld werden. Verder lieten patiënten, gemiddeld genomen, vergelijkbare prestaties met gezonde controle deelnemers zien op de neurocognitieve taken. Een kanttekening hierbij is dat de individuele prestaties van patiënten zeer ver uiteen lagen. Er kan worden geconcludeerd dat patiënten die langdurig behandeld worden vergelijkbare prestaties laten zien met een gezonde controlegroep in de domeinen van rijvaardigheid en neurocognitief functioneren. De waargenomen verslechtering van prestaties in de groep was primair terug te zien in patiënten die korter dan 3 jaar behandeld werden.

\section{Hoofdstuk 6}

Rijvaardigheid van patiënten met een centrale aandoening van hypersomnie met een stabiele behandeling

Het doel van dit hoofdstuk was het in kaart brengen van de rijvaardigheid van patiënten met een centrale aandoening van hypersomnie. Deelnemende patiënten kregen een stabiele behandeling en waren gediagnostiseerd met narcolepsie (met en zonder kataplexie) of idiopathische hypersomnie. De prestaties van deze patiëntgroepen werden primair vergeleken met een normatieve controlegroep van gezonde deelnemers. De verscheidene metingen waren een gestandaardiseerde rijtest op de snelweg en subjectieve vragenlijsten betreffende 
slaperigheid. Resultaten lieten zien dat de rijvaardigheid van patiënten, als één grote groep, niet significant verschilde van de gezonde controlegroep. Vervolganalyses laten echter zien dat patiënten gediagnostiseerd met narcolepsie en kataplexie een verslechterde rijvaardigheid hebben. Subjectieve slaperigheid liet een positief verband zien met de rijvaardigheid zoals gemeten gedurende de rijtest op de weg. Tevens was de mate van slaperigheid aanzienlijk hoger in patiënten die niet in staat waren om de rijtest op de weg volledig af te ronden. Er kan worden geconcludeerd dat patiënten met de diagnose narcolepsie en kataplexie nog steeds een vorm van rijvaardigheidsbelemmering laten zien ondanks een stabiele behandeling. Het is daarom van belang om in de klinische praktijk de bepaling van de rijgeschiktheid bij patiënten met een centrale aandoening van hypersomnie te baseren op een individuele beoordeling.

\section{Hoofdstuk 7}

\section{Algemene discussie}

Resultaten laten zien dat de waargenomen belemmering in rijvaardigheid in patiënten die langdurig behandeld worden mogelijkerwijs afneemt door onderliggende factoren zoals een reductie in klinische symptomatologie, tolerantie ontwikkeling voor de farmacologische interventie en duur van medicatiegebruik. Deze factoren spelen een rol in het verklaren van interindividuele verschillen in een patiëntenpopulatie. Het combineren van de resultaten van de voorheen beschreven hoofdstukken, biedt een rationale voor het uitvoeren van onderzoek naar het mogelijkerwijs voorspellen van rijvaardigheid bij patiënten in een klinische setting. 

VALORISATION ADDENDUM 
The valorisation addendum addresses the translation of research output to societal relevance and impact for the general public. The five cornerstones of valorisation are discussed: 1) Relevance for society, 2) Target group, 3) Activities and Products following from the mentioned research output, 4) Innovation within the area of research expertise, and last, 5) Implementation of knowledge. For each of the five cornerstones, the central question (Q) and answer (A) is displayed.

\section{Relevance}

\section{Q: What is the social relevance of these research results?}

A: The goal is to inform the general public about potential drug induced driving impairment, given that the latter is of increasing public and governmental concern (Compton and Berning 2015). Within modern day society, many individuals will at some point in their lifetime experience an affective- (e.g. anxiety, depression) or sleep/wake disorder. Given that one of the treatment options is a pharmacological intervention, it is of importance to correctly inform individuals about the potential driving hazards associated with medication usage (Food Drug Administration 2015; Kay and Logan 2011). Graded level warning systems for medicinal drug usage have been developed to inform individuals about the initial side-effects of medication and how it affects operating a vehicle. Although pharmacological interventions are not meant to be used for a prolonged period of time, a proportion of individuals will develop persistent symptomatology that requires long-term pharmacological treatment. For this group of individuals, it is important to expand the current knowledge of acute- and short-term medicinal drug effects. With long-term usage, ideally, the components of underlying symptomatology and pharmacological intervention should both be examined.

From chapter 2, it can be concluded that treated patients develop forms of tolerance for benzodiazepine induced impairment, but, that a general re-classification for the risk of benzodiazepine-induced driving impairment could not be given. Chapter 4 provides evidence that depressive symptomatology plays a role in driving related impairment and that pharmacological interventions can possibly reduce its severity. Chapter 3 and 5 show that duration of treatment in individuals receiving long-term antidepressant and benzodiazepine treatment is associated with the degree of driving related impairment. In chapter 6, results show individuals diagnosed with central forms of hypersomnolence receiving long-term pharmacological treatment show an absence of driving related impairment, although individual differences exist. Societal relevance from the above-mentioned results comes from expanding 
the currently knowledge beyond acute drug effects and by including long-term treatment effects into drug classification systems. In such systems, the impact of disorder and prolonged pharmacological treatment can lead to new recommendations with regard to operating a vehicle safely.

\section{Target group}

\section{Q: To whom are the research results interesting and why?}

A: The results of the various studies mentioned in this dissertation are interesting for patients receiving medicinal drug treatment, health professionals, and regulatory authorities. In a general sense, the investigation of prolonged pharmacological treatment and its effects on measures of driving performance gives patients information about traffic accident related risk. It also gives patients insight to what extend their underlying symptomatology may play a role in driving related impairment. For health professionals, it is important to be informed about the newest research developments and to share this information first-hand with treated patients. Finally, regulatory authorities benefit by expanding existing guidelines for operating a vehicle when taking psychoactive substances by incorporating information about treatment duration and symptomatology severity.

\section{Activities}

Q: Into which concrete products, services, processes or (commercial) activities can these results be translated and shaped?

A: The mentioned studies in this dissertation should contribute to the general perspective of lowering drug-related traffic accidents. A suitable option for achieving this goal is to prevent traffic accidents from happening by informing or screening the corresponding target populations. One of the products that can be derived from the research results is an information leaflet that can be added to new and ongoing drug subscriptions to ensure successful communication with patients. Via this method, practitioners remain updated about the current regulations about driving under the influence of psychoactive substances. Possible services arise from providing the scientific information as a public accessible self-service application. One of these applications are websites that provide the general public with information about driving under the influence with psychoactive medication and its possible consequences. Such a website is already openly available in the Netherlands (rijveiligmetmedicijnen.nl) and provides patients and practitioners with information about responsible medication use when 
operating a vehicle. Results mentioned in this dissertation could be communicated via such a channel and incorporated as an add-on service. Finally, activities include the organisation of trainings for healthcare professionals or patient education programs. Via different communication channels, such as lectures, target groups stay informed about the developments in the field of long-term medication use and the consequences for participating in traffic. In summary, the above mentioned activities will lead to successful knowledge communication to the designated target groups.

\section{Innovation}

\section{Q: To what degree are the obtained results innovative?}

A: The work described in the current dissertation differs from previous research in several ways. While most studies within the field of drugs and driving focus on epidemiological data or more acute drug effects, the research presented in this dissertation expands this knowledge by investigating neurocognitive and real-world driving performance in patients who take medication for a prolonged time. The research findings of the various chapters presented in this dissertation contribute to expanding the knowledge in the field of drugs and driving in the following way:

First, the review presented in chapter 2 provides an up-to-date overview of the long-term benzodiazepine literature and solely describes objective measures of driving related performance obtained in a controlled environment. Previous research has mainly focussed on assessing acute effects of benzodiazepine impairment or benzodiazepine related epidemiological crash risk. The review is one of the first to conclude that, within a controlled environment, forms of tolerance develop for benzodiazepine impairment in patient populations.

Second, the studies mentioned in chapter 4 and 6 provide new insights in how prolonged pharmacological treatment can stabilize or improve driving related performance. The research in chapter 4 shows that depression severity is related to driving impairment and that a pharmacological intervention with antidepressants can reduce the severity of driving impairment. This gives the notion that besides estimating the risk of the potential influence of pharmacological treatment on driving performance, the type of clinical disorder seems to share similar impact. Moreover, it contributes to the understanding that pharmacological interventions in depressed patients can be beneficial in reducing driving related impairment. In chapter 6 , prolonged pharmacological treatment in patients diagnosed with a sleep/wake 
disorder (i.e. narcolepsy) shows that performance parameters were not impaired when compared to a group of normative controls. This study differentiates from earlier work given that the included tests have proven sensitive for the impairment effects of sleep loss and drugs. In addition, the tests show moderate to high validity with actual driving skills. This is also one of the first studies to include patients with minimal practical restrictions (e.g. patients may take a nap, smoke or have co-medication). Combined with controlled assessment through observational research, the study outcomes have high external validity and reflect the performance of patients during their everyday lives.

Third, the research mentioned in chapter 3 and 5 implemented a large test battery of various neurocognitive measures in combination with the on-the-road highway driving for assessing long-term drug-effects. The inclusion of a normative control group, different facets of driving related skills and a measure of actual driving makes these experiments stand out from previously conducted research. In addition, both studies are one of the first to assess the influence of treatment duration and provide evidence that the duration of pharmacological treatment plays a role in the amount of measurable driving related impairment in patient populations. This may lead to the establishment of an experimentally supported criteria cut-off for treatment duration and being able to safely operate a vehicle.

\section{Implementation}

\section{Q: How will the above mentioned information be communicated with a broad audience?}

A: To ensure successful knowledge dissemination, the current research findings have been communicated in various ways with a broad audience. Researchers within the research field (i.e. drugs \& driving) have been kept up-to-date with our ongoing research projects with several oral presentations at international congresses organised by the International Council of Alcohol Drugs and Traffic Safety (ICADTS). The research projects in chapter 3, 5 (and partially in chapter 6) have been summarized in a report for the Dutch Ministry of Infrastructure and the Environment and was made accessible for the general public. Furthermore, the work presented in chapter 2 and 4 have been published in the international journal "Pharmacopsychiatry" that target practitioners as a key audience. To make the general public aware of the drugs and driving research conducted at the department of Psychopharmacology, we have collaborated with national television, a regional newspaper, the national magazine for driving instructors and we released a press release about the research described in chapter 3 and 5 in collaboration with the University of Maastricht, Utrecht and Groningen. In addition, the results of chapter 2, 3 and 
6 have been incorporated in a report of the Dutch Health Council (Gezondheidsraad 2019), which forms an independent scientific advisory body for the Dutch government and parliament. In the future, we continue to promote our research findings via the above mentioned channels to spread awareness and gain recognition within the international research community and general public.

\section{References}

Compton RP, Berning A (2015) Drug and alcohol crash risk. Journal of Drug Addiction, Education, and Eradication 11: 29.

Food Drug Administration (2015) FDA guidance for industry: evaluating drug effects on the ability to operate a motor vehicle guidance for industry (Draft Guidance)

Gezondheidsraad (2019) Herziening eisen rijgeschiktheid bij gebruik geneesmiddelen, Den Haag

Kay GG, Logan BK (2011) Drugged driving expert panel report: a consensus protocol for assessing the potential of drugs to impair driving. National Highway Traffic Safety Administration, Washington, DC 




\section{ACKNOWLEDGEMENTS}


In this section, I would like to show my gratitude to all those involved. After all, their efforts contributed to the completion of this dissertation.

First of all, I would like to thank my promoter prof. dr. J.G. Ramaekers and co-promoter dr. A. Vermeeren. Jan and Annemiek, thank you both for the support during the PhD program. You were always available for discussion and questions. I learned a lot from your feedback and assistance as a researcher. Much gratitude for my assessment committee being: prof. dr. A. Blokland., prof. dr. W.J. Riedel., prof. dr. J.J. de Gier., dr. B.E. Smink, and dr. E.L. Theunissen, for reading and assessing the scientific content of this dissertation.

The successful completion of all mentioned research projects is largely due to a wellfunctioning research team. I would like to thank the interns (Jorn, Caroline, Shamyra, Myrthe and Frederick) for the pleasant cooperation, the indispensable value during the conduction of the research projects and for taking care of the participants. I would also like to thank: Henk, Hans, Anita, Irma and Cees for their contribution to all mentioned research. Henk and Hans, thank you for your supervision during the on-the-road driving test. Anita and Irma, thank you for providing the logistic planning of the research projects. Cees, thank you for your medical expertise and supervision. Furthermore, I would like to thank the colleagues of the collaborative centres in Groningen, Utrecht, Heemstede and Kempenhaeghe for the successful completion of the projects described in this dissertation.

Completing a $\mathrm{PhD}$ is a lot more enjoyable with nice colleagues. I had a pleasant time in room 2.737 thanks to my ex-roommates Stefan, Myreen, Joep, Maren, Nadia and Stephanie. I would also like to thank my colleagues of the department of Neuropsychology and Psychopharmacology for all the activities. Whether it's birthday-vlaai, having drinks, escape rooms, whisky night, a weekend to the Ardennes, karaoke, movie night or drinking a bottle of liquor in a hotel room, it will be times that I'll remember. I would like to thank the colleagues from the field of Drugs \& Driving for the pleasant time during the conferences in Venice, Gramado, Bled and Ghent. Furthermore, I would like to thank my colleagues from the Education Office for the warm welcome as an Exam coordinator and for guiding me throughout my new workplace.

Paranymphs Stefan and Frederick, I would like to thank you for helping me out during the completion of this dissertation and during the preparations of the $\mathrm{PhD}$ defence. The following moments that I experienced with you will stay with me, these include, but are not limited to: "partying on Wibiza", "running ashore an (deserted) island", "romantic dining in Venice", 
Acknowledgements

"singing songs about Mothersday", "laying stretched on a couch" and "being locked in a room several times".

Finally, I would like to thank family and friends for their support during the process of obtaining a $\mathrm{PhD}$ and for the necessary distraction. In particular, I thank Mayra for her love and support. 

CURRICULUM VITAE 


\section{Curriculum Vitae}

ENGLISH: Nick obtained his secondary school diploma at the Stedelijk Lyceum in Roermond. Subsequently, he started to study Psychology at Maastricht University and obtained a Bachelor degree in 2011. Afterwards, he continued his study with a Specialisation in Cognitive Neuroscience in which he conducted fMRI (functional Magnetic Resonance Imaging) research in Germany at Research Centre Jülich, INM-4 (Institute of Neuroimaging and Medicine, department 4 of Medical Imaging Physics). He obtained a Research-Master degree in Cognitive Neuroscience in 2013. On the first of April 2014, he started his doctoral research investigating the influence of long-term medication usage on driving performance in patient populations, under the supervision of prof. dr. Johannes G. Ramaekers and dr. Annemiek Vermeeren, at the Department of Neuropsychology and Psychopharmacology at Maastricht University. The doctoral research resulted in the current dissertation. During his doctoral research he obtained the BROC (Quality Assurance and Quality Control in Clinical Research), the UTQ (University Teaching Qualification), completed courses as part of a second master in clinical psychology, attended international conferences as a speaker, received scientific awards, appeared in the media, and published national \& international articles. In the finalising phase of his doctoral research, he started his job as an Exam coordinator, combined with a Teaching position, at the Education Office of the Faculty of Psychology and Neuroscience.

NEDERLANDS: Nick behaalde zijn VWO diploma aan het Stedelijk Lyceum te Roermond. Aansluitend begon hij aan zijn studie Psychologie aan de Universiteit Maastricht en behaalde zijn Bachelor diploma in 2011. Hierna begon hij aan zijn Master studie waarin hij de afstudeerrichting cognitieve neurowetenschappen heeft gevolgd en verrichtte hij functionele Kernspintomografie onderzoek in Duitsland aan het Forschungszentrum Jülich, INM-4 (Instituut voor Neurowetenschappen en Medicijnen, departement 4 voor Medische beeldvorming en Fysica). In 2013 behaalde hij zijn onderzoeks-masterdiploma in Cognitieve Neurowetenschappen. Op 1 april 2014 is hij gestart met het promotieonderzoek naar de invloed van langdurig medicatie gebruik op de rijvaardigheid, onder begeleiding van prof. dr. Johannes G. Ramaekers en dr. Annemiek Vermeeren, bij de capaciteitsgroep Neuropsychologie en Psychofarmacologie aan de Universiteit Maastricht. Het promotieonderzoek heeft geresulteerd in het huidige proefschrift. Tijdens zijn promotietraject behaalde hij zowel het BROK (Basis cursus Regelgeving en Organisatie voor Klinisch onderzoekers) als het BKO (Basis Kwalificatie Onderwijs) certificaat, volgde hij cursussen als onderdeel van een tweede master in de klinische psychologie, bezocht hij internationale conferenties als spreker, ontving hij wetenschappelijke prijzen, verscheen hij in de media en publiceerde hij zowel nationale als 
internationale artikelen. In de afrondende fase van zijn promotietraject begon hij aan zijn baan als Examencoördinator, in combinatie met een Docentschap, bij Bureau Onderwijs aan de faculteit der Psychologie en Neurowetenschappen.

PORTUGUÊS DO BRASIL: Nick obteve seu diploma de segundo grau na escola Stedelijk Lyceum em Roermond. Estudou Psicologia na Maastricht University, obtendo seu diploma de Bacharel em 2011. Nick seguiu seus estudos, realizando uma Especialização em Neurociência Cognitiva, conduzindo pesquisa em neuroimagem, com uso de fMRI (ressonância magnética funcional), na Alemanha, no Centro de Pesquisa de Jülich, no Instituto de Neuroimagem e Medicina, Departamento 4 de Física de Imagem Médica (INM-4). Através desta especialização, em 2013, ele obteve o título de Mestre em Pesquisa em Neurociência Cognitiva. No dia $1^{\circ}$ de abril de 2014, Nick iniciou sua pesquisa de Doutorado, investigando a influência do uso prolongado de medicação na habilidade de dirigir, numa população de pacientes, sob supervisão do Prof. Dr. Johannes G. Ramaekerse e da Dra. Annemiek Vermeeren, no Departmento de Neuropsicologia e Psicofarmacologia da Maastricht University. Esta pesquisa de doutorado resultou na presente tese. Durante o seu doutoramento, ele obteve o certificado BROC (Garantia de Qualidade e Controle de Qualidade em Pesquisa Clínica), o certificado UTQ (Qualificação de Ensino Universitário) e completou cursos referentes a um Mestrado em Psicologia Clínica. Nick também participou como palestrante de conferências internacionais, recebeu prêmios científicos, divulgou sua pesquisa em jornais, em emissoras de televisão e de rádio, além disso, publicou artigos em jornais científicos nacionais e internacionais. $\mathrm{Na}$ fase final da sua pesquisa de Doutorado, Nick iniciou seu trabalho como Coordenador de Exames, além de seguir lecionando no Escritório de Educação da Faculdade de Psicologia e Neurociência.

DEUTSCH: Nick erhielt sein Abitur am Städtischen Gymnasium in Roermond. Daraufhin begann er sein Studium der Psychologie an der Universität Maastricht und erreichte zunächst den Bachelorabschluss im Jahre 2011. Er setzte sein Studium mit einem Masterstudiengang in kognitiver Neurowissenschaft, in welcher er Forschung mit funktioneller Magnetresonanztomografie (fMRT) am Institut für Neurowissenschaften und Medizin (INM4) am Forschungszentrum Jülich betrieb, fort. Dieses schloss er im Jahre 2013 erfolgreich ab. Am 1. April 2014 begann er mit der Arbeit an seiner Doktorat unter Herr Prof. Dr. J.G. Ramaekers und Frau Dr. A. Vermeeren an der Fakultät für Neuropsychologie und Psychopharmakologie an der Universität Maastricht, wofür er den Einfluss von Langzeitmedikation auf die Fahrtüchtigkeit untersuchte. Diese Forschungsarbeit mündete in dieser Dissertation. Während 


\section{Curriculum Vitae}

seiner Doktorandenzeit erhielt er die Zusatzqualifikationen BROK (Grundkurs für Verordnungen und Organisation für klinische Forscher); den UTQ (Universität Lehramt); er schloss mehrere Kurse als Teil seines zweiten Masters in klinischer Psychologie erfolgreich ab; er gab Vorträge auf internationalen Konferenzen, erhielt mehrere wissenschaftliche Auszeichnungen, erschien in den Medien und veröffentlichte Forschungsartikel auf nationaler und internationaler Ebene. In der Schlussphase seines Doktorats trat er eine Stelle als Prüfungskoordinator, zusammen mit einer Lehrposition, am Dezernat für studentische und akademische Angelegenheiten der Fakultät für Psychologie und Neurowissenschaften, an. 


OUTPUT 
Output

\section{PUBLISHED ARTICLES}

van der Sluiszen, N.N.J.J.M., Vermeeren, A., Verster, J.C., van de Loo, A.J.A.E., van Dijken, J.H., Veldstra, JL., Brookhuis, K.A., de Waard, D., Ramaekers, J.G. (2019). Driving performance and neurocognitive skills of long-term users of benzodiazepine anxiolytics and hypnotics. Human Psychopharmacology: Clinical and Experimental, 34(6), e2715, DOI: 10.1002/hup.2715.

Vinckenbosch F.R.J, Wingen, M., van der Sluiszen, N.N.J.J.M, Vermeeren, A., Jongen, S., Ramaekers, J.G. (2019). Het effect van een langdurige behandeling met tweede generatie antidepressiva op de rijvaardigheid van depressieve patiënten. Neuropraxis, volume 23:1, pp 26, DOI: 10.1007/s12474-018-00212-0.

Jongen, S., van der Sluiszen, N.N.J.J.M., Brown, D., Vuurman, E.F.P.M. (2018). Single- and dual task performance during on-the-road driving at a low and moderate dose of alcohol: a comparison between young novice drivers and more experienced drivers. Human Psychopharmacology: Clinical and Experimental, 33(3), e2661, DOI: 10.1002/hup.2661.

van der Sluiszen, N.N.J.J.M., Vermeeren, A., Verster, J.C., van de Loo, A.J.A.E., Brookhuis, K.A., Veldstra, J., van Dijken, J.H., Ramaekers, J.G. (2017). Long-term effects of benzodiazepine usage on actual driving and neurocognitive performance. Sleep-Wake Research in the Netherlands, volume 28, ISBN: 978-94-028-0824-7.

van der Sluiszen, N.N.J.J.M., Vermeeren, A., Jongen, S., Vinckenbosch, F.R.J., Ramaekers, J.G. (2017). Influence of long-term benzodiazepine use on neurocognitive skills related to driving performance in patient populations: a review. Pharmacopsychiatry, 50(5), 189-196, DOI: 10.1055/s-0043-112755.

van der Sluiszen, N.N.J.J.M., Wingen, M., Vermeeren, A., Vinckenbosch, F.R.J., Jongen, S., Ramaekers, J.G. (2017). Driving performance of depressed patients who are untreated or receive long-term antidepressant (SSRI/SNRI) treatment. Pharmacopsychiatry, 50(5), 182-188, DOI: 10.1055/s-0043-111600.

Jongen, S., Vermeeren, A., van der Sluiszen, N.N.J.J.M., Schumacher, M., Kuypers, K.P.C., Vuurman, E.F.P.M., Ramaekers, J.G. (2017). A pooled analysis of on-the-road studies measuring standard deviation of lateral position (i.e. "weaving") while driving at a blood alcohol concentration of 0.5g/L. Psychopharmacology, 234: 837-844, DOI: 10.1007/s00213-016-4519-z.

van der Sluiszen, N.N.J.J.M., Vermeeren, A., Jongen, S., Theunissen, E.L., van Oers, A.C.M., Maret, A., Desforges, C., Delarue, A., Ramaekers, J.G. (2016). On-the-road driving performance after use of the antihistamines mequitazine and 1-mequitazine, alone and with alcohol. Psychopharmacology, 233: 3461-3469, DOI: 10.1007/s00213-016-4386-7.

van der Sluiszen, N.N.J.J.M., Jongen, S., Vermeeren, A., Vuurman, E.F., Kuypers, K.P.C., Theunissen, E.L., Ramaekers, J.G. (2015). Effecten van antidepressiva, anxiolytica en hypnotica op de rijvaardigheid. Tijdschrift voor Neuropsychologie, 10(3), 221-233. 


\section{GOVERNMENT REPORTS}

Urbanus, B., Overeem, S., Vermeeren, A., van der Sluiszen, N.N.J.J.M., Lammers, G.J. (2017). Gebruik van de SART voor rijgeschiktheidskeuringen van personen met narcolepsie en idiopathische hypersomnie. Ministerie van Infrastructuur en Milieu.

Verster, J.C., van de Loo, A.J.A.E, Vermeeren, A., van der Sluiszen, N.N.J.J.M., van Dijken, J.H., Veldstra, J.L., Brookhuis, K.A., de Waard, D., Ramaekers, J.G. (2016). Beïnvloeding van de rijvaardigheid bij langdurig gebruik van ICADTS-categorie III geneesmiddelen. Ministerie van Infrastructuur en Milieu.

\section{PROSPECTIVE ARTICLES}

van Dijken, J.H., Veldstra, J.L., Verster, J.C., van de Loo, A.J.A.E., van der Sluiszen, N.N.J.J.M., Ramaekers, J.G., Vermeeren, A., Brookhuis, K.A., de Waard, D. (in revision). The influence of alcohol $(0.5 \%$ ) on the control and manoeuvring level of driving behaviour: a simulator study. Transportation Research Part F: Psychology and Behaviour.

van der Sluiszen, N.N.J.J.M., Vermeeren, A., van Dijken, J.H., van de Loo, A.J.A.E., Veldstra, JL., de Waard, D., Verster, J.C., Brookhuis, K.A., Ramaekers, J.G. (in revision). Driving performance and neurocognitive skills of long-term users of sedating antidepressants. Human Psychopharmacology: Clinical and Experimental.

van der Sluiszen, N.N.J.J.M., Urbanus, B., Lammers, G.J., Overeem, S., Ramaekers. J.G., Vermeeren, A. (in revision). On-the-road driving performance of patients with central disorders of hypersomnolence. Traffic Injury Prevention.

Bruijel, J., Vermeeren, A., van der Sluiszen, N.N.J.J.M., Jongen, S., Stapert, S., van Heugten, C. (submitted). Measuring fatigue following acquired brain injury: a validation study of the Psychomotor Vigilance Test. Brain Injury.

Vinckenbosch, F.R.J., Vermeeren, A., Vuurman, E.F.P.M., van der Sluiszen, N.N.J.J.M., Verster, J.C., van de Loo, A.J.A.E., van Dijken, J.H., Veldstra, J.L., Brookhuis, K.A., de Waard, D., Ramaekers, J.G. (submitted). An explorative approach to understanding individual differences in driving performance and neurocognition in long-term benzodiazepine users. Human Psychopharmacology: Clinical and Experimental

Urbanus, B., van der Sluiszen, N.N.J.J.M., Vermeeren. A., Overeem, S., Lammers, G.J. (in preparation). Validity of the sustained attention to response task in narcolepsy and idiopathic hypersomnia patients evaluated for fitness to drive.

Urbanus, B., van der Sluiszen, N.N.J.J.M., Vermeeren, A., Overeem, S., Lammers, G.J. (in preparation). Comparing maintenance of wakefulness test and sustained attention to response task with on-the-road driving performance in narcolepsy and idiopathic hypersomnia. 
Output

\section{CONFERENCE CONTRIBUTIONS}

Vinckenbosch, F.R.J., Vermeeren, A., Vuurman, E.F.P.M., van der Sluiszen, N.N.J.J.M., Verster, J.C., van de Loo, A.J.A.E., van Dijken, J.H., Veldstra, J.L., Brookhuis, K.A., de Waard, D. and Ramaekers, J.G. (2019) An explorative approach to observing the impairing effects of chronic benzodiazepine use on driving in a clinical population. International Council on Alcohol, Drugs and Traffic Safety (ICADTS), Canada, Edmonton. Oral presentation.

van der Sluiszen, N.N.J.J.M., Vermeeren, A., Verster, J.C., van de Loo, A.J.A.E., van Dijken, J.H., Veldstra, JL., Brookhuis, K.A., de Waard, D. and Ramaekers, J.G. (2018). Long-term effects of antidepressant and benzodiazepine usage on actual driving and neurocognitive performance. The International Association of Forensic Toxicologists (TIAFT), Belgium, Ghent. Oral presentation.

Vinckenbosch, F.R.J., Vermeeren, A., Vuurman, E.F.P.M., van der Sluiszen, N.N.J.J.M., Verster, J.C., van de Loo, A.J.A.E., van Dijken, J.H., Veldstra, J.L., Brookhuis, K.A., de Waard, D. and Ramaekers, J.G. (2018). An explorative approach to observing the impairing effects of chronic benzodiazepine use on driving in a clinical population. The International Association of Forensic Toxicologists (TIAFT), Belgium, Ghent. Oral presentation.

Urbanus, B., van der Sluiszen, N.N.J.J.M., Vermeeren. A., Overeem, S. and Lammers, G.J. On-theroad driving performance in narcolepsy and idiopathic hypersomnia patients: a comparison with healthy controls. $9^{\text {th }}$ European Narcolepsy Day, France, Montpellier. Poster presentation.

Bruijel, J., Vermeeren, A., van der Sluiszen, N.N.J.J.M., Jongen, S., Stapert, S.Z. and van Heugten, C.M. (2018). The Psychomotor Vigilance Task: a measure of objective fatigue following acquired brain injury? $15^{\text {th }}$ Neuropsychological Rehabilitation Special Interest Group, Czech Republic, Prague. Oral presentation.

van der Sluiszen, N.N.J.J.M., Vermeeren, A., Verster, J.C., van de Loo, A.J.A.E., van Dijken, J.H., Veldstra, JL., Brookhuis, K.A., de Waard, D. and Ramaekers, J.G. (2017). Long-term effects of antidepressant and benzodiazepine usage on actual driving and neurocognitive performance. International Council on Alcohol, Drugs and Traffic Safety (ICADTS), Slovenia, Bled. Oral presentation.

van der Sluiszen, N.N.J.J.M., Vermeeren, A., Verster, J.C., van de Loo, A.J.A.E., van Dijken, J.H., Veldstra, JL., Brookhuis, K.A., de Waard, D. and Ramaekers, J.G. (2016). Determining thresholds for driver fitness in long-term users of ICADTS category III medication. International Council on Alcohol, Drugs and Traffic Safety (ICADTS), Brazil, Gramado. Oral presentation.

van der Sluiszen, N.N.J.J.M., Vermeeren, A., Verster, J.C., van de Loo, A.J.A.E., van Dijken, J.H., Veldstra, JL., Brookhuis, K.A., de Waard, D. and Ramaekers, J.G. (2016). Determining thresholds for driver fitness in long-term users of ICADTS category III medication. International Academy of Legal Medicine (IALM), Italy, Venice. Oral presentation.

van der Sluiszen, N.N.J.J.M., Urbanus, B., Vermeeren. A., Overeem, S. and Lammers, G.J. (2016). On-the-road driving performance of narcolepsy patients receiving long-term sodium oxybate treatment: preliminary results. Dutch Neuroscience Meeting (DNM), The Netherlands, Lunteren. Poster presentation. 


\section{ACADEMIC PRESENTATIONS}

van der Sluiszen, N.N.J.J.M. (2018). Future career perspectives for FPN students. Faculty of Psychology and Neuroscience Psychological perspectives, Maastricht University, The Netherlands. Oral presentation.

van der Sluiszen, N.N.J.J.M. \& Vinckenbosch, F.R.J. (2018). Drugs \& Driving: current and future perspectives. $9^{\text {th }}$ Annual research day Neuropsychology \& Psychopathology, Maastricht, The Netherlands. Oral presentation.

van der Sluiszen, N.N.J.J.M. (2017). Effects of medication and drugs on driving ability. Institute for Mobility (IMOB), Hasselt University, Belgium. Invited lecture.

van der Sluiszen, N.N.J.J.M. (2017). Sleep. Maastricht Science Programme (MSP), Maastricht University, The Netherlands. Invited lecture.

van der Sluiszen, N.N.J.J.M. (2017). Future career perspectives. Faculty of Psychology and Neuroscience Psychological perspectives, Maastricht University, The Netherlands. Oral presentation.

van der Sluiszen, N.N.J.J.M., Vermeeren, A. and Ramaekers, J.G. (2016). On-the-road driving performance and antihistamines. Faculty of Psychology and Neuroscience 20 year Lustrum, Maastricht University, The Netherlands. Oral presentation.

van der Sluiszen, N.N.J.J.M. (2016). Sleep. Maastricht Science Programme (MSP), Maastricht University, The Netherlands. Invited lecture.

van der Sluiszen, N.N.J.J.M., Vermeeren, A. and Ramaekers, J.G. (2015). Driver fitness in long-term users of ICADTS category III medication. $6^{\text {th }}$ Annual research day Neuropsychology \& Psychopathology, Maastricht, The Netherlands. Oral presentation.

\section{ACADEMIC CERTIFICATION}

2018

University Teaching Qualification (UTQ)

2015 - 2023 Quality Assurance and Quality Control in Clinical Research (BROC)

\section{MEMBERSHIPS}

2015 - 2018 ICADTS (International Council on Alcohol, Drugs and Traffic Safety)

2015 - 2018 NSWO (Nederlandse vereniging voor Slaap- en Waak Onderzoek)

2016 - 2018 NIP (Nederlands Instituut van Psychologen) 
Output

\section{AWARDS \& NOMINATIONS}

\section{Wiley's Top 20 most read paper award}

Awarded for the paper on "Single- and dual task performance during on-the-road driving in young novice drivers" published in Human Psychopharmacology: Clinical and Experimental

\section{Nomination dr. Peter Moleman award}

Short-listed (among 15 other nominees) for the prize of best article in the field of Human Psychopharmacology by a Dutch author. Nominated for the paper on "Driving performance of depressed patients who are untreated or receive long-term antidepressant (SSRI/SNRI) treatment" published in Pharmacopsychiatry

Early career researcher award

Awarded in Gramado (Brazil) during the T2016 - 21st ICADTS Conference

Young scientist travel award

Awarded in Venice during the IALM International Symposium - Medicine \& Justice

\section{Poster award (first place)}

Awarded in Maastricht during the $3^{\text {rd }}$ Annual Psychology and Neuroscience Research Day

\section{MEDIA COVERAGE}

\section{Roadtests in Limburg onderzoeken of iemand slingert}

Magazine article, Rij-instructie: onafhankelijk vakblad voor de verkeersopleiding

Kan je rijden met een pilletje op?

Television fragment, Nederlandse Omroep Stichting (NOS)

Onderzoek naar invloed langdurig medicijngebruik en rijvaardigheid

Press release, by Maastricht University, Utrecht University and University of Groningen

\section{Wakker rijden na een slaappil?}

Newspaper article, Dagblad de Limburger 